\title{
General-Purpose Heat Source Development: Safety Verification Test Program
}

\section{Explosion Oyerpressure Test Series}

\author{
T. A. Cull \\ T. G. George \\ D. Pavone
}

\section{DISCLAIMER}

\begin{abstract}
This report was prepared as an account of work sponsored by an agency of the United State employees. makes any warranty, express or implied, or any agency thereof, nor any of their precess disclosed ary. commeteness, or usefulness of assumes any legal liability or responsience herein to any represents that its use would not infringe pation, apparatus, product, or manufacturer, or otherific commercial product, process, or service by inendation, or favoring by does not necessarily constitute or imply it ente name, trademark, and opinions of authors the United States Government or anyly its endorsement, recom. United States Government expressed herein do not necessarily state agen theresf. The vicws

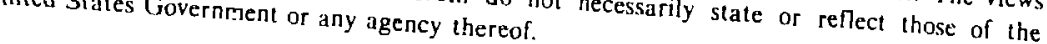




\title{
GENERAI-PL RPOSE IIFIT SOL RO DE VELOPNIEYT: SAFEIY IERHFIC IIION IFSI PRO(;RIM
}

\author{
Fiplosion Oierpressure lest Series
}

by

T. A. Cull, T. C. Ceorge, and D. Pawone

\begin{abstract}
ABSIRAC I
The General-Purpose lleat Source (GPHS) is a modular, radioisotope heat source that will be used in radioisotope thermoelectric generators ( $R$ TGS) to supply electric poser for space missions. The first two uses will be the Vist Galileo and the ESA l lysses missions. The RT (; for these missions will contain 18 GPHS modules, each of which contains 60 r ${ }^{218} \mathrm{PuO}_{2}$-fueled clads and generates $250 \mathrm{~W}_{(0)}$. A series of Safety Verification Tests (STTS) was conducted to assess the ability of the GPHS modules to contain the plutonia in accident ensironments. Because a launch pad or postlaunch explosion of the Space Transportation System rehicle (space shuttle) is a conceivable accident, the SVT plan included a series of tests that simulated the overpressure exposure the RTG and GPHS modules could experience in such an event. Results of these tests, in which we 4 - i depleted $\mathrm{LO}_{2}$ as a fuel simulant, suggest that exposure to overpressures as high as $15.2 \mathrm{MPa}(2200 \mathrm{psi})$, without subsequent impact, does not result in a release of fuel.
\end{abstract}

\section{INIRODI ("IION}

The (jencral-Purpose Heat Source (CPHS) is a modular component of a radioisotope thermoclectric generator (RTG) that will provide power for space missions. The first two flights will be the NASt Galileo and the E.SA Lilysses (formerly International SolarPolar) missions. The RTG provides electric power by using the heat of ${ }^{238} \mathrm{Pu} \alpha$-decay to create a temperature differential across a thermoclectric array. The Galileo spacecraft will use two RTGis. and the Ulysses will use a single RTG. Each RTG contains 18 GPHS modules.

A. GPHS module contains four ${ }^{238} \mathrm{PuO}_{2}$-fucled clads and provides a total thermal output of $250 \mathrm{~W}(t)$ at the beginning of life. Each fueled clad consists of a ${ }^{278} \mathrm{PuO}_{2}$ nellet encapsulated in an iridium-alloy ( $0.3 \%$ tungsten) containment 'hell. Two fueled elads are held in a Fincweave-Plerced Fabric* (FWPF) graphite impact shell icils), and two (illis are contained within an

\footnotetext{
* Fineweave-Plerced Fabric 3-1) carhon carbon composite.

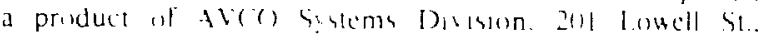
Wilmingion. $M+111 \mathrm{~KB}^{-}$
}

FWPF aeroshell (Fig. 1). One of the goals of the GPHS module design was to minimize the release of plutonia in an accident environment.'

In the Galileo and Ulysses missions, a liquid-fueled Centaur rocket will be transported with cach spacecraft in the cargo bay of the Space Transportation System vehicle (space shuttle). An Air Force Rocket Propulsion Laboratory analysis indicates that a launch explosion. fueled by the shuttle and Centaur propellants. would expose the RTG and GPHS modules to high overpressures. ${ }^{2}$ Consequently, the Safety Verification Test (SVT) plan included a series of tests to determine the response of the GPHS components to such overpressures. $^{3}$

\section{THE TEST PROGRAM}

The explosion overpressure tests simulated the overpressure cxpocure that a $\mathrm{PuO}_{2}$-containing (jPHS module would experience in a launch explosion. Twelve overpressure tests weic conducted. In the first three tests 


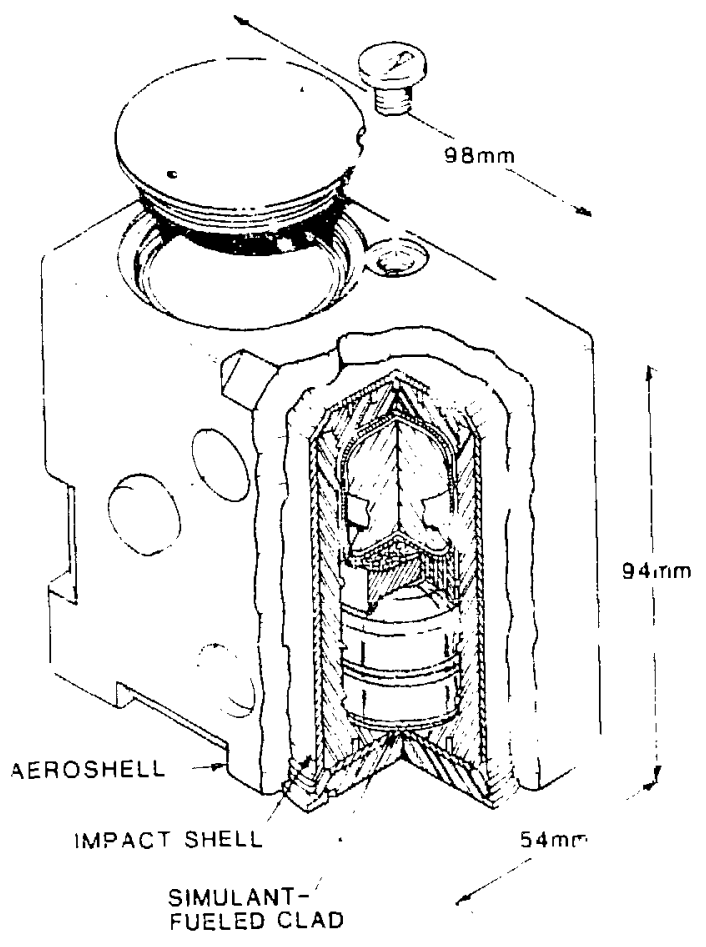

Fig. 1. Each GPitS module contain four ${ }^{238} \mathrm{~F}$ ، '2fueled capsules.

(bare module tests or + iTs) ba.. GPHS indules were exposed to the erpit sure environment. At thai ame, these were con idered conscrvative tests. because we helicied that the RTC; housing would pr, an some protection to the GPHS modules. We had pla..ned to lest at incrementally higher "erpressu es (to naxImum of $(3.8 \mathrm{MPa})$ in $\mathrm{L}_{\text {. }}$. st series. bu he tesi. was suspended because an analyis of is DIRECT COURSE test (a l-k' equivale'. nucl. . simule*ion suggested that the Rici conve:- hous g increases rather than decreases damage to ... GPHS modules in an explosion. ${ }^{4}$ When the hock tube tests were res' 'med, a simulated RTG housin was included (converter segment tests or (STis).

The CSTs were conducted to determine he effect of the RTG housing on the response of the $\mathrm{G}_{:} \quad 5$ modules and to more accurately sir ulate ti.' actual expis ion environment. The first two sts were similai $\eta$ magnitude to BMT-2 and B.MT-? so that the effect of the housing could be determined. The remaining ists were conducled at incemertally higher orerpressures.

\section{A. Components}

t fuel smulant of smitered urantum dioxide liepleted I $n_{2}$ ) was used in all of the ests because the tor facility was no: equipped to contain plutonium oxide. The bulk $\therefore$ insity and dimensiors of each $\mathrm{iO}_{2}$ pellet were adjusted to match the mass and "iiguration of an average putonia fuel pellet. Other components are described below.

'. Ba:e Module Tests. The lesi object was a fully loaded GPiS module. One bulk griphite niudule, with the same external dimensions as the CPHS module, was placed above and another was placed below the lest module. All FW PF components were flight-quality material and were machined to flight configurations. The iridiunt-ailoy containment shells were also flight-quality units and were provided by the Mound Facility. Los Alamos National Laboratory fabricated the fuel pellets, elliapsulated the pellets in the col.iainment shells, and assernbled the target components. Datal describing the iridium and US, components used in these tests are presented in lable I.

2. Converter Segment rests. In the CSTs, a module stack identical to the BMT assembly was exposed to a blast wave actiug through an RTG housing simulant. However, in CST-6-RTG-2, the module stack consisted of three fully loaded GPHS modules with a half-thickness bulk giaphite module placed above and below.

Two different RTG simulants were used in the tests. In the first four CSTs, the RTG simulant was a Cshaped, 6.35 -mm-thick aluminum-alloy (6C6I-T6) plate with a $7.62-\times 17.27-\mathrm{cm}$ window at the center. A $1.52-$ mnt-thick aluminum $(606 \mathrm{l}-\mathrm{T} 6)$ plate with flight-quality thermoelements and insulation (Fig. 2), provided by the General Electriz Company (GE), was inserted into the window of the C-shaped plate and pop-riveted in place (Fig. 3).

In the last five CSTs, a cylindrical mockup with 1.52mm-thick 6061-T6 aluminum walls (Fig. 4) was provided $b_{y}$ GE to simulate the RTG housing. The cylinder contained flight-quality thermoelements and insulation in the canter of the upstream and downstream sides. The remainder of the RTG simulant was filled with stainless steel weights to bring it to a mass and moment of inertia equal to a flight RTG. In CST-5RTG-1, the stainless steel weights were $4.7-\mathrm{mm}$-thick piates of various sizes (as shown in Fig. 4). These plates $u$ are replaced with layers of stainicss steel foil in the last four tests.

The fuel pellets used in (ST-1, CST-2, and the CST-8RTG-4 A-GIS were encapsulated in containment shells at Los Alamos National Laboratory. The remaining fuel pellets were encapsulated at the Savannah River Laboratory. The iridium and $U \mathrm{O}_{2}$ components used in these tests are presented in Table $\bar{I}$. 


\begin{tabular}{|c|c|c|c|c|c|}
\hline \multirow[b]{2}{*}{1 est } & \multirow[b]{2}{*}{ Capsule } & \multicolumn{2}{|c|}{ Iridium Clad } & \multirow[b]{2}{*}{10, Pellut } & \multirow{2}{*}{$\begin{array}{c}\text { Fusled (apsule } \\
\text { Wright (g) }\end{array}$} \\
\hline & & Vent C up & Blind (up & & \\
\hline \multirow{2}{*}{$\begin{array}{l}B \backslash 1 I-I \\
\text { and }\end{array}$} & IR(;-115 & $1 \mathrm{k} 28.3-5$ & 1.265 .8 & $62-1110$ & 208.236 \\
\hline & $18(;-110$ & $1 \mathrm{R} \geq \mathrm{K}+\mathrm{I}$ & I.R $284-2$ & $62-1111$ & 201.760 \\
\hline \multirow[t]{2}{*}{ B.11-2 } & IR $:-11 ?$ & $1.628+-8$ & 1.R $28+-5$ & 62.94 & 208.077 \\
\hline & IRG:-118 & I. R286-8 & I.R286-6 & $62-105$ & $204.6+1$ \\
\hline \multirow[t]{4}{*}{$B \backslash 11-3$} & $1 R(;-1196$ & I. RZ91)-- & I. R $29(1)-8$ & $62-8^{7}$ & 204.079 \\
\hline & $\operatorname{lRG} ;-119^{7}$ & I.R242-7 & 1.R271-7 & $62-81$ & 202.698 \\
\hline & $\operatorname{lRC} ;-(098$ & $1.294-5$ & I.R3111-5 & $62-76$ & 199.760 \\
\hline & IRGi-(199) & $1.294^{-7}$ & 1. $R 286-5$ & 02.68 & 201.56 .3 \\
\hline \multirow[t]{4}{*}{$(>1+1$} & $1 \mathrm{R}(;-10 ?$ & 1.265 .2 & $1.264-8$ & $62-7.3$ & 206.266 \\
\hline & IRGi-108 & $1.26 .5-6$ & $1.265-5$ & $62-84$ & 204.179 \\
\hline & IR(i-109 & $1.266-6$ & I.R $292-8$ & $62-74$ & 199.7111 \\
\hline & $\operatorname{IR}(;-110$ & I.RZج4.5 & I.R293-3 & $62-97$ & 20.3 .149 \\
\hline \multirow[t]{4}{*}{$(S 1-2$} & $1 K(;-125$ & $1.2,320-4$ & I.R319.5 & $62-11.3$ & 209.107 \\
\hline & $1 R C_{i}-126$ & MFR28-4 & MER23. & $62-115$ & 2011.880 \\
\hline & IRG $+12 ?$ & IIFR24-6 & NER2A-1 & $02-116$ & 2001.871 \\
\hline & $1 R G_{-1}-128$ & $M I F R \geq 3-3$ & MIFK24-3 & $62-117$ & 201.718 \\
\hline \multirow[t]{4}{*}{$(\leq 1-3$} & 1.12 & $x .34 .3-6$ & $1 R \geq 2+R-1$ & $6.3-117$ & 203.0014 \\
\hline & $1 .-14$ & $1 R+23-1$ & $18+24-3$ & $0.3-06$ & 203.572 \\
\hline & $1 .-16$ & $Y R+20-4$ & $1 R+20.5$ & $63-15$ & 20.3 .344 \\
\hline & $1 .-19$ & $Y R+22-5$ & $Y R+21-6$ & $6.3-10$ & 204.843 \\
\hline \multirow[t]{4}{*}{$(S \leq 1-4$} & L. -9 & ZR571-5 & T103-1 & $62-118$ & 204.591 \\
\hline & I. -10 & $1211-4$ & IR1 $25-5$ & $6.3-04$ & 204.574 \\
\hline & $1 .-15$ & YRA23-3 & YR423-4 & $63-08$ & 203.030 \\
\hline & $1 .-23$ & $1+12-1$ & $1416-5$ & $63-13$ & 200.706 \\
\hline \multirow[t]{4}{*}{ GST-S-R IC:-1 } & $1 .-17$ & Z508-5 & $2510-4$ & $63-16$ & 203.712 \\
\hline & $1 .-18$ & TR129-6 & $Z 505-6$ & $6.3-09$ & 202.963 \\
\hline & 1.22 & $2521-1$ & $7520-4$ & $6.3-12$ & 205.056 \\
\hline & $1 .-24$ & $7.56 .3-3$ & $7.5601-2$ & $63-14$ & 203.266 \\
\hline \multirow[t]{12}{*}{$(\rightarrow I-6-R I) ;-2^{4}$} & $M 1-10$ & 5.313 & 53.35 & $85-11$ & 202.4 .34 \\
\hline & $M-11$ & 5334 & 5351 & $85-12$ & $201.66^{\circ}$ \\
\hline & $.11-12$ & 5273 & 5124 & $85-13$ & 202.019 \\
\hline & $.11-15$ & 2361 & 5544 & $85-14$ & 203.262 \\
\hline & $11-9$ & 5235 & 5.33 .3 & $85-110$ & 205.648 \\
\hline & $.11-22$ & 5405 & 547.3 & $85-15$ & 207.193 \\
\hline & $1: 23$ & $5+11$ & 5475 & $85-27$ & 206.575 \\
\hline & .11 .26 & 0172 & 0185 & $85-17$ & 207.359 \\
\hline & $M 1-8$ & 5284 & 5331 & $85-09$ & 203.630 \\
\hline & $11-17$ & 4294 & 5484 & $85-2.3$ & 205.212 \\
\hline & $.11-18$ & 5485 & 7313 & $85-21$ & 205.136 \\
\hline & $11-20$ & $538 \%$ & 5444 & $85-26$ & 204.125 \\
\hline \multirow[t]{4}{*}{ CSI - - R I $6 ;-3$} & $.11-30$ & TR1,32-1 & $1 \mathrm{~K}+23-2$ & $85-30$ & 202.689 \\
\hline & $.11-32$ & $7558-3$ & $2562-2$ & $85-32$ & 202.076 \\
\hline & $.11-34$ & $7.562-5$ & $7.558-2$ & $85-34$ & 201.8 .15 \\
\hline & $.11-35$ & 2548.2 & $2.562-6$ & $85-35$ & 201.102 \\
\hline \multirow[t]{4}{*}{$(5 I-8-K:(;-4$} & $\operatorname{lR}(;-132$ & $0806-3$ & IIER26-2 & 62.122 & 202.082 \\
\hline & $1 \mathrm{RC} ;-1.33$ & $P R=211-2$ & MHR27-4 & 62.124 & 201.304 \\
\hline & $11-24$ & 50111 & 5015 & $85-16$ & 207.325 \\
\hline & $11-48$ & $1.55(1 .-4$ & PR731-2 & $85-45$ & 206.0 .30 \\
\hline \multirow[t]{4}{*}{$\left(S \mathrm{~L}-4 \cdot \mathrm{R} 1 \mathrm{C}_{-5}\right.$} & $11-40$ & $\angle E 6 \geq-1$ & $7.5+5-3$ & $85-37$ & 205.260 \\
\hline & 11.42 & 1558.1 & ZR571-? & $85-39$ & 2016.878 \\
\hline & 11.44 & SR069.3 & $7550-1$ & $85-41$ & 205.896 \\
\hline & $.11-46$ & I.K571-3 & $7.550-5$ & $85-43$ & 206.52 .3 \\
\hline
\end{tabular}




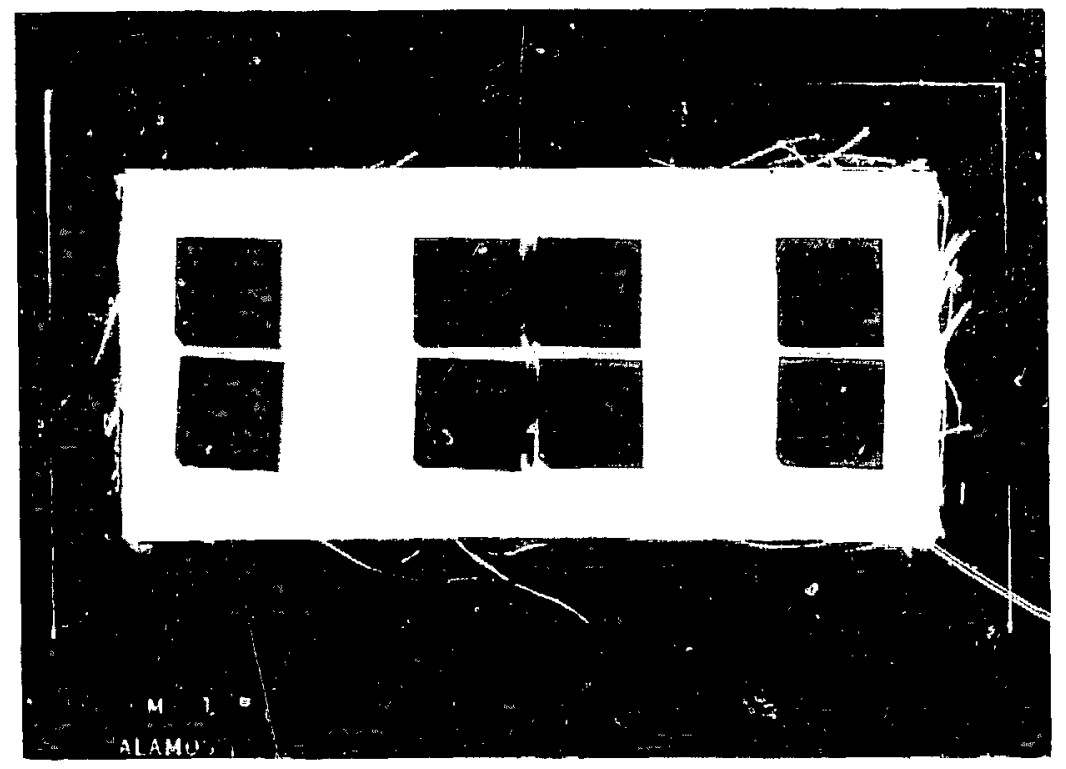

(a)

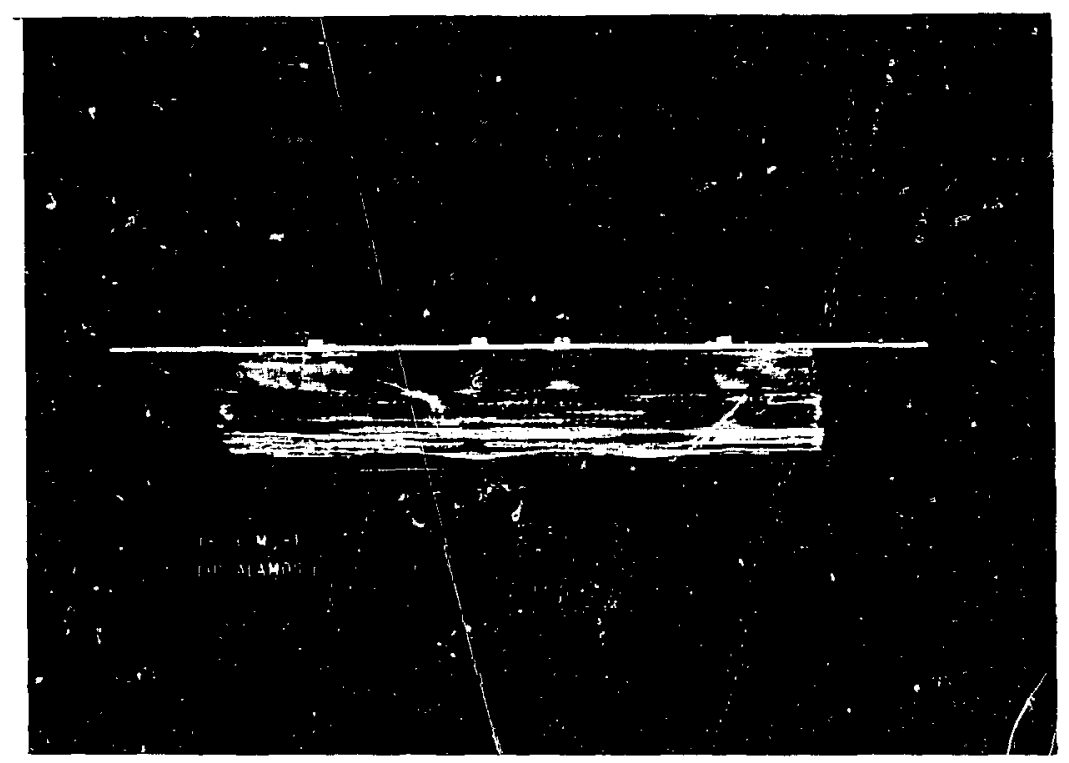

(b)

Fig. 2. The GE segment for the shock tube tests ( $C$-shaped housing simulant) consisted of a $1.52-\mathrm{mm}$-thick aluminum $(6061-\mathrm{T} 6)$ plate with flight-quality thermoelements and insulation attached: (a) face-on view and (b) overhead view. 


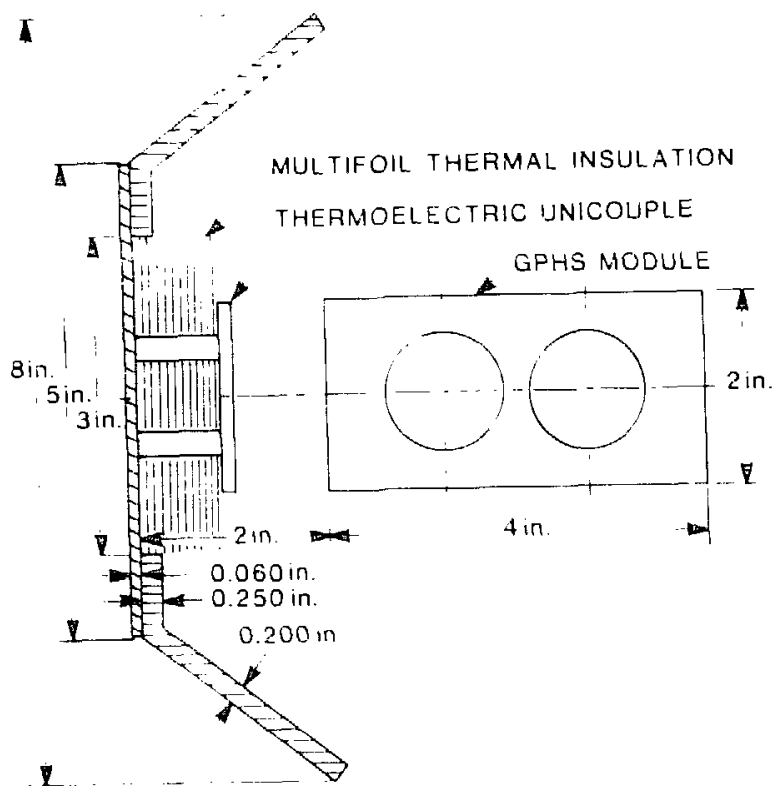

Fig. 3. The ('shaped housing simulant with (if segment in place (dimensions approxinute)

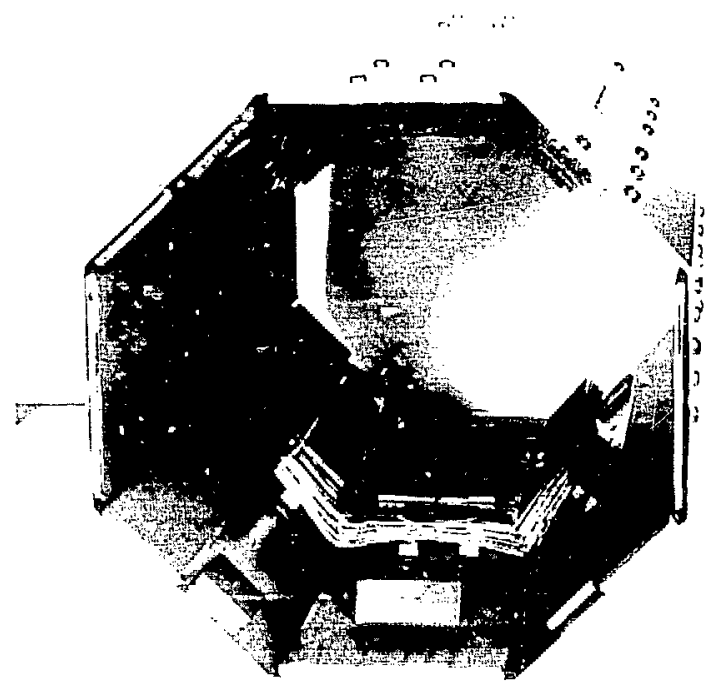

Fig. 4. The 1.52-mm-thick aluminum (6061-T6) (iE cylindrical housing simulant contained thight-quality thermoclements and insulation in the cencer of the upstream and downstream sides.

\section{B. Procedures}

All of the uverpressure tests were conducted at Sandia National Laboratories' (SNLA) Coyote III Test Area in Albuquerque. New Mexico. SNLA was responsible for charge calculation, fabrication, detonation, shock tube preparation. and shock tube diagnostics. Los Alamos was responsible for test section assembly and operation. flash $x$-ray setup, and posttest recovery and analysis.

In each test, the main shock tube was a seamless pipe of ASTM 53-Grade B steel, nominally $60.96 \mathrm{~cm}$ o.d. by $2.54 \mathrm{~cm}$ thick. A $175-\mathrm{cm}$-long test section (Fig. 5) containing the test object was boled to the main shock tube. Pressure transducers mounted in the shock tube wall sensed the time of shock wave arrival and the static pressure time histories from which the overpressure at the test object location was calculated.

The total shock tube length varied, depending on the desired overpressure and impulse. Los Alamos specified the test parameters, and SNLA calculated the charge size and tube length required to achieve the desired conditions at the test object location. A large charge required a longer shock tube than would a smaller charge to achieve the same overpressure at the test object location. However, is larger charge and longer tube were neressary if a longer imoulse was desired.

Before each test, the stork iube ends were sealed with aluminum foil and plastic, and a ritrogen gas flow to the furnace and shock rube was initiated. Flash $x$-ray units were positioned at the exit end of the shock tube so that velocity measurements of the test objects could be calculated based on test object positions and elapsed time. The $x$-ray units were triggered after a calculated delay time from detonation.

1. Bare Module Tests. In each test, the GPHS module was heated in a cylindrical furnace insulated with bulk graphite and carbon felt insulation. The module stack was placed in a graphite cradle suspended from the fur nace lid. The temperature of the module stack was read directly from a Type $\mathrm{K}$ thermocouple inserted between the test module and the top bulk graphite module. When the test stack reached about $1110^{\circ} \mathrm{C}$ (about $20^{\circ}$ above the target test temperature of $1091^{\circ} \mathrm{C}$, the average temperature of clads in an on-pad RTG), a 2 -min countdown was initiated. An explosive-actuated pin was retracted at about $T-30 \mathrm{~s}$ to lower the furnace. leaving the heated stack suspended in the shock tube. A second explosive pin was detonated to release a counterweight steel plate that closed a sliding door over the retracted furnace to eliminate blast wave reflection from the furnacc exicnsion. The module stack cooled to the desired test temperature while the door was being closed. 

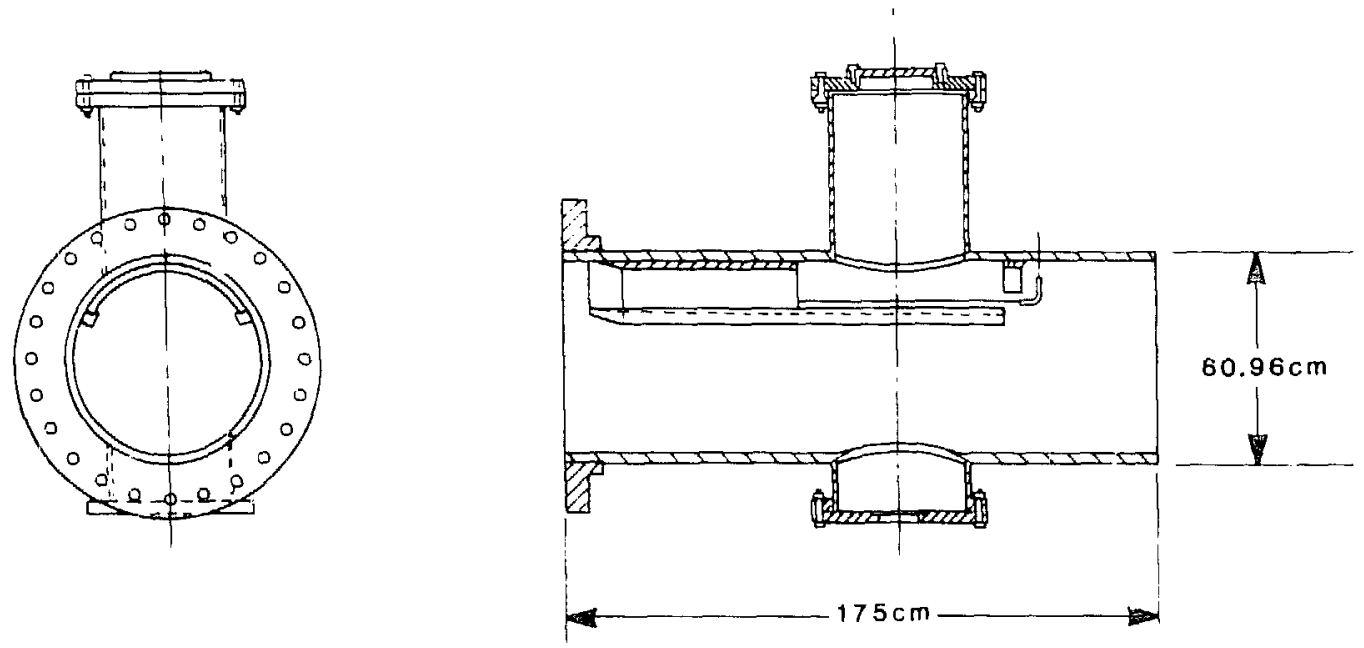

Fig. 5. The test assembly was contained in a seamless steel (ASTM 53-Grade B) test section bolted to the main shock tube.

An SNLA hand-packed Composition ( -4 explosive ( $5 \%$ TNT), fitted with a point detonator, was detonated after test readiness was verified on a video monitor in the instrumentation bunker. The test objects were recovered from a vermiculite-filled catch tube by sifting the filler through $6.35-\mathrm{mm}$ screens.

Recovered items were examined, photographed, and transported to Los Alamos for postmortem examination. The clads were photographed again at Los Alamos, $x$-rayed. and measured for deformation. The most deformed clad in each test was selected for metallography

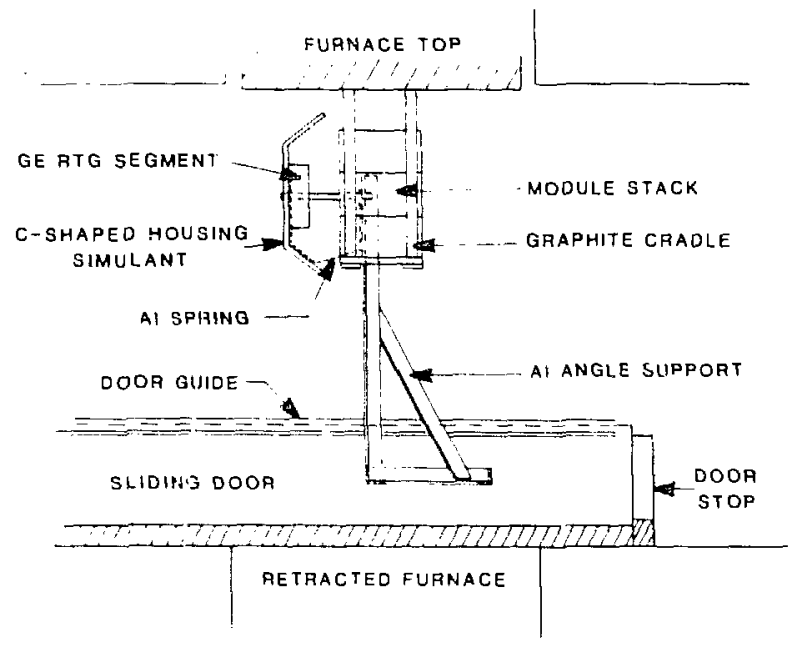

(a) and was sectioned; the fuel simulant was observed and photographed.

2. Converter Segment Tests. In the first four CSTs, the $\mathrm{C}$-shaped housing simulant was attached to an aluminum bracket mounted to the sliding door. The test procedures were identical to those used in the BMTs, except that the sliding door was closed by an automatic electric winch, positioning the RTG simulant with thermoelements and insulation $3.81 \mathrm{~cm}$ upstream from the test module (Fig. 6).

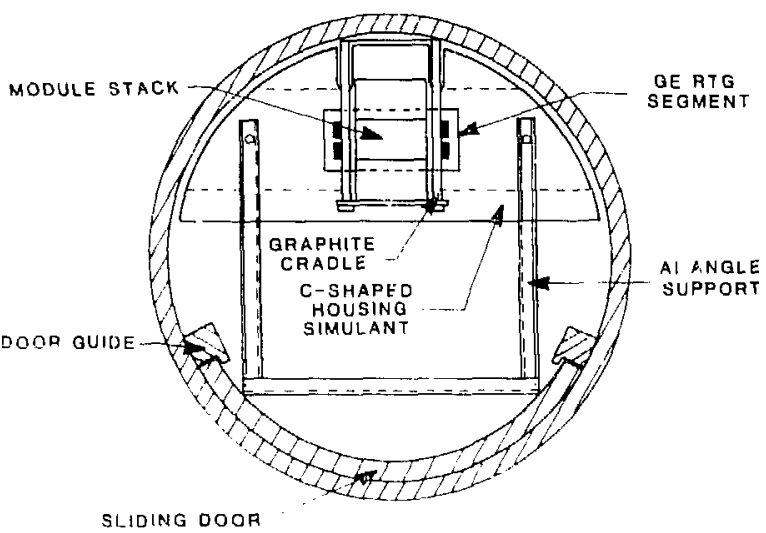

(b)

Fig. 6. Shock tube test setup with (-shaped RTG simulant: (a) section view and (b) end view. 


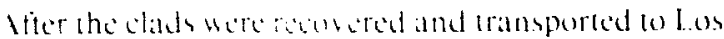
tlamos, they were grit-biasted with $\mid 1$-pm aluminal abrasive of renues the athering wermicahte. The clads were then measured fir deformation. and the most

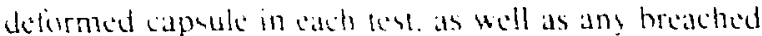

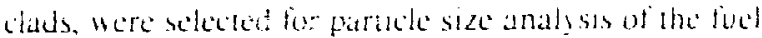
and for metallogiapli!. I rania particle size data are listed in Table Il. Specimens for metallography were cut from the vent and wad steded cupe of the capsules. Grain sizes of the iridium cups are fisced in Table 111.

In the last tive (STs (cylindrical housing simutant), the module stack was healed in a stationary furnale insulated with alumina. Marinite, and Fiberfiax Duriblankat insulatum. The lest stack was mounted to a romuvable furnace base with a graphite holder. An atended alr elinder, with graphote insulating hlocks atlached to the end of the piston. held the module stack in the furnativ during heating. When the stack reached the desired lemperature, it was lowered with the furnace base into the converter stmulant at the center of the shock tube hy remote uperatlon of the arreylinder.

The temperature of the module stack was not measured direcily when it was in the test position. Instead, the impact temperature was in ferred from prior ealibration measurements. After the module stack was lowered, an electric winch pulled the sliding door closed under the furnace cavity to reduce blast wave reflection at the iest object location (Fig. 7). Except in CST-9. RTG-5, a Composition (-4 explosive was detonated after test readiness was veriticd on a video monitor in the instrument bunker. In CST-9-RTCi-5, a Los Alamostaist and -mathined composition B explosive $140 \%$ $\Gamma$ VT) was detonated with a plane-wave generator. The calch tube filler in (ST-5-RTC-1 was vermiculite. which was sifted through $6.35-\mathrm{mm}$ screens. The test objects in the final four CSTs were recovered from a sawdust-filled catch tube hy sifting the tiller through 12.7-mm sereons.

The sawdust was substituted for vermiculite in the last four tests because fueled clads recovered from previous tests exhibited signs of possible chemical interactions with the vermiculite, and we felt that these clads should not be used in follow-on tests. We chose sawdust as a vermiculite substitute beause of its availability. light weight. and high carbon content. In addition, no chemical interation between sawdust and iridium had been seen in a seriesof los tlamos lests in which fueled clads wore heated to 11$) 4$ ( $^{\circ}$ and cooled in a sawdustfilled stecl drum.

- Fibertrax Durablanket insulatum, a product of arborundum Company. Insulatum Dovisun. PO Box 808. Niagra Falls. vi 14312

\section{RESLLTS}

The conditions and results of each lest are summaried in Tables IV and V. Details of the individual ests and posimortem examinations are given below.

\section{A. Bare Modult Test I}

In the first shock tube overpressure test (BMT-1), an explosive charge of $5.9 \mathrm{~kg}(1.3 \mathrm{lb})$ was detonated at the end of a 20.1-m-lung shock lube, exposing the heated $\left.(109) \pm 5^{\circ} \mathrm{C}\right)$ module stack to a blast wave of $1.4 \pm 0.07$ $\mathrm{MPa}(200 \pm 10 \mathrm{psi})$ overpressure and $8.4 \pm 1.4 \mathrm{kPa} \cdot s$ $(1.22 \pm 0.2 \mathrm{psi} \cdot \mathrm{s})$ impulse. The module penetrated $0.8 \mathrm{~m}$ into the catch tube. The only external damage to the module consisted of pitting on the surlace facing the blast wave and a minor chip on one corner. The chip apparentiy occurred when the test module collided with one of the bulk graphite modules.

Radiugraphic examination of the test module revealed that neither the impact shells nor the capsules had been damaged. Fueled clad diametral measurements ranged from a maximum:minimum diameter ratio $(\mathrm{M} / \mathrm{m})$ of 1.001 to an $\mathrm{M} / \mathrm{m}$ of 1.003 . Because the clads in this test module were to be used in the next overpressure test, they were not sectioned.

\section{B. Bare Module Test 2}

In this test (BMT-2). we heated the BMT-1 test module to $1093 \pm 5^{\circ} \mathrm{C}$, and we detonated $27.2 \mathrm{~kg}(60 \mathrm{lb})$ of explosive at the end of a $20.1-\mathrm{m}$-long shock tube to create a blast wave of $5.1 \pm 0.21 \mathrm{MPa}(735 \pm 30$ psi) overpressure and $22.1 \pm 2.8 \mathrm{kPa} \cdot \mathrm{s}(3.2 \pm 0.4 \mathrm{psi} \cdot \mathrm{s})$ impulse. The test module was driven $1 \mathrm{~m}$ into the catch tube. The recovered module is shown in Fig. 8 . The aeroshell fractured on a broad face that had been oriented parallel to the blast direction. The C-GIS (Fig. 9) was broken and fueled clad IRG-118 was visible. The AGIS (Fig. 10), which was on the blast side of the module, appeared undamaged.

The clads were removed from the impact shells and photographed (Fig. 11). None of the clads breachud. Diametral measurements indicated an $\mathrm{M} / \mathrm{m}$ ranging from 1.002 to 1.029. Capsule IRG-118. which had the greatest local deformation, was selected for microscopic examination. The IRG-118 fuel simulant (Fig. 12) was broken into relatively large pieces. 


\begin{tabular}{|c|c|c|c|c|c|c|c|c|c|}
\hline 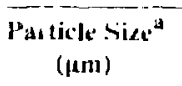 & $\begin{array}{c}(S I-1(\text { lad I }) \\
5.1 \text { MIl'a }\end{array}$ & $\begin{array}{c}(S I-2(I R(;-128) \\
7.1 \mathrm{MI} \cdot \mathrm{u}\end{array}$ & $\begin{array}{l}(51-3(1 .-12) \\
11.6 \mathrm{MPa}\end{array}$ & $\begin{array}{l}(\mathrm{SI}+4(1-10) \\
1 \geq .1 \mathrm{NIA}\end{array}$ & $\begin{array}{c}(51.5(1-24) \\
12.5 \mathrm{NIPa}\end{array}$ & $\begin{array}{c}(25[-7(1)-35) \\
12.9111^{4}\end{array}$ & $\begin{array}{c}(S 1-8(1 \mathrm{~K}(;-133) \\
2.46 \mathrm{MPa}\end{array}$ & $\begin{array}{c}\left(S 1-9\left(\mathrm{M}-4(6)^{1}\right.\right. \\
15.3 \mathrm{M}(\mathrm{Pa}\end{array}$ & $\begin{array}{l}(51-4)(1-40) \\
15.311 \mathrm{P}^{3}\end{array}$ \\
\hline+6001 & 0.6774 & $0 . \div 26.3$ & 0.3567 & $0.8+107$ & 0.8407 & 0.8705 & 0.9004 & 0.1276 & 0.3720 \\
\hline$b(0)(0)+20000$ & 0.18 .36 & 0.04 .37 & 0.19015 & 0.0580 & 0.0701 & 0.0818 & 0.0556 & 0.3027 & 0.24 .50 \\
\hline $2000+8+1$ & 0.0850 & 0.0179 & 0.2794 & 1. 0572 & $0.0+81$ & $0.02+2$ & 0.0274 & 0.2912 & 0.2076 \\
\hline $841+420$ & 0.0 .308 & 0.0058 & 0.1044 & 0.0394 & 0.0212 & 0.0075 & 0.0007 & 0.1374 & $0.0 \% 68$ \\
\hline $420+177$ & $0.01+1$ & 0.0033 & 0.0 .379 & 0.0228 & 0.0121 & 0.00145 & 0.00144 & 0.10825 & 0.05130 \\
\hline $177+125$ & 0.01024 & 0.0007 & $0.01+10$ & 0.0037 & 0.0023 & 0.0011 & 0.0011 & 0.0177 & $0.0(1) 1$ \\
\hline $125 \cdot 74$ & 0.0024 & 0.00104 & 0.01054 & 0.0037 & 0.0023 & 0.0011 & 0.001 .3 & 0.0179 & W. \\
\hline $74+44$ & 0.00112 & 0.00104 & $(0.001) 22$ & 0.0018 & 0.0009 & 0.00007 & 0.00018 & 0.0080 & 0.001 .33 \\
\hline$+4+30$ & 0.000109 & 0.60003 & $(0.19015$ & 0.0010 & 0.0008 & b.00005 & 0.00006 & 0.00152 & 0.0029 \\
\hline+20 & 0.00004 & 0.0001 & 0.00007 & 0.0005 & 0.00012 & $0.00(104$ & 0.0010 .3 & $(1.0019$ & $(0.001 .3$ \\
\hline $20+10$ & 0.00105 & 0.0002 & 0.0007 & 0.0006 & 0.0003 & 0.00006 & 0.000 .3 & 0.0020 & 0.0017 \\
\hline 10 & 0.001 .3 & 0.00014 & 0.0017 & 0.0010 & 0.0008 & 0.0010 & 0.0006 & 0.005 .3 & 0.001 .39 \\
\hline $1,00($ mal $)$ & $0.0000 ! 69$ & 0.000002 .3 & 0.000218 & $0.0001+I$ & 0.000108 & 0.0000076 & 0.0000030 & 6.0.000 140 & $0.00(0) 235$ \\
\hline $2.00(\mathrm{max})$ & 0.0000152 & 0.0000 .38 & 0.000 .327 & 0.000318 & 0.000126 & 0.000050 & 0.0000991 & 0.0000273 & 0.0000578 \\
\hline 3.00 (ntav) & 0.0001949 & (0.004)05? & 0.000029 .3 & 0.000149 & 0.00013 .3 & 0.0100084 & 0.000117 & $0.00(0890$ & $0.0(100) 7.37$ \\
\hline 4.00 (Inia) & 0.00026 .3 & 0.000046 & 0.000066 & 0.000173 & 0.000085 & 0.000134 & 0.000101 & 0.001021 & 000015.36 \\
\hline 5.001 (mal) & 15.0000128 & 0.000059 & 0.000100 & 0.000095 & 0.000066 & 0.00010146 & 0.000054 & 0.001050 & 0.000 .390 \\
\hline 6.00(max) & 0.000101 & 0.000035 & 0.000123 & 0.000018 & 0.000069 & 0.000078 & (1).0(1)(0)4-4 & 0.0001668 & $0.00002+6$ \\
\hline $7.00(\operatorname{mos})$ & 0.01000 .32 & 0.400tji.35 & 0.00000 .39 & 0.000000 & 0.000055 & 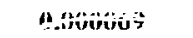 & $4 . j 01106$ & 0.0001327 & 0.00011 .3 \\
\hline $8.00($ mid $)$ & 0.000096 & 0.000030 & 0.0002 .34 & $0.01300-3$ & 0.00001027 & 0.000001 & 0.000052 & $0.0611+87$ & 0.00003 .37 \\
\hline 9.00 (max) & 0.0000688 & 0.0000011 & $0 .(100008.3$ & 0.000000 & (3.000077 & 0.000088 & 0.000019 & 0.00010174 & 0.000 .359 \\
\hline $10.00(\mathrm{max})$ & 0.0000093 & $0.000(3030)$ & 0.000228 & 0.000085 & 0.000053 & 0.000282 & $0.000007 b$ & 0.000238 & 0.000 .329 \\
\hline
\end{tabular}

a Falues are exicesod as a fraction of total pellet weight.

${ }^{b}$ Recotered weight $=64.3809 \mathrm{~g}$. 


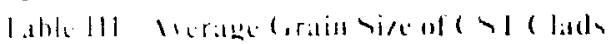

\begin{tabular}{|c|c|c|c|}
\hline ( lat & $10+4$ & $(11)$ & 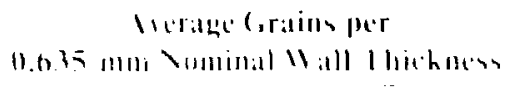 \\
\hline ( lad l & $1+11$ & $\begin{array}{l}\text { linil } \\
\text { olindel }\end{array}$ & $\begin{array}{l}21.4 \\
23.1\end{array}$ \\
\hline $1 K C,-12 k$ & $(+12$ & $\begin{array}{l}\text { I.tut } \\
\text { tivicld }\end{array}$ & $\begin{array}{l}21.8 \\
21.6\end{array}$ \\
\hline 1.12 & $151 \cdot i$ & $\begin{array}{l}\text { lind } \\
\text { Yhicitl }\end{array}$ & $\begin{array}{l}26.2 \\
23.2\end{array}$ \\
\hline $1 \cdot 111$ & $1>1 \cdot 1$ & $\begin{array}{l}\ln (\mathrm{n} l \\
\text { linislel }\end{array}$ & $\begin{array}{l}27.4 \\
11.7\end{array}$ \\
\hline 1.24 & $t \rightarrow 1 ; R \mid 1,1$ & $\begin{array}{l}\text { Iint } \\
\text { stivide }\end{array}$ & $\begin{array}{l}28.4 \\
26.3\end{array}$ \\
\hline 118 & $|-|=K \mid 1,-1$ & $\begin{array}{l}\text { Indit } \\
\text { vlitelu }\end{array}$ & $\begin{array}{l}2 \neg .2 \\
20.3\end{array}$ \\
\hline 11.15 & $1>1-7, K 11, .1$ & $\begin{array}{l}\text { Inthl } \\
\text { Thinglu }\end{array}$ & $\begin{array}{l}24.2 \\
24.8\end{array}$ \\
\hline 121.133 & $(>1,4 R \mid 1,4$ & $\begin{array}{l}\text { Iant } \\
\text { shiclel }\end{array}$ & $\begin{array}{l}20.8 \\
21.2\end{array}$ \\
\hline $11 \cdot 41$ & $(-1,4) \mathrm{K} / \mathrm{d}, 5$ & $\begin{array}{l}\text { Iint } \\
\text { Shitidu }\end{array}$ & $\begin{array}{l}26.3 \\
23.3\end{array}$ \\
\hline
\end{tabular}
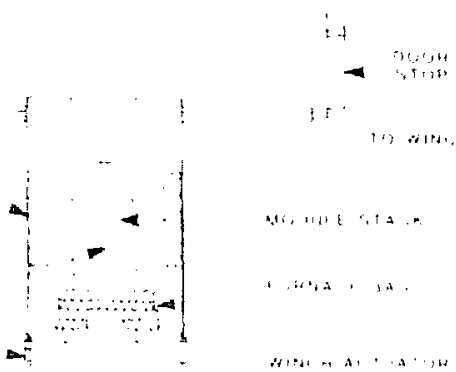

i

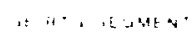
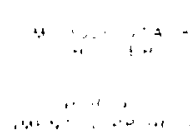

$\ldots+\cdots+4$

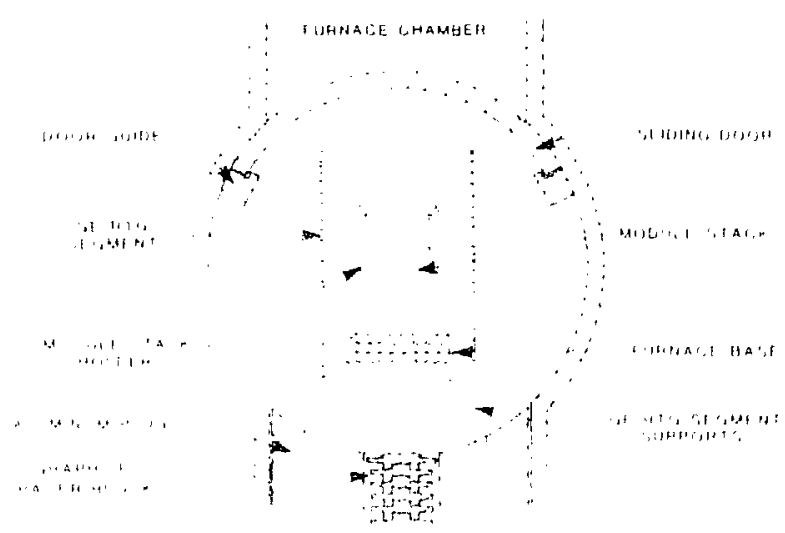

(h)

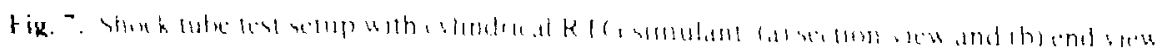




\begin{tabular}{|c|c|c|c|c|c|c|}
\hline \multirow{2}{*}{$\frac{\text { Iest }}{\text { B.11-1 }}$} & \multicolumn{2}{|c|}{$\begin{array}{c}\text { Oierpressure } \\
\text { (IIPa) }\end{array}$} & $\begin{array}{l}\text { Impulse } \\
\left(k t^{3} a \cdot s\right)\end{array}$ & \multirow{2}{*}{$\begin{array}{l}\text { Tube l.tugth } \\
-\frac{(\mathrm{mI})}{20.1}\end{array}$} & \multirow{2}{*}{$\begin{array}{l}\text { Charge } \\
\text { (kg) } \\
5.90-4\end{array}$} & \multirow{2}{*}{ Catch Medium } \\
\hline & 1.4 & -11.117 & $8.4=1.4$ & & & \\
\hline$B \backslash I I-2$ & 5.1 & 0.21 & $22.1+2.8$ & 20.1 & $27.2(-4$ & vermiculite \\
\hline B.11-3 & 7.4 & +0.34 & $25.9+3.5$ & 20.1 & $49.9(-4$ & vet ificulite \\
\hline $\mathrm{CST}-1$ & 5.1 & +0.48 & $22.1 \pm 2.8$ & 17.7 & $27.2(-4$ & vermiculite \\
\hline$C \rightarrow 1-2$ & 7.1 & $=0.69$ & $25.9=5.2$ & 18.6 & $48.1(-4$ & rermiculite \\
\hline $\mathrm{CSI}-3$ & 11.6 & $=2.1$ & $29.0+5.5$ & 20.7 & $81.0(-4$ & vermiculite \\
\hline $\operatorname{cst} 4$ & 122 & +1.2 & $27.6+5.5$ & 18.9 & $116.40-4$ & vermiculite \\
\hline CSI-5-KI(i-1 & 12.5 & $=1.2$ & $27.6 \pm 5.5$ & 18.9 & $116.40-4$ & vermiculite \\
\hline (CY-6-RTLi-2 & 13.5 & +1.3 & $23.2+4.8$ & 14.9 & $136.2(-4$ & sawdust \\
\hline C $S \mathrm{~T}-7-\mathrm{RTG} \mathrm{C}-3$ & 12.4 & +2.5 & $23.5 \pm+.8$ & 14.6 & $125.8 C^{\prime}-4$ & sawdust \\
\hline CSI-8-RIC;-4 & 2.96 & $=0.28$ & $14.5 \div 2.8$ & 19.5 & $12.56-4$ & Gawdust \\
\hline CSl-4-RICi-5 & 15.3 & +1.5 & $16.6 \pm 3.5$ & 14.6 & 9.3 .1 comp B & sandust \\
\hline
\end{tabular}

\section{(C. Bare Module lest ?}

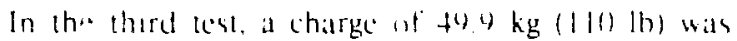
detonated at the end of a 20.1 -m-long shock tube to (reate a hlast watce of $7 .+ \pm(1.34 \mathrm{MPa}(10) 70) \pm 50$ psi) werpressure and $25.9 \pm 3.5 \mathrm{kPa} \cdot 3(3.75 \pm 0.5 \mathrm{psi} \cdot 3)$ impulse at the test molute locituon. The hlast wave stripped the graphite compunents from the heated $11095+561$ test clack three of whath were recovered approxumatcly $36 \mathrm{~m}$ deep in the catch tube. A fourth capsule penetrated the plyword bulkhead at the rear of the catch tube and came to rest about 10 ? me behind It (an dirt). Vone of the clads breatehed. Fragments of the FWPF cumponents (acroshell and impact shells) were recovered throughout the calch tube.

The four fucted clads are shown in Fig. 13. Pisstest sentification of the specific fueled clads was not possible, so the were lateled A. B, C. and D. (apsule D had penetrated the plywond bulkhead. but tt did not exhibit the highest strain. (apsule' $($. which was sectioned before a gross diametral strain could be determined. had a local bend strain of $-4.7 \%$. The diametral strains of the uther fueled clads ranged from 1.9013 to 1.020). The l:0) pellet remored from capsule ( is shown in Fig. If. ()ne end of the pellet was iragmented.

\section{D. rionverter Segment lest 1}

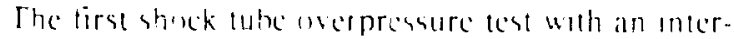
sonong RTCi humbeng smulitm was conducted on "saluale the eflect ut such a heusing on melluke damage.

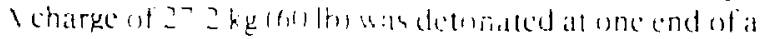

17.7-m-long shesk tuhe lo create a blabl of $5.1 \pm 0.4 \mathrm{k}$ MPa (73h $570 \mathrm{ps})$ averpressure and $22.1 \pm 2.8 \mathrm{kPa} \cdot \mathrm{s}$ $(3.2 \pm(0.4 \mathrm{psi} \cdot \mathrm{s})$ impulse at the test nodule location. The FWPF graphite components were eompletely stripped away from the four simulant-fucled clads. which were recovered at a alch tube depth of about $2.2 \mathrm{~m}$. None of the clads breached. We recovered 30 pieces of the GE segment with an average weight of $2.43 \mathrm{~g}$ ) and small fragments of the thermolements and insulation from the catch tube.

The four fueled clads are shown in Fig. 15. Postlest identification of the specific fueled clads was not possible. so the clads were labeled 1, 2, 3, and 4, in the order they were recovered. The fucled clad diametral strains ranged from 1.02210 !.(1) 69 . with Clads 1 and 3 showing the greatest $\mathrm{M} / \mathrm{m}$. (lad I was sectioned and the urania was sized. Particle size data are shou'n in Table II.

Macroscopic examination of ("lad 1 revealed a deep crater (Fig. 16) on the vent cup radius. Subsequent microscopic examination revealed that at its decpest point, the crater penetrated less than $25^{\prime \prime} \%$ of the total wall thickness. Significant grain elongation occurred in the cratered area (Fig. 17).

Both iridium cups were tine grained. The average grain size of the vent cup was 21.9 grains/thickness, and the average grain sizc of the weld thicld cup was 23.1 grains/thickness (Sece Table III). No areas of grain coarsening were observed on either cup.

Examination of the capsule weld revealed a normal microstructure with full penetration. The capsule vent (Fig. 18) was negligibly deformed and contained no mechanical defects. The rent assembly and decomtamination coser welds were line gramedi. 


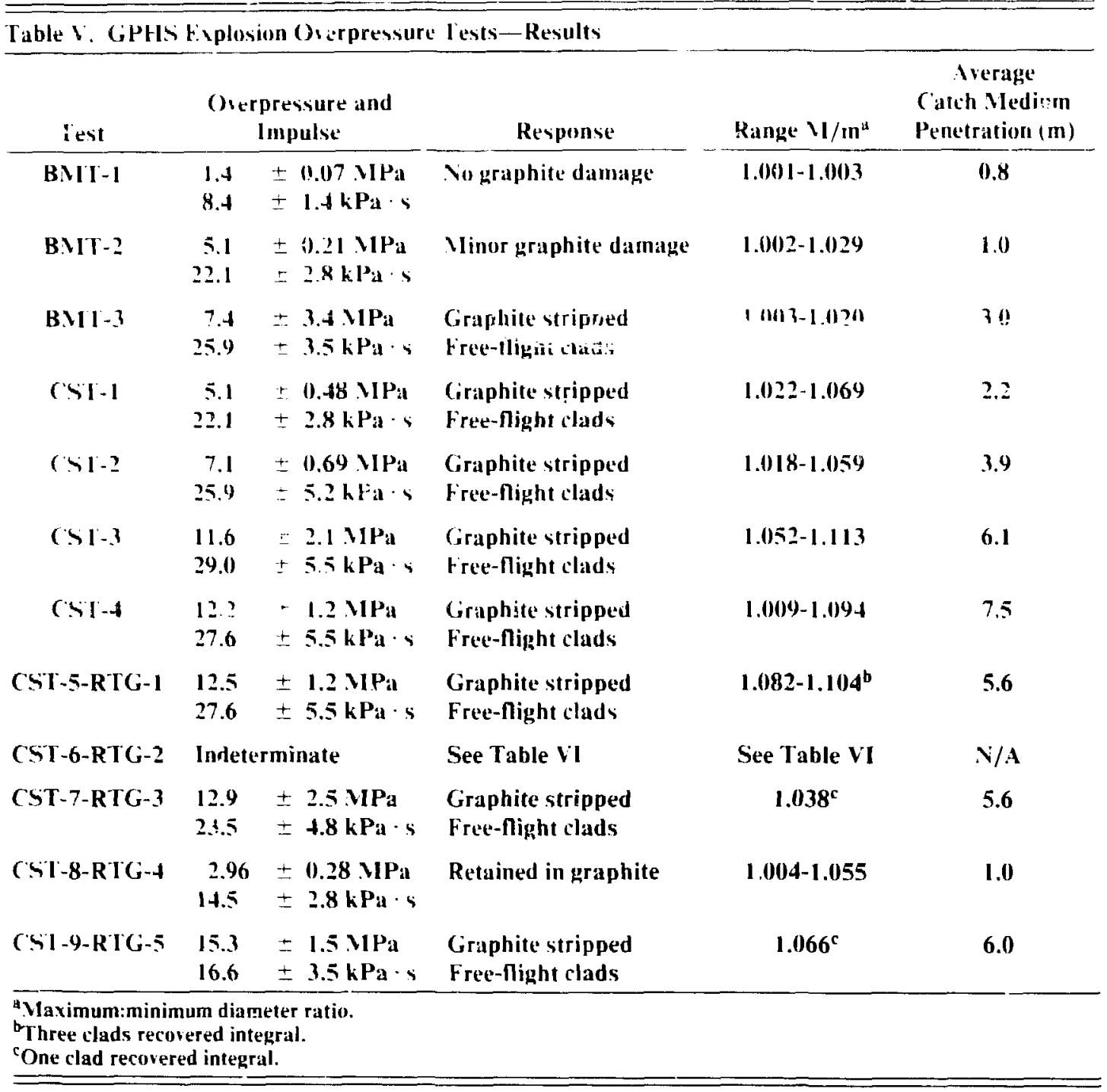

\section{E. Converter Segment Test 2}

A second test with an intervening RTG housing simulant (CST-2) was conducted at a slightly higher overpressure. A blast of $7.1 \pm 0.64 \mathrm{MPa}(1028 \pm 100$ psi) overpressure and $25.4 \pm 5.2 \mathrm{kPa} \cdot \mathrm{s}(3.75 \pm 0.5 \mathrm{psi} \cdot \mathrm{s})$ impulse was calculated at the lest mixlule location when a 48 . I-kg (l)6-lb) calarge was detonated at the other end of the 18.6-m-long shock lube. The blast stripped the FWPF graphite components from the four fueled clads hut none of the clads hreached. The clat's were recovered at a calch tube depth of about $3.9 \mathrm{~m}$. We also recovered 31) pleces of the (iE. RTC i segment. atveraging $1.45 \mathrm{~g}$. and smail preces of the thermetements and inculation.
The four fueled clads are shown in Fig. 19. We were able to identify specific fucled clads bu comparing pretest and posttest clad vent photographs. The fucled clad diametral strains ranged from 1.018 to 1.059. Clad IRG-128. with an $\mathrm{M} / \mathrm{m}$ of 1.059 . was sectioned and the fuel simulant was sized. Sec Table: Il for particle size data.

Macroscopic examination of the exterior of clad IRG-128 did not revcal any cracks. craters. or other defects. Microscopic examination of the capsule weld revealed a porous but otherwise acceptable microstructure. The weld bead was narrow and fully penetrated the capsule wall. Both iridium cups were uniformly fine grained (Table III). 
The capsule venl (Fig. 20) was undeformed and contained no mechanical defects. The vent assembly and decontamination cuer welds were tree of grain growth.

\section{F. Converter Segment Test 3}

In CST-3, the charge was increased to $81 \mathrm{~kg}(178.5 \mathrm{lb})$ to generate a blast of $11.6 \pm 2.1 \mathrm{MPa}(1684 \pm 300 \mathrm{psi})$ overpressure and $29.0 \pm 5.5 \mathrm{kPa} \cdot \mathrm{s}(4.2 \pm 0.8 \mathrm{\Gamma si} \cdot \mathrm{s})$ impulse at the test module location. Time-ofarrival data from pressure transducers indicated an accorating shock wave in the $20.7 \mathrm{~m}$-long shock lube. This phenomenon, probably caused by side-wall turbulence. increased the uncertain's of the calculated overpressure. The FWPF graphite components were again stripped away, but none of the clads breached. The clads were recoverd about $6.1 \mathrm{~m}$ cerp in the vermiculite. We recovered 35 pieces of the GE segment with an average weight of $0.52 \mathrm{~g}$. Small pieces of the thermoclements and insulation were also recovered.

The four tueled clads are shown in Fig. 21. The clads. which were identified from laser etchings on the clad exteriors, had diametral strains ranging from 1.052 to 1. 1 13. Clad L-12, with an $\mathrm{M} / \mathrm{in}$ of 1.080, was selected for secioning because a deep crater was observed on the weld shield cup. Pariicle size data are listed in Table II.

Microscopic examination of clad $\mathrm{L}-12$ revealed that the crater on the wcld shield cup penetrated $38 \%$ of the wall thickness (Fig. 22). The capsule wall within the crater displayed significant luctility (Fig. 23).

Hthough the closure weld (Fig. 24a) was completely free of porosity and other defects, it had an abnormal microstructure (Fig. 24b). While it is unclear how such an unusual microstructure could form, the orientation of long columnar grain: along the weld centerline would substantially reduce the tensile strength of the weld. No cracks or other defects were observed at any point on iin weld surface.

As in previous C.ST clads. the irldium cups were uniformly fine grained (Table (II). and the capsule vent was undeformed and free of mechanical defects (Fig. 25). However, a small, nonpenctrating crack was observed on one side of the vent assembly (Fig. 26). The vent cover and assembly welds were completely frec of abnormal grain growth.

\section{G. Converter Segment Test 4}

In this test. a $116.4-\mathrm{kg}(256.5-1 \mathrm{~h})$ charge was detonated at the end of an $18 . \%$-m-long shuck tube to produce a hlast of $12.2 \pm 1.2 \mathrm{MPa}(1750 \pm 175 \mathrm{psi})$ uverpressure and $27 . h \pm 5.5 \mathrm{kPa} \cdot \mathrm{s}(4.0)=0.8 \mathrm{psi}-\mathrm{s})$ impulse at the tes, module location. The elads were recovered at a vermiculite depth of about $7.5 \mathrm{~m}$; nonc were breached. Small impact craters, ranging in size from pin points up $106.4 \mathrm{~mm}^{2}$. were observed on all of the clad exteriors; no iridiun sracking was observed within or adjacent to any of the craters. Only eight pieces of the (iE segment, with an average weight of $0.99 \mathrm{~g}$, were recovered from the catch tuhe. No pieces of the thermoelenents or insulation were recovered.

On an $x$-ray film, one fueled clad appeared approximately $3.2 \mathrm{~m}$ from its original test position. The $x$-ray geometry is shown in Fig. 27. If we assume a delay time of 12 ms from detonation and :se a 4.3 -ms shock wave arrival time at the test position, the clad velocity was approximately $414 \mathrm{~m} / \mathrm{s}$ (neglecting acceleration).

The clads, shown in Fig. 28, were identified from laser etchings on the clad exteriors. The diatectral strains ranged from 1.009 to 1.094. Clad L-10. with an $\mathrm{M} / \mathrm{m}$ of 1.094 , was sectioned. Particle size data are shown iti Table II.

A large crater occured on the blind cun of capsule L-10. A transverse section, which contained the iarge crater and a smaller indentation (Fig. 29), was removed for metallography. Examination of the large crater rovealed that it penetraled more than $70 \%$ of the wall thickness (Fig. 30). The crater rim exhibited a small amount of interual grain be ndary crinking. The capsule wall within the crater (Fig. 31, was severcly deformed with significant gram elongition and little recrystallization. The sma!l indentation (Fig 32) was similar to the large crater, differing only in size and in the symmetry of deformation.

A cratered section of the L-10 vent cup (Fig. 33) was also removed for examination. A large crater in this cup penetrated approximately $40 \%$ of the wall thickness. The deformation pruduced a remarkable pattern of internal grain boundary cracks (Fig. 34) on one side of the crater.

The $\mathrm{I}-10$ closure weld had no observable defects and had a typical microstructure. Both of the L-10 iridium cups were uniformly fine grained (Table III).

Examination of a vent cross section (Fig. 35) revealed that the vent was undeformed and free of mechanical defects. However, both sides of the vent assembly weld were cracked (Fig. 36). No abnormal grain growth occurred at the vent assembly or decontamination cover welds.

\section{H. Converter Segment Test 5}

In CST-5-RTri-1, the C-shaped converter simulant used in the first four (STs was replaced with a cylindrical RTG sintulant. As in CST-4. a charge of $116.4 \mathrm{~kg}$ $(256.5 \mathrm{lb})$ was detonated at the end of an $18.9-\mathrm{m}$-long shock tube. A blast of $12.5 \pm 1.2 \mathrm{MPa}(1815 \pm 180 \mathrm{psi})$ overpressure and $27.6 \pm 5.5 \mathrm{kPa} \cdot 5(4.0 \pm 0.8 \mathrm{psi} \cdot \mathrm{s})$ 
impulse impacted the heated $\left(1091 \pm 10^{\circ} \mathrm{C}\right)$ module stack suspended inside the simulated RTG. The FWPF graphite components were stripped from the clads, three of which were recovered intact at a depth of about $5.6 \mathrm{~m}$. The fourth clad. recovered $9.0 \mathrm{~m}$ into the catch tube. breached. This clad was embedded in a plywood bulkhead that separated the dirt backfill from the catch tube media. Approximately 0 pleces of the RT Li siniulant, with an average weight of $0.54 \mathrm{~g}$. were recovered. Most of the $4.7-\mathrm{mm}$-thick stainless steel weight segments and a few small pieces of therrioclements were also recovered.

All four clads were recorded on the $x$-ray films. The images showed that the capsules were integral and were close to a spinning high-density fragment. We belic ve that the high-density fragment. identified as a stainless steel weight. collided with one of the clads. This collision breached the clad and accelerated it, so that it penetrated the catch media much deeper than did the other clads. Clad velocities determined from the $x$-ray films (Fig. 37) ranged from about 409 to $424 \mathrm{~m} / \mathrm{s}$ (neglecting acceleration time)

The four fucled clads are shown in Fig. 38. Diameter ratios of the integral clads ranged from 1.082 to 1.104 . Clad L-24, with an $\mathrm{M} / \mathrm{m}$ of 1.104 . was sectioned and submitted for particle size analysis. Urania particle size uata ar" shown in Table 11.

Metallographic specimens were removed from both of the L-24 iridium cups. Examination of a severely daformed shield cup section (Fig. 39) reveaied slight surface gouging and an unusual amount of grain elongation (Fig. 40). Similar grain elongation was observed in a deformed section of the vent cup (Fig. 41). Both cups were uniforml: fine graned (Table III). The closure weld did not contain any observable defects ard had an acceptable microstructure.

The capsule vent (Fig. 42) was not significantly deformed and was free of mechanical defects. However. one side of the vent assembly weld (Fig. 43) was cracked. The vent cover and assembl: welds were free of abnormal grain growth.

Clad L-18, which struck the plywood, had a total breach area of $155.1 \mathrm{~mm}^{2}$ through which approximately half of the fuel was released. A cross section of the capsule breach (Fig. 44) was carefully examined. A notable feature of this section was the deep gouging and surface cracking observed mainly on one side (vent cup radius. toward weld) of the breach (Fig. 45). Both sides of the liacture had a brittle. intergranular appearance (Fig. 46) with only slight grain clongation. Significant grain elongation (Fig. 47) did. howcver. occur in other areas of the weld shield cup.

Examination of a mildly deforn. ad sent cup section (Fig. 48 ) revealed a deep crack that penet ated $80^{12}$ of the capsule wali. The crack was intergraılular and originated on the interior surface.

Both L-18 iridium cups were uniformly fine grained (Table 111). The closure weld was defect free and had an acceptable microstructure.

Examination of the capsule vent reveaied that it had been severely deformed (Fig. 49). The vent assembly and decontamınation cover welds had very tine-grained microstructures.

\section{Converter Segment Test 6}

in the sixth CST, we generated a blast of $13.5 \pm 1.3$ $\mathrm{MPa}(1902 \pm 190 \mathrm{psi})$ overpressure and $23.2 \pm 4.8$ $\mathrm{kPa} \cdot \mathrm{s}(3.36 \pm 0.7 \mathrm{psi} \cdot \mathrm{s})$ impulse at the test module location. In order to have an adequate supply of overpressure-tested clads available for seguential tests. the test assembly consisted of a 3-module stack containing 12 sinulant-fucled capsules. One bulk graphite halfmodule was placed above and another was placed below the stack. The catch tuhe was filled with sawdust, instead of vermiculite, to avoid a suspected chemical interaction of the tridium and vermiculite. The stainless steel weights in the RTG simulant were also replaced with layers of stainless steel foil to eliminate the possibility of clad failure from collision with one of the highdensity weights.

The test assembly was not exposed to the intended overpressure. Instead, the module stack remained in the furnace and was ejected through the top of the furnace extension. Apparently, a thermocouple inserted in to the top bulk grapiaite half-module failed to release, causing the module stack to become wedged in the furnace. However, we had no evidence that the module stack tiad remained in the furnace. Meanwnile, the vidco monitor in the insirumentation bunker showed the actuation of the winch, indicating that the air cylinder piston had lowered, but a cable connecting the winch to the sliding door failed before the door was completely closed. The countdown was placed on hold while the decision was made to conduct the test with the sliding door only partially closed.

Test debris was scattered over a wide area as stown in Fig. 50. We recovered all clads except for two from the bottom module, A-GIS (open) and C-GIS (blind). Four of the recovered fueled clads were still retained in graphite as shown in Fig. 51. Six clads were recovered barc, three of which were integral (Fig. 52). The remaining breached clads are shown in Fig. 53. All clads werc positivcly identified from laser etchings on clad exteriors. Results from this test are summarized in Table VI. No urania particle size data were obtained. 


\begin{tabular}{|c|c|c|c|c|c|}
\hline $\begin{array}{c}\text { Clad } \\
\text { location }\end{array}$ & Clad & $\begin{array}{l}\text { Recovery } \\
\text { Condition }\end{array}$ & $.11 / \mathrm{m}$ & $\begin{array}{c}\text { Breach Area } \\
\left(\mathrm{mm}^{2}\right)\end{array}$ & $\begin{array}{c}\text { Fuel } \\
\text { Kelleased } \\
\text { (g) }\end{array}$ \\
\hline \multicolumn{6}{|l|}{ I up Vlodulc } \\
\hline 1-(is (blind) & $11-10$ & Integral (in (ils) & 1.0 .33 & $21 / 1$ & $x / A$ \\
\hline (opt:in) & 3111 & Integral (in (ilS) & 1.106 & $\dot{V} / \mathrm{A}$ & $N / A$ \\
\hline ('-GIS (blind) & $11-12$ & Integral (in Gis) & 1.011 & $Y, A$ & $N / A$ \\
\hline (open) & $.11-15$ & Integral (hare) & 1.026 & $x / A$ & $Y / A$ \\
\hline \multicolumn{6}{|l|}{ Middle Vlodule } \\
\hline A-cis (blind) & $11-9$ & Integral (in Gis) & $1.0-48$ & $V / A$ & $N / A$ \\
\hline (open) & $.11-22$ & Breached (bare) & --- & Vot measurable & $113.8(75 \%)$ \\
\hline ( -cils (blind) & $11-23$ & Integral (bare) & 1.100 & $V / A$ & $N / A$ \\
\hline$(0 p+n)$ & $11-26$ & Integral (bare) & 1.015 & $N / x$ & $y / A$ \\
\hline \multicolumn{6}{|l|}{ Bottom Module } \\
\hline A-Gls (blind) & $11-8$ & Breached (bare) & $\cdots$ & 123.8 & $5.752\left(2.8^{\circ} \cdot 0\right)$ \\
\hline (open) & $.11-17$ & Vint recovered & --- & $\cdots$ & $\cdots$ \\
\hline (-cils (blind) & $.11-18$ & Vet recovered & $\cdots$ & --- & --- \\
\hline (open) & $.11-20$ & Breached (bare) & $\cdots$ & Vot measurable & $150.3(1000 \%)$ \\
\hline
\end{tabular}

\section{J. Converter Segment T-i 7}

CST-7-RTG-.) was a second attempl all exposing the (iPHS RTC simulant lo a nominal $13.8 \mathrm{MPa}$ (2000 psi) (verpressure. The iest setup was similar to CST-6$R T(i-2$ with the folluwing exceptions:

(1) ()nly a sungle test modulc containing four simulant-lueled clads was exposed.

(2) + thermexiuple was suspended between the $R T$ C ismulant and the module stack to verify test stack position.

(3) An indicator was installed to verifi complete door closure

(t) A thermocouple was not inserted in the top bulk graphite module of the module stack. instead, stack temperalure was estimated by extrapolating from curnace lemperature and data of previous tests.

We detonated $125.8 \mathrm{~kg}(277 \mathrm{lb})$ of explosive at the end of a 14.6-m-long shock (ube to create a blast wave of $12.9 \pm 2.5 \mathrm{MPa}(1873 \pm 360$ psi) overpressure and $23.5 \pm 4.8 \mathrm{kPa} \cdot \mathrm{s}(.4 .4 \pm 0.7 \mathrm{psi} \cdot \mathrm{s})$ impulse at the test

: vdule location. Timc-of-arrical data indicated an accelerating shock wave, probahly due to a turbulent or nonplanar shock front. This shock wate phenomenon increased the uncertainty in the calculated overpressure and mat hate significantly affected the lest module response.

Clad $11-35$ from the open end of the (-) (ils was recoureded integral at a sawduse deptin uf 56 m (Fig. 54).
Clad M-30 from the blind ent of the A-GIS and six iridium fragments were recovered at a depth of about $3.5 \mathrm{~m}$. Clad M-30 (Fig. 55) was breached. and over half of the fuel simulant had been released. The total recovered weight of the six clad fragments was $45 \mathrm{~g}$. The two remai sing fueled clads were not recovered. We believe that misalignment of the shock tube and catch tube before the test and shock tube movement during the test caused these clads to miss the catch tube.

The six clad fragments ranged in size from $9.37 \mathrm{~mm}^{2}$ to $28.9 \mathrm{~mm}^{2}$. All of the fragments contained deep striations and cracks on the exterior surfaces, suggesting impact against a large object or by high-velocity metal fragments. The clad fragment containing the decpest striations (Fig. 56) was selected for scanning clectron microscope (SEM) examination.

Macroscopic examination of the fragment extcrior revealed numerous surface cracks and deep gouges containing deposits of unknown origin. Microscopic analysis of ene of the cracks (Fig. 57) indicated the presence of only iridium in the crack (Fig. 58). Microscopic analysis of a gouge (Fig. 54a) indicated the presence of both iridium and iron (Fig. (0)). Elemental dot-mapping of the gouge clearly identified the iron (Fig. 59h) and iridium (Fig. 59c) areas. The analyses show that iron deposits were present in striations on the clad exterior: no iron was detceted in cracks that postdated the striations. These results indicate that the clads were cither struck by stecl fragments or were thrown against the shock tube or catch tube walls. 
Clad $11-35$, with an $\$ 1 / \mathrm{m}$ of 1.038 . Was sectioned and the fuel simulant was sized. Lirania particle size data are listed in Table 11. Macroscopuc examination of clad M-35 revealed a l-ent-diameter dent and a smali fragment puncture. typical of craters observed in other (ST clads, on th: vent cup radius. A section of the M-35 clad. contanning the small crater, was submilted for clectron mucoprobe anilysis te identifi the material in the crater. The analysis indicated that the principal constituents were aiuminum and silicon. with lower concentrations of potassium. calcium. and tron. The $\mathrm{x}$ ray spectrum produced was similar to that fron clay minerals such as orthoclase.

1 deformed section of the $11-35$ vent cup (Fig. b1) revealed slight grain clongation along the external surfice and a reduetion in thickness of about $27 \mathrm{~m}_{0}$. The capsule weld (Fig o2) was unusually coarse grained. but it fully penetraled the capsule wall. Both indium cups were untivenly line grained tTable lll).

\section{k. Converier Segment Iest 8}

(ST-\&-RTGi-t wals designed to delermine tive minimum overpressure at which the graphite is stripped away from the fueled clads. A charge of $12.5 \mathrm{~kg}(275 \mathrm{lb})$ was detonated at one end of a $19.5-\mathrm{m}-$ !ong shock tube to (reate a hlast wate of $2.96 \pm 0.28 \mathrm{MPa}(429 \pm 40 \mathrm{psi})$ overressure and $11.5 \pm 2.76 \mathrm{kPa} \cdot \mathrm{s}(2.1 \pm 0.4 \mathrm{psi} \cdot \mathrm{s})$ impulse a: the lest moduic location. Test setup and procedures were identical to those in CST-7-RTG-3. except that two simulant-fucled Light Weight Radioisotope Healer (init (LWRHt s) mounted to the side walls of the shock tube were also exposed to the hlast wave.

The graphite was not stripued from the tueled clads. The test module. recotered at a sawdust depth of $1 \mathrm{~m}$. had two cracks coincidene with the A-GIS major diameler on each side of the broad faces of the aeroshell (Fig. 63). tll graphite remained in place including the module closure caps. The $A$ - and (-GISs were cracked (Fig. $6+1$ and the carbon-bonded carbon-filament (CBCF) graphite insulation was about $50 \%$ powdered. We recovered 28 fragments of the RTG simulant. with a total weight of $898.78 \mathrm{~g}$. from the eatch media: the RTG fragments ranged in weight from $0.5710164 .14 \mathrm{~g}$.

The four fueled clads are shown in Fig. 65. The clad deformations ranged from 1.10)4 to 1.055. Clad IRG-13.3. With an $.11 / \mathrm{m}$ of 1.1155 . was sectioned and the sumulant fuel was siged (lable ll). Macroscopic examinaton of the exterior of IR $(-1,3.3$ did not reveal any cracks. craters, or wer defects. Micrescopic examinalun of the capsule weld reveated an acceptable mierestructure. The weld head uas marrou and fulls pein. .rated the capsule wall. Both iridium cups were uniformly tine grained ( Tabic ili).

The simulant-fucled LWRHL's (tig. to) were recovered integral from the catch tube at a depth of about $2 \mathrm{~m}$. The external casing on each unit was slightly pitted and gouged. and the insulation was slightly cracked. but no significant deformation oceurred

\section{Converier Segment Test 9}

(ST-9-RTG-5 was a third attempt at exposing the GPHS module to a nominal $13.8 \mathrm{MPa}(2000$ psi) overpressure. To nunimiec a recocillence of the hlast wave turbulence observed in (ST-7-RTG-3, we used a Lus tlamos-cast and -machined composition B charge and a plane-wave detonation generator. An enginecring test (CST-ENC) was conducted to test the charge response and permit nocessary adjustments before the actual test. The charge fo- (ST-EN(i. $116.2 \mathrm{~kg}(256 \mathrm{lb})$, performed favorably according to the increased time-of-arrival data. However. the blast wave overpressure, $15.2 \pm 1.4$ $\mathrm{MPa}(2200 \pm 200 \mathrm{psi}$ ). was higher than anticipated.

The charge for CST-4-RTG-.5 was reduced to $93.1 \mathrm{~kg}$ $(205 \mathrm{lb})$. After the test selup was verified, the charge was detonated and a blast wave of $15.3 \pm 1.5 \mathrm{MPa}(2212 \pm$ $220 \mathrm{psi})$ overpressure and $16.6 \pm 3.5 \mathrm{kPa} \cdot \mathrm{s}(2.4 \pm$ $\mathrm{psi} \cdot \mathrm{s})$ impulse impacted the heated (1091 $\left.110^{\circ} \mathrm{C}\right)$ module stack. The high overpressure was attributed to a change in the length-to-diameter ratio $(L / D)$ of the charge, which modified the directed blast energy. The $L / D$ of the cylindrical charge in CST-ENG was 0.49 . whereas the charge L/D in CST-9-RTG-5 was 0.39 . According to SNLA data. there is little variation in charge response of Composition $\mathrm{C}-4$ explosives when the $L / D$ is in the range of 0.4 to 0.6 for identical weight charges. We assumed that Composition B charges would follow the same guidelines.

The blast wave stripped the graphitics from the simulant-fueled clads. Clad M-46, from the blind end of the C-GIS (Fig. 67), was recovered in two pieces at a sawdust depth of $3.8 \mathrm{~m}$. Most of this clad was recovered $0.76 \mathrm{~m}$ south of, and $0.70 \mathrm{~m}$ lower thar. the original shock tube centerline. It contained approximately half of the simulant fuel. Particle size data of the retained fuel are shown in Table II. An iridiun fragment identified as part of clad M-46 was recovered about $0.61 \mathrm{~m}$ north of the centerline. The larger portion containing the fuel appeared to have a downward trajectory as judged by its position in the sawdust.

A second clad. M-40 from the blind end of the A-Cils. was recosered integral at about $6.0 \mathrm{~m}$ deep and $(1.4 \mathrm{~m}$ north of the original certerline (Fig. 68). The two remaining fieled clads were not recosered. The entire 
shock tube was displaced about $0.5 \mathrm{~m}$ ioward the catch tube and about $0.7 \mathrm{~m}$ north by the blast. We believe that the iwo missing clads. which had been on the nutth side of the module stack, had trajectories that missed the catch tube.

The iridium fragment from $M-46$ was examined to determine the probable cause of tailure. Macroscopic examination revealed striations and cracks (Fig. 69) on the exterior surface, suggestive of collision with a large object or high-velocity metal fragment. Energy dispersive spectrometer (EDS) analysis of the fragment fracture surface at low magnitication produced spectra indicating iridium and iron (Fig. 70). The specimen (Fig. 7la) was dot-mapped to clearly identify the iridium (Fig. $7 / \mathrm{b}$ ) and iron (Fig. $7 / c$ ) areas. Highmagnification EDS spectra (Fig. 72) of the same area (Fig. 73a) also indicated the presence of iridium and iron on the exterior surface. Dot mapping of the area shows the surface distribution of iridium (Fig. 7.jb) and iron (Fig. $73 \mathrm{C}$ ). These results suggest that the clad collided with a steel object (either the shock tube or catch lube walls).

Clau M-40 was sectioned and the fuel simulant was sized. Particle size data are listed in Table ll. Examination of a cratered section removed from the vent cup (Fig. 74) revealed significant grain slongation (Fig. 75). The crater pene';ated approximately $35 \%$ of the capsule wall. The capsule weld had a typical microstructure. and both irıdium cups were uniformly fine grained (Table (II).

\section{DISCLSSION}

The results of the postnortem examinations indicate a correlation between overpressure and fueled clad damage. (lad deformation (Table $\mathrm{V}$ ) shows a tendency to increase as the overpressure increases. The overpressure. acting through an RTG housing, strips the graphite away from the fueled clads at a minimum overpressure between $2.96 \mathrm{MPa}(429 \mathrm{psi}$ ) and $5.1 \mathrm{MPa}$ (736 psi), leaving only bare capsules to resist subsequent impacts. Without the intervening housing, the graphite is stripped away at an overpressure between $5.1 \mathrm{MPa}$ $(735 \mathrm{psi})$ and $7.4 \mathrm{MPa}(1070 \mathrm{psi})$.

The RTG housing does not act as a protective shicld for the GPHS modules as was originally assumed in prior RTG design and test programs. The first CST. conducted at the same hlast parameters as BMT-2. showed a marked increase in damage to the (iPHS module. The intervening RTC; housing apparently acts as a flyer-plate-type fragment. The housing fragment suess are inversely proportional to the overpressure.
None of the fucled clads appeared to be breached by the overpressure alone. All of the breached clads (in CST-5-RTG-I, CST-7-RTG-3, and CST-9-RT (i-5) apparently collided with high-densitv fragments. The breached fueled clad in CST-5-RTG-1 may have been hit by a stainless steel weight segment from the GE RTG simulant, and clads in CST-7-RTG-3 and CST-9-RTG-5 apparently breached as a result of collision with the shock tube or catch tube walls.

Surface cratering on the fueled clads does not appear to be directly related to the overpressure exposure. Electron microprobe analysis of a typical erater in the CST-7-RTG-3clad indicated that a possible causc of the crater was dirt, which was probably propelled down the shuck tube with the blast wave.

The explosion overpressure hydrostatically compresses the rlad around the fuel, reducing or eliminating the gaps between components. This effect becomes more pronounced as the overpressure increases.

fll of the iridium cups had fine-grained microstructures (Table III). The average grain sizes ranged from 21.9 to 31.7 grains $/ 0.635-\mathrm{mm}$ nominal wall thickness. Although the test temperatures varied slightly, from $1080^{\circ} \mathrm{C}$ io $1110^{\circ} \mathrm{C}$, the performance of the iridium cup: used in the overpressure test series should he considered representative of flight-quality clad response.

\section{v. CONCLUSIONS}

On the basis of the test results described above, we conclude the following about the response of the GPHS to pressures generated in shock tubes by high explosives:

(1) The static pressure required to strip the graphite components from the fueled clads of a bare module is between $5.1 \mathrm{MPa}(735 \mathrm{psi})$ and $7.4 \mathrm{MPa}(1070 \mathrm{psi})$.

(2) The static pressure required to strip the graphite components from fueled clads with an intervening $R T G$ simulant is between $2.96 \mathrm{MPa}(429 \mathrm{psi})$ and $5.1 \mathrm{MPa}$ (736 psi).

(3) Overpressures of up in $15.2 \pm 1.5 \mathrm{MPa}(2200 \pm$ $220 \mathrm{psi}$ ) alone do not appear to result in a fucl release; subsequent collision with a high-density fragment or impact against an unyiclding surface is necessary to breach the clad.

(4) Clad deformation ( $\mathrm{M} / \mathrm{m}$ ) and fuel fragmentation increase with overpressure magnitude.

(5) Fueled clad deformation appears to be independent of location within the moduls. 


\section{H. RECOMMENDATIONS}

It is important for the onerall rafely analysis of the GPHS to determine it: actual oserpressure at which only the acroshell is renoved and that at wheh the (ils

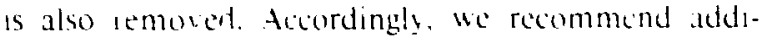
tional testing ?o determinc

(1) The unerpressure threshold at whoth the atershell is removed white still leaving the impact shells intact:

(2) The arerpessure threshold at whict the impact shells are removed from the clads.

\section{ACKVOWLEDGMENTS}

We thank the following people for their valuable assistance in completing these tests: ( $:$ M. Seabourn for his supervision of the hare module lests; L. Berg. F. Mathews. B. Berg and other SNL.A personnel for test range operations and shock wave diagnostics: A. Herrera. M. Anstey. W. Hults, and R. E. Tate for test assembly and postlest recovery; I trcinuleta for metallography and SEM analyses: D. Caringer for particle siec analyses: J. Lucero and $H$. Ciasca for $x$-ray support: (: Baca. [) ( inurl, and F. Martias for design and assembly support; and L. Vaughn for graphite outgassing.

\section{REFFRENCES}

1. "Space Shuttle Diad for Planetary Mission Radioisotope Thermoelectric Generator (RTGi) Safety Analysis." National Aeronautics and Space Administration document JSC 081!6 (February 1985).

2. A. B. Willoughhy. C. Whiton, and J. Mansiicld, "Liquid Propellanı Explosive Hazards," U/RS Corporation document. AFRPL-TR-68-9? (Decenber 1968).

3. "GPHS Safely Verification Test Series Procedures Manual," Los Alamos National Laboratory document MST-5-C-83-19 (April 14. 1983).

4. "CiPHS-RTG System Explosion Test. DIRE'T COURSE Experiment 5000," Advanced Energy Programs Departh.ent, General Elertric (ompany document GESP-7181 (March 1984).

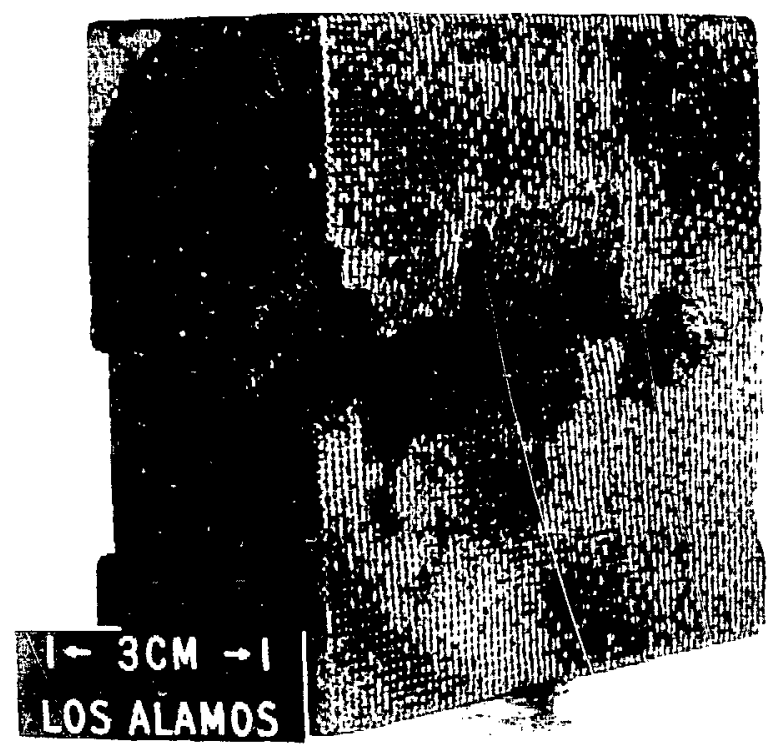

Fig. 8. After the sequential 1.4- and 5.1-MPa overpressure tests, the (iPHS aeroshell was fractured. The blast impacted the narrow surface of the (iPHS module facing up in the figure. 


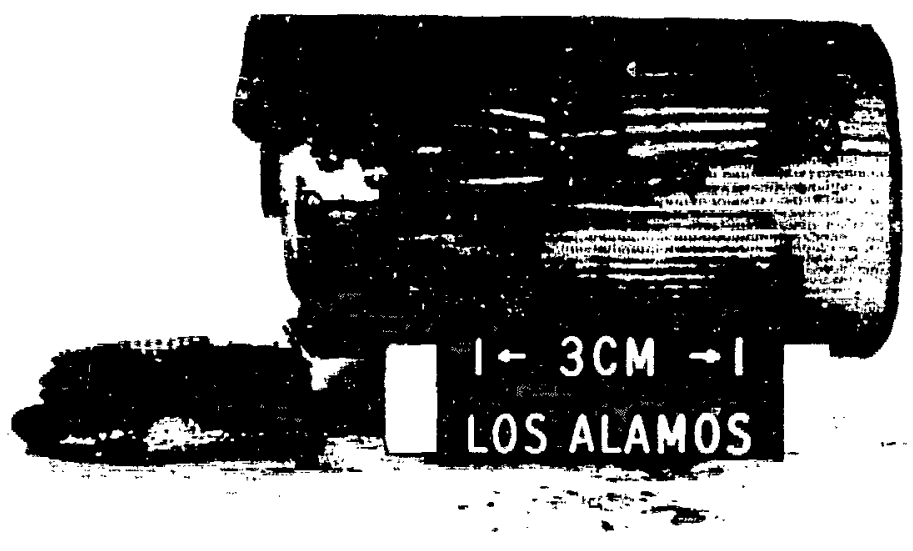

Fig. 9. The ( - ils contanning capsules IR $(\mathrm{j}-1) 7$ and IR ( $\mathrm{j}-118$ was broken after the 5.1.MPa blast. Simulant-fueled clad IR $(i-11 k$ is visble.

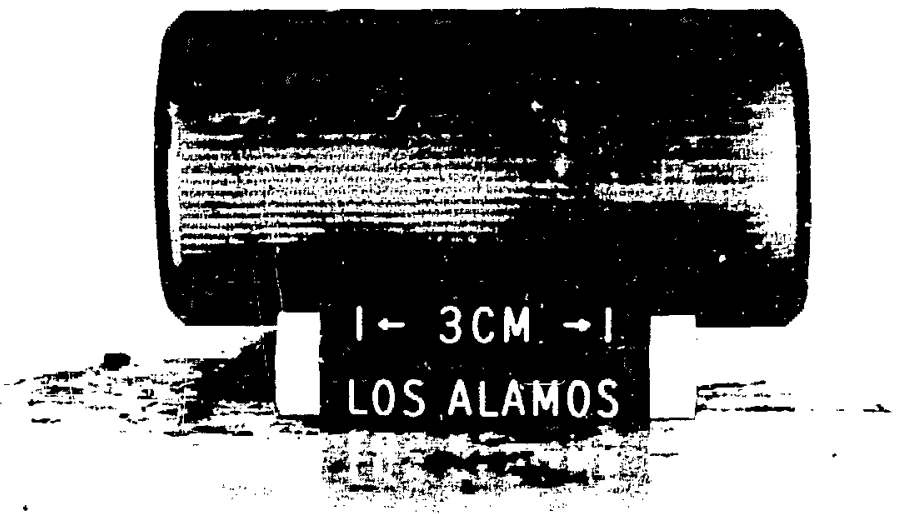

Fig. 10. The d-(iIS containing simulant-fueled clad $I R(i-1] 5$ and $\left[R\left(i-1 \mid f_{1}\right.\right.$ appeated undamaged after the 5 1-.MPa blast. The A-Cils was on the hlast side i) the mendulic 


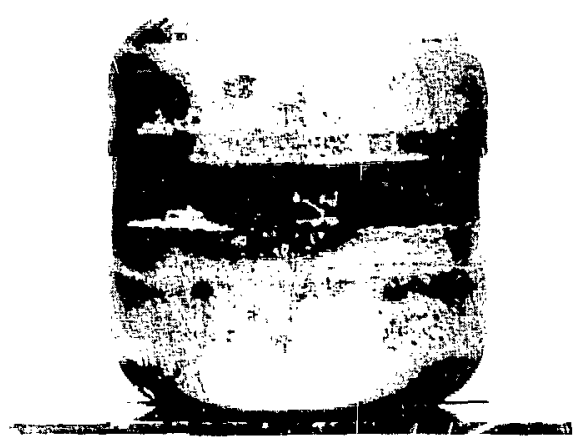

IRGi-115

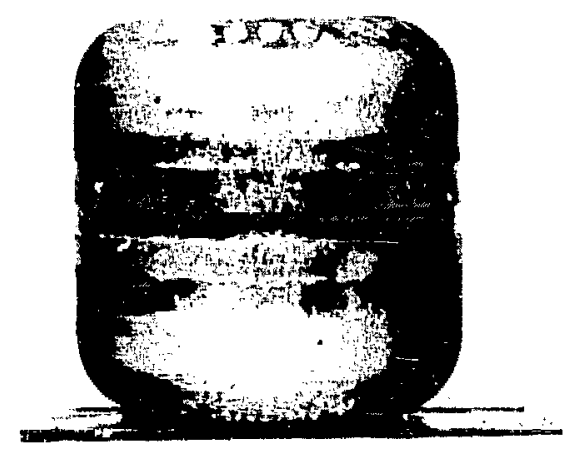

IRG-116

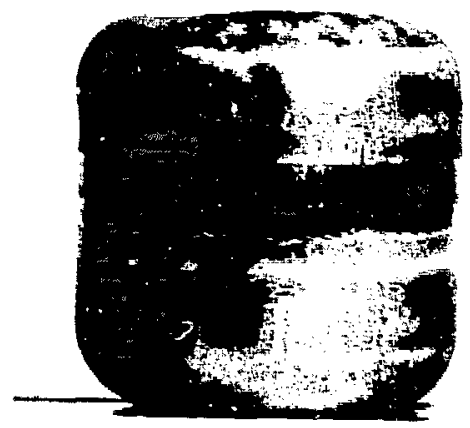

IR $;-117$

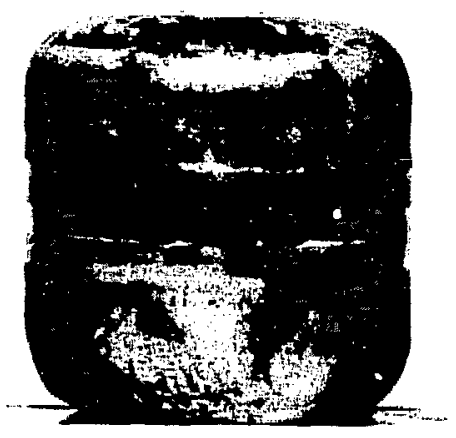

IRG-118

Fig. 11. Simulant-fueled clads after sequential overpressure tests at 1.4 and 5.1 MPa. 


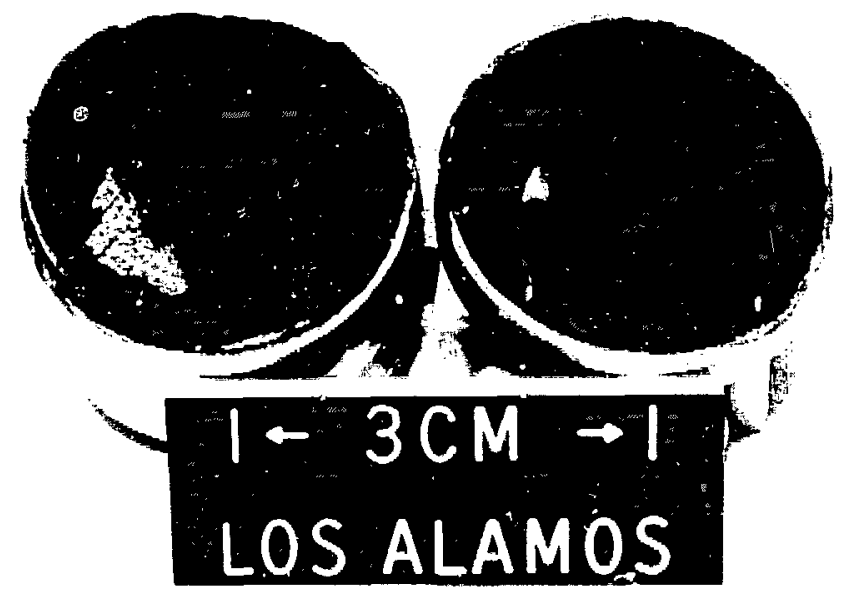

Fig. 12. The simulant fuel $\left(\mathrm{UO}_{2}\right)$ in clad $I R \mathrm{~F}_{3}-118$ was broken into relatively large fragments after the two scquential explesion tests.

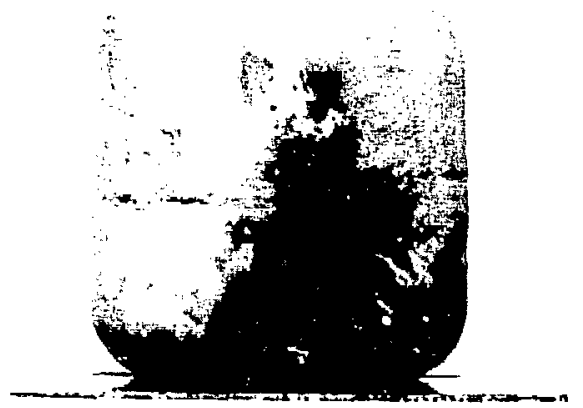

Capsule il

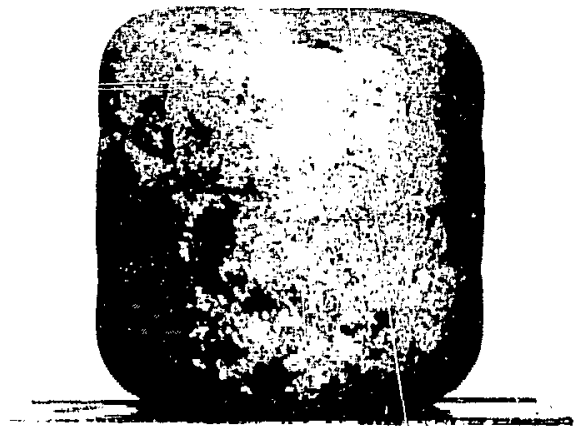

Capsule B

Fig. 13. Simulant-fueled clads after overpressure test at ?.4 MPa. (apsule D penetrated the plywood buikhead at the end of the catch tube. 

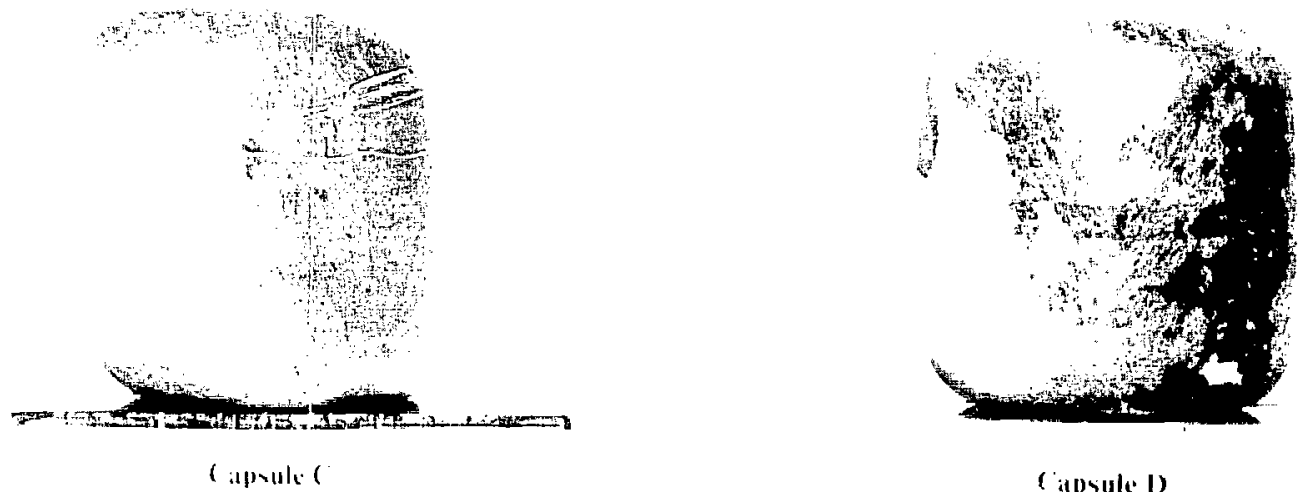

(ipsule I)

Fig. 13. (cont)

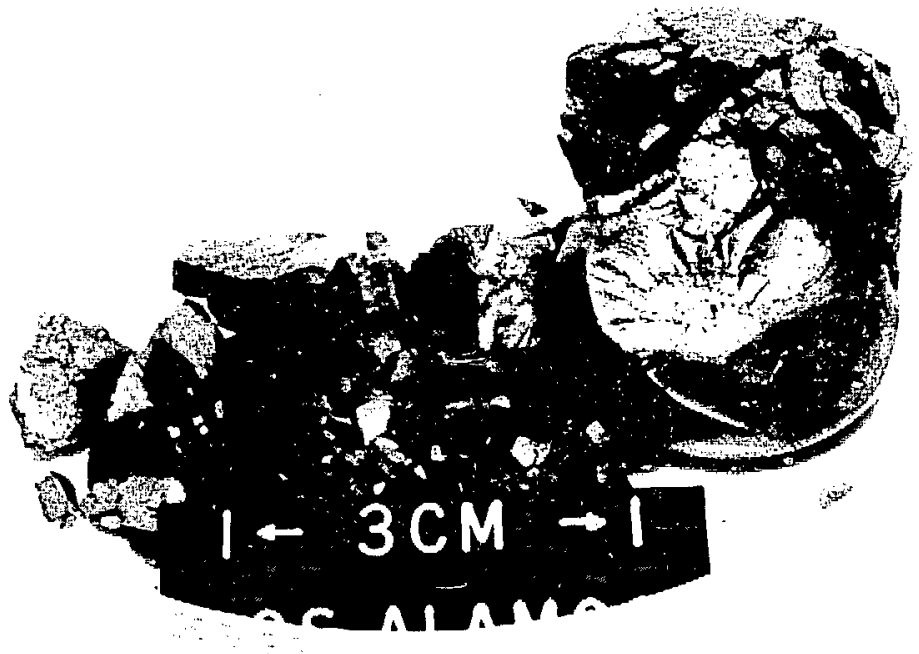

Fig. 14. One end of the l'(), pellet from capsule ( 10 BMT.3 was fragnented: 1.5 .5 . 


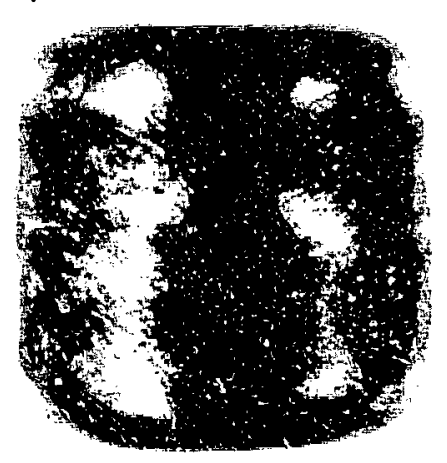

Clad 1

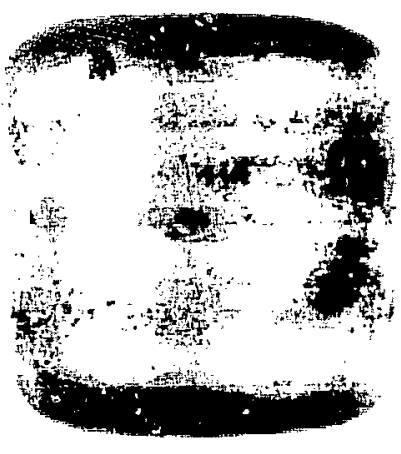

Clad 2

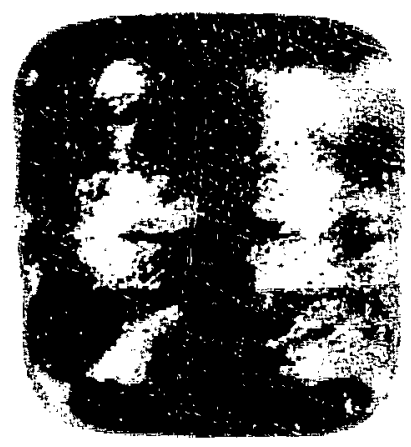

Clad 3

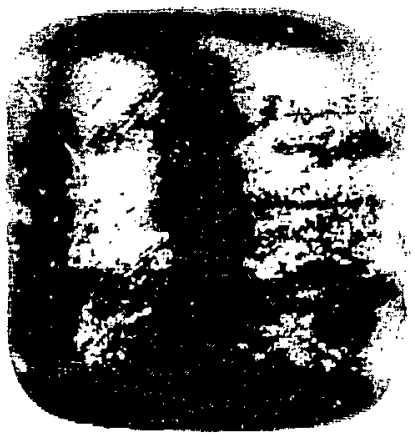

Clad 4

Fig, 15. Simulant-fueled clads after CST-1 at 5.1-MPa overpressure. 


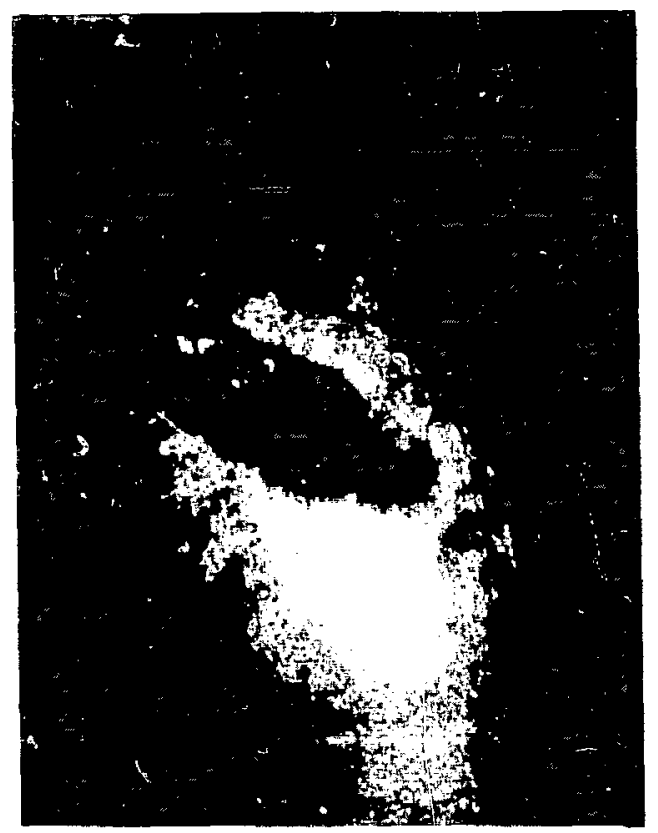

Fig. 16. A deep crater was observed on the CST-1 clad selected for examination: $10.5 \mathrm{X}$.

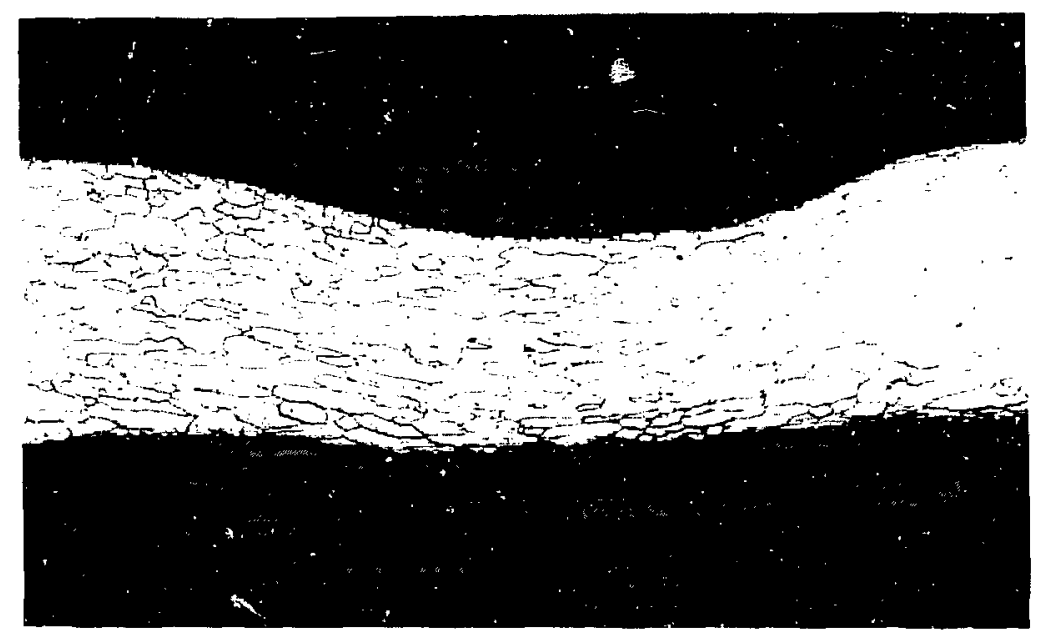

Fig. 17. The iridium grains were elongated in the Clad 1 cratered area: etched. $50 x$. 


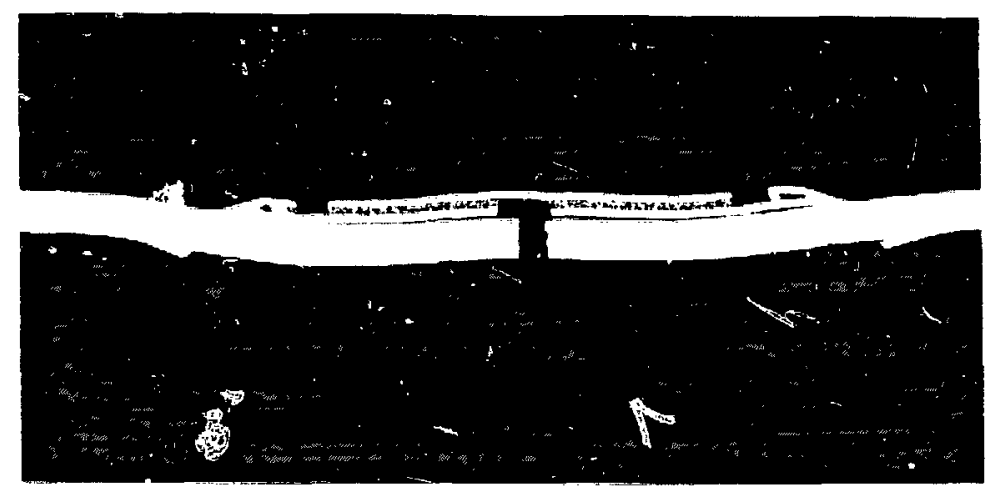

Fig. 18. The CST-1 capsule vent was undeformed: as polished, $7 \mathrm{X}$.

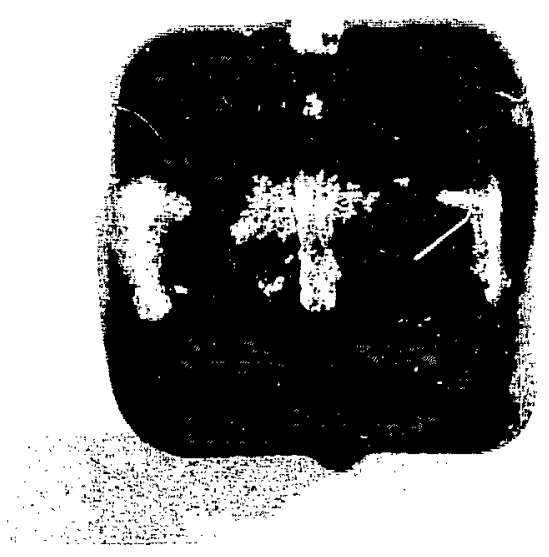

IRG-125

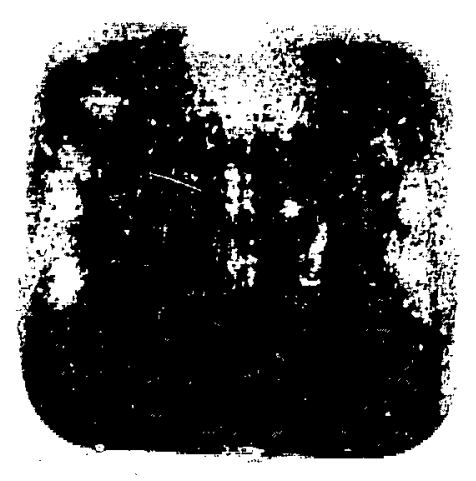

IRG;-126

Fig. 19. Simulant-fueled clads after ( $४$ Т-2 at 7.1-MPa overpressure. 


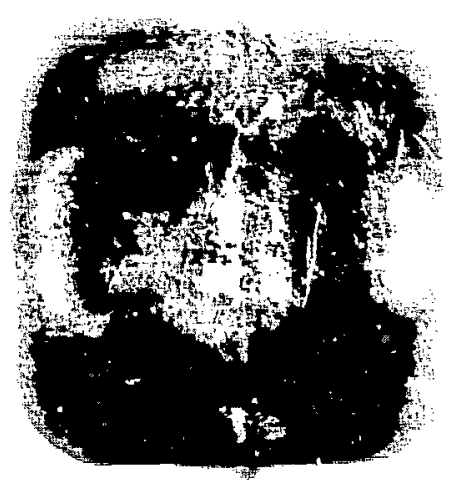

IRG,-127

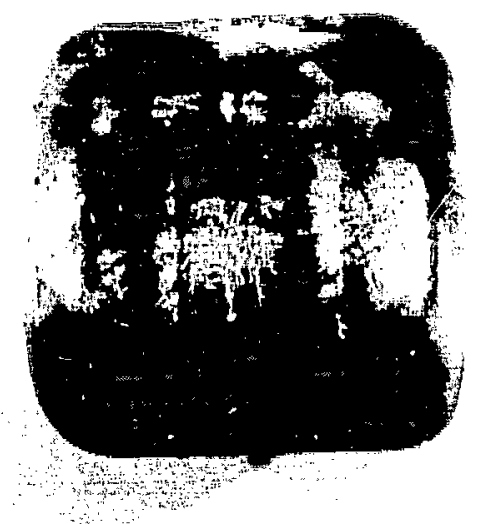

IRG-128

Fig. 19. (cont)

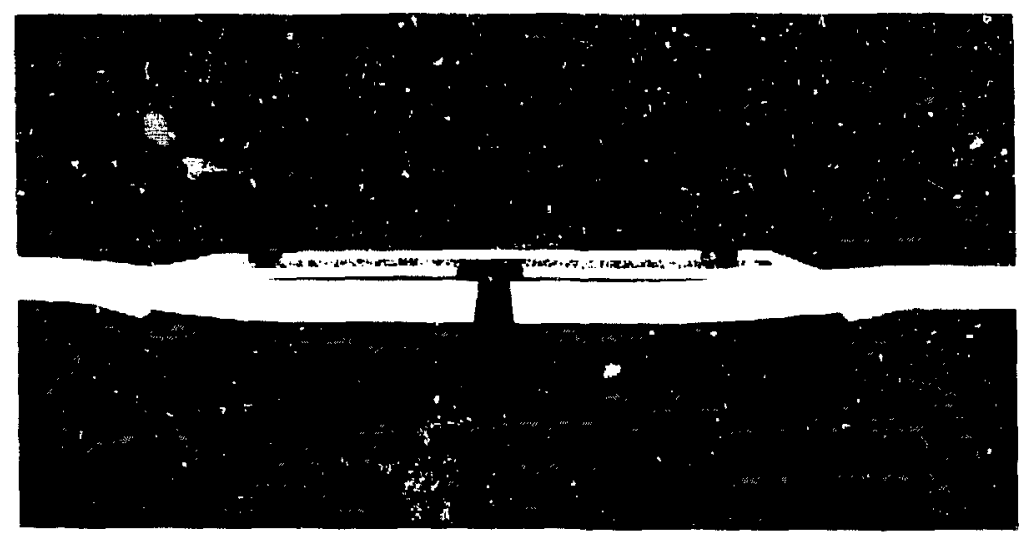

Fig. 20. The CST-2 capsule vent was undeformed and contained no mechanical defects: as polished. $7 \mathrm{X}$. 


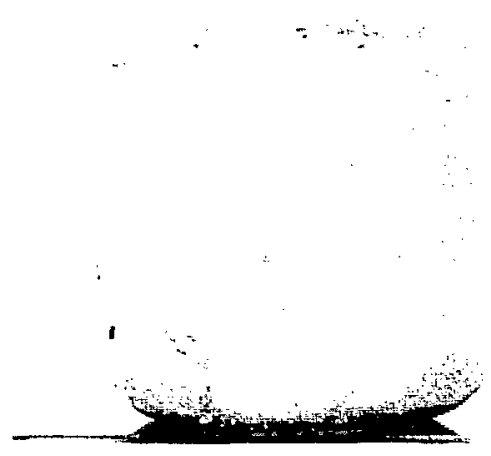

L-12

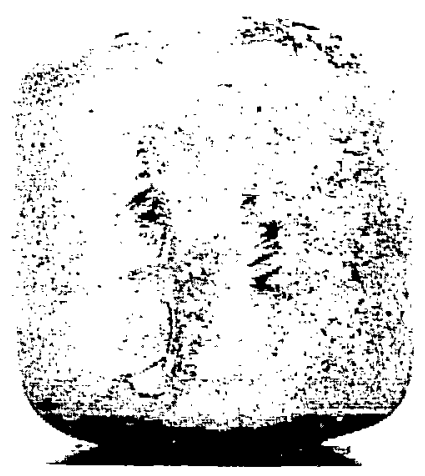

1. -16

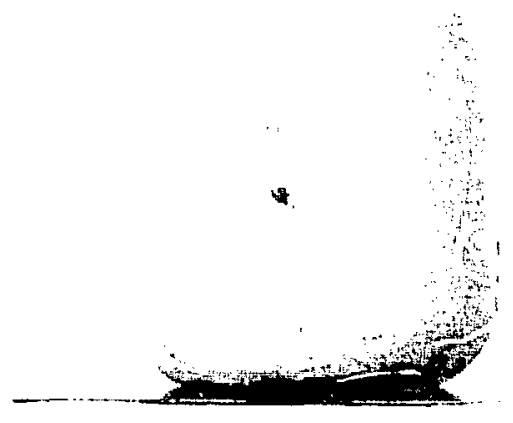

L-14

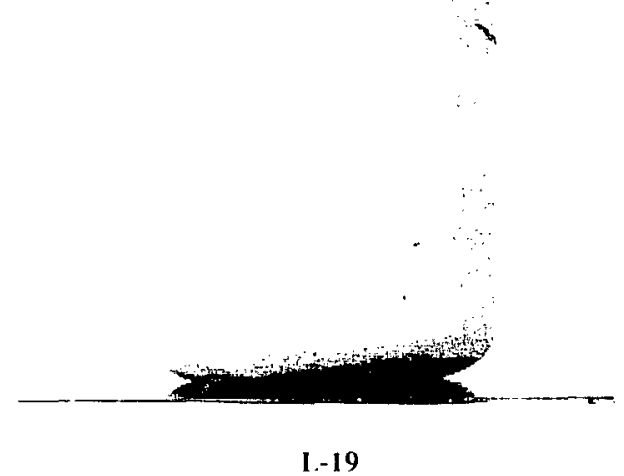

Fig. 21. Simulant-fueled clads after CST-3 at 11.6-MPa overpressure. 


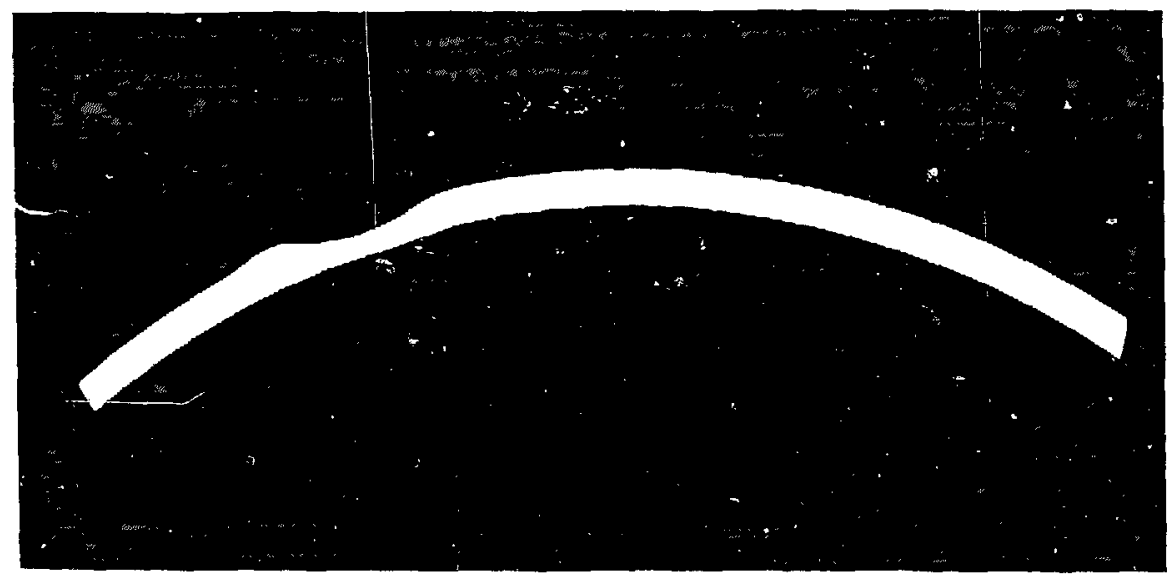

Fig. 22. The crater on the L-12 weld shield cup penetrated $38 \%$ of the wall thickness; as polished. $7 \mathrm{X}$. 


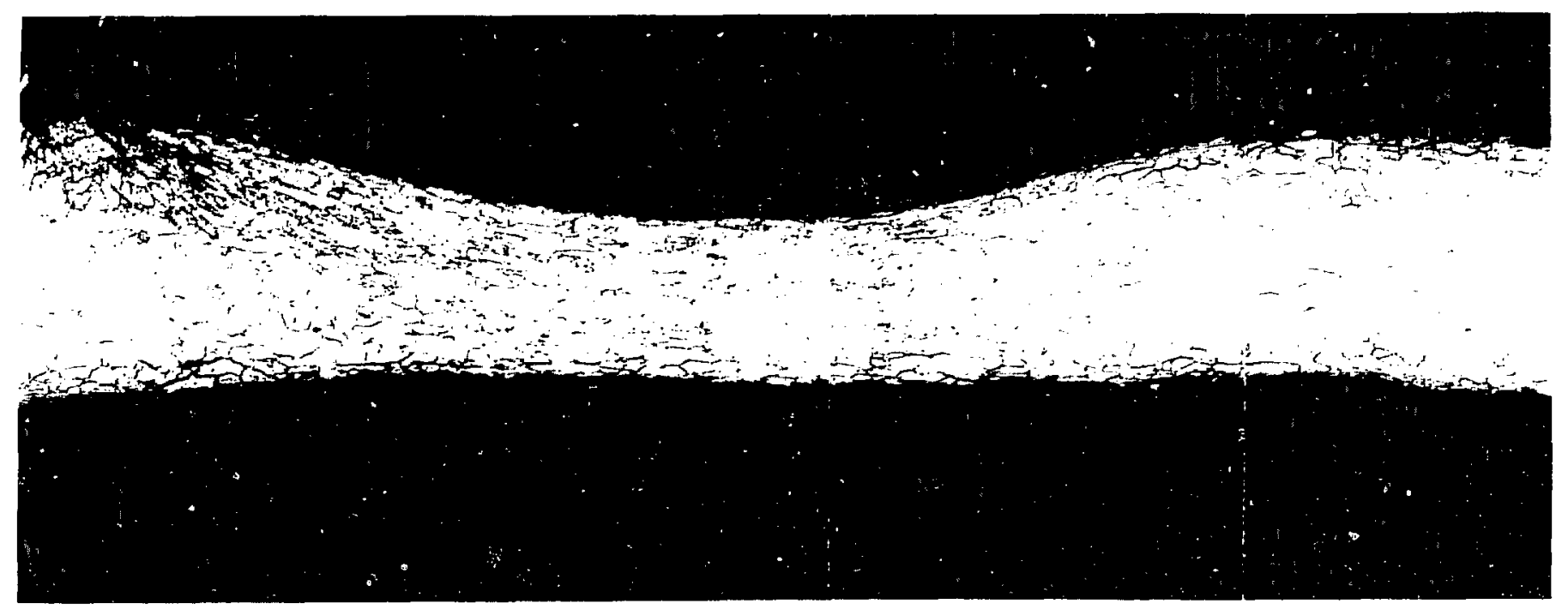

Fig. 23. The L-12 capsule wall within the crater displayed significant ductility: etched. $50 \mathrm{X}$. 

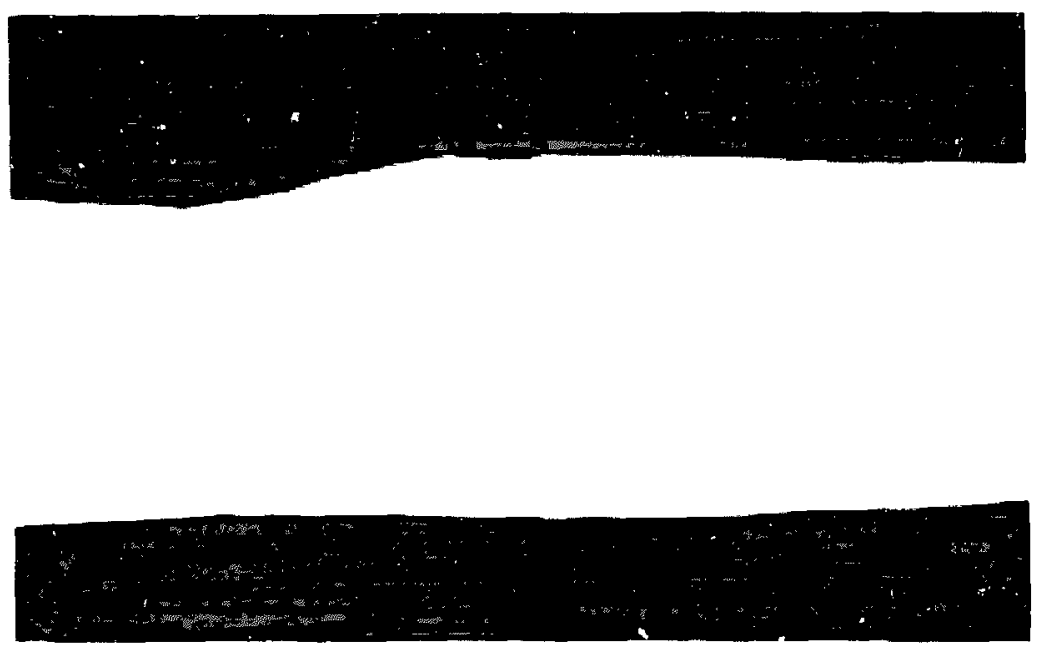

(a)

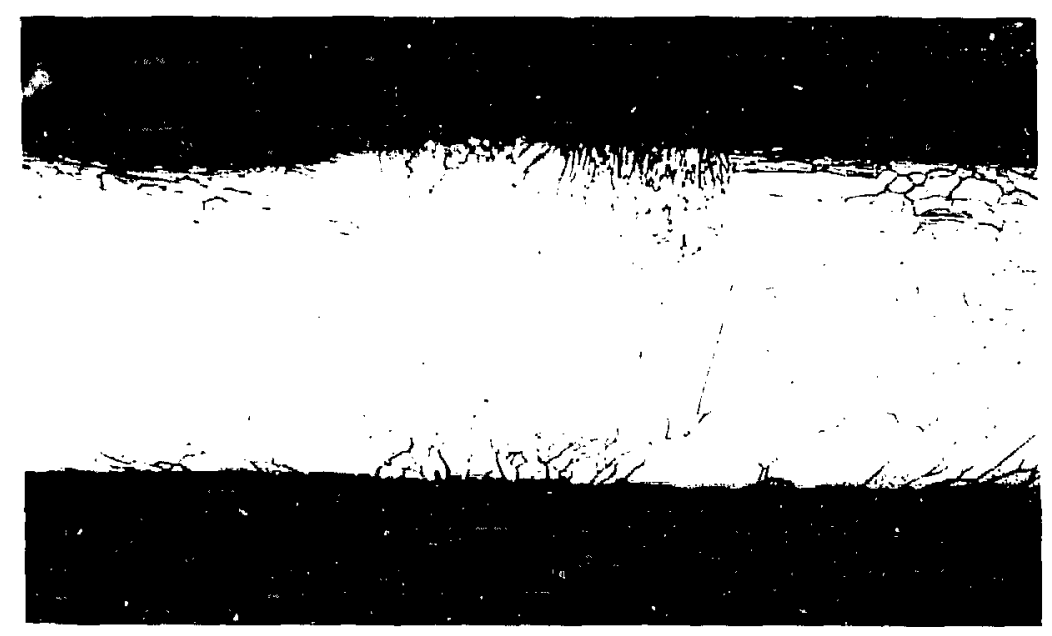

(b)

Fig. 24. The L-12 closure weld had a very unusual microstructure, (a) is polished and (b) etched: hoth at $50 \mathrm{X}$ 


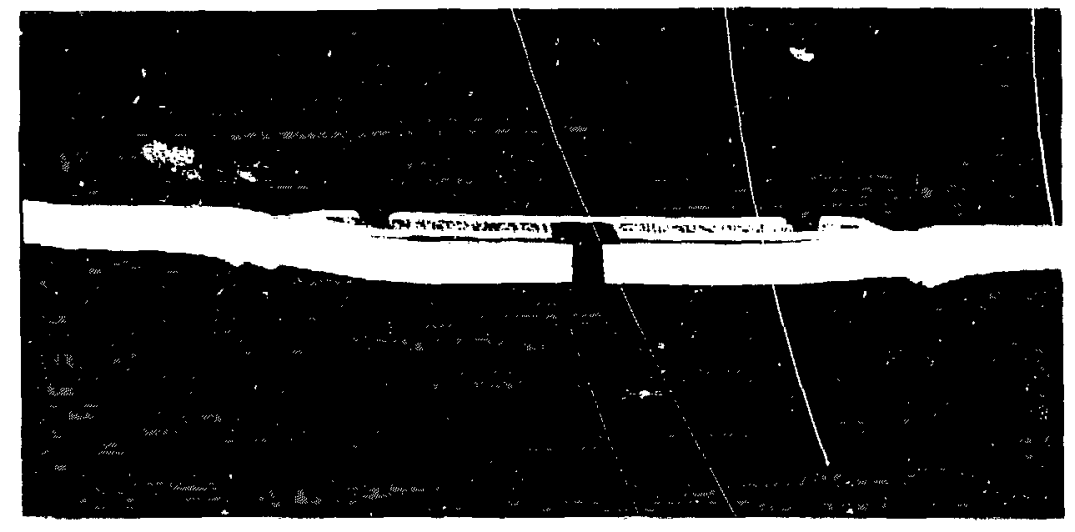

Fig. 25. The L-12 capsule vent was undeformed; as polished, $7 \mathrm{X}$.

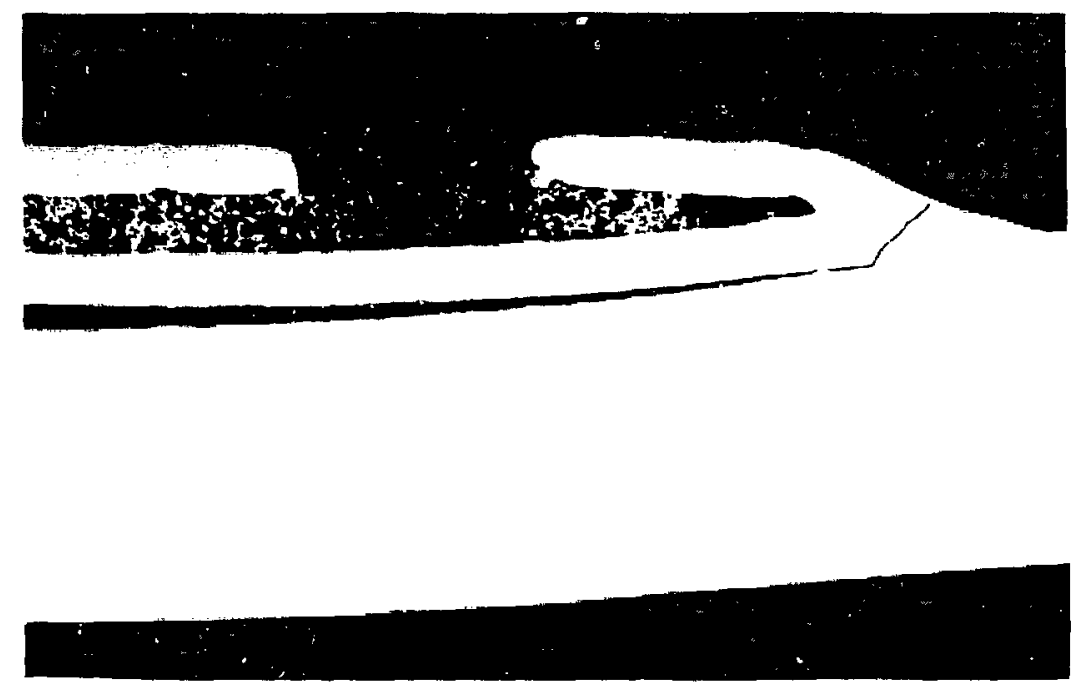

Fig. 26. A small crack was observed on one side of the L-12 vent assembly; as polished, 50X. 
CST-4

$X$-RAY GEOMETRY

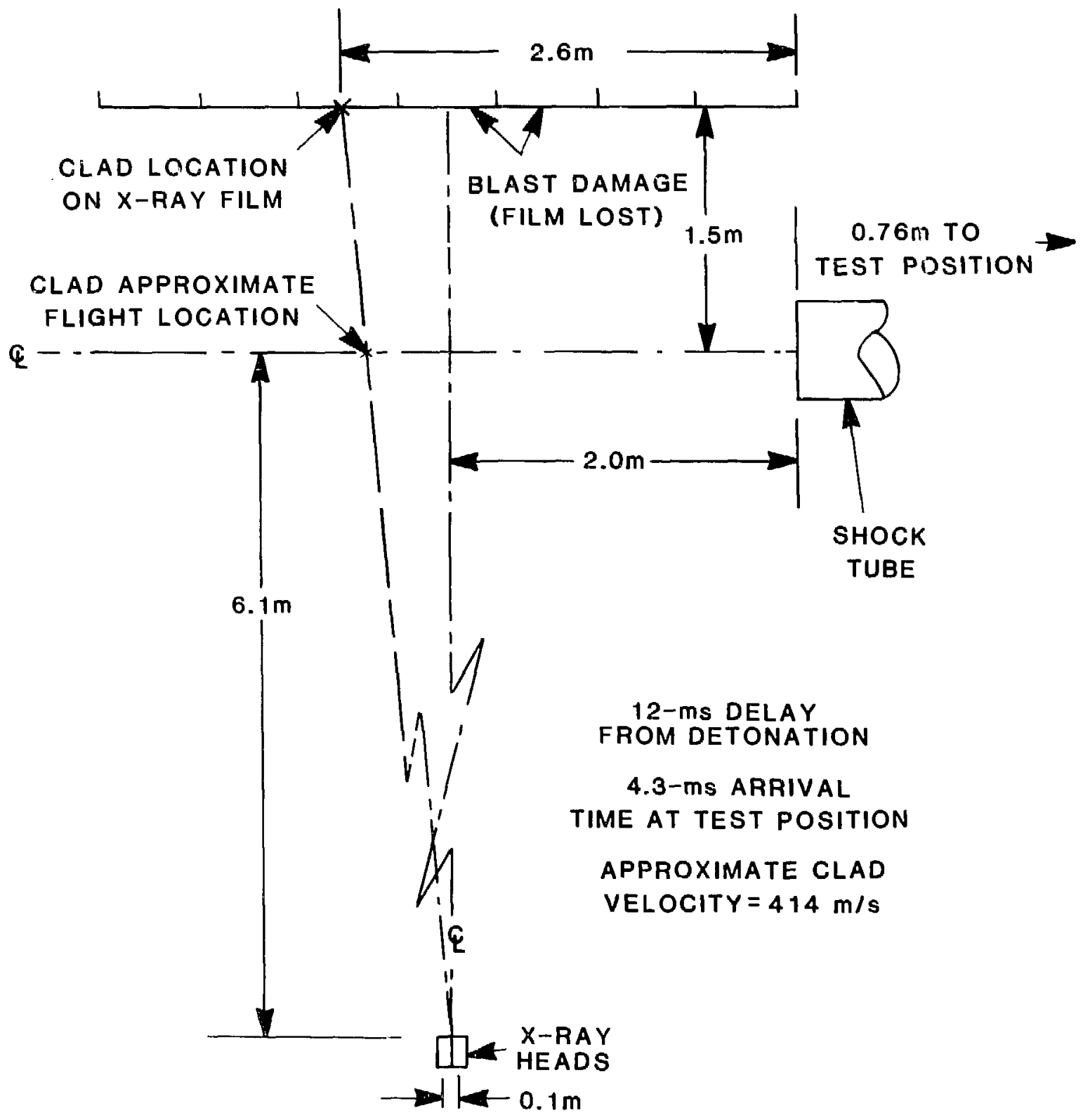

Fig. 27. The (ST-4 simulant clad traveled $3.2 \mathrm{~m}$ in $7.7 \mathrm{~ms}$ (assuming it was traveling on the shock tube centerline). 


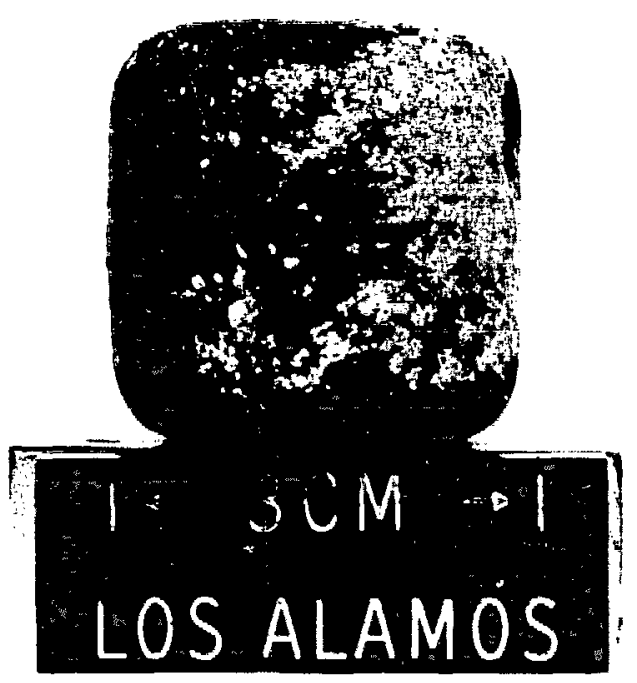

L-9

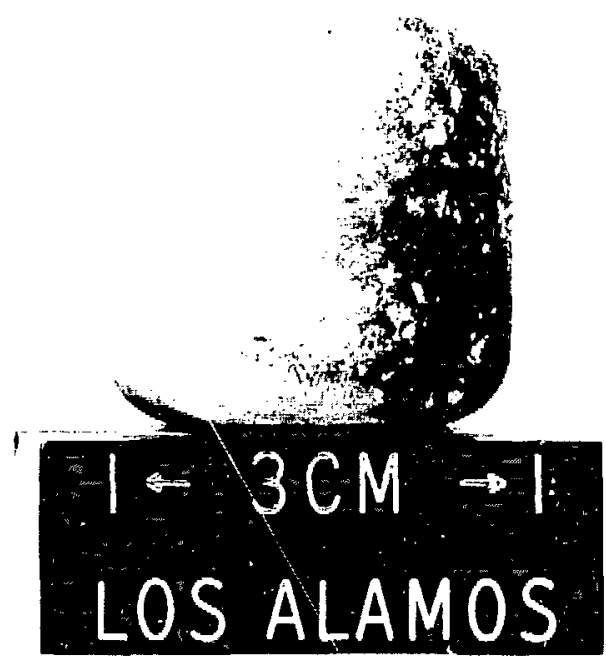

I.- 10

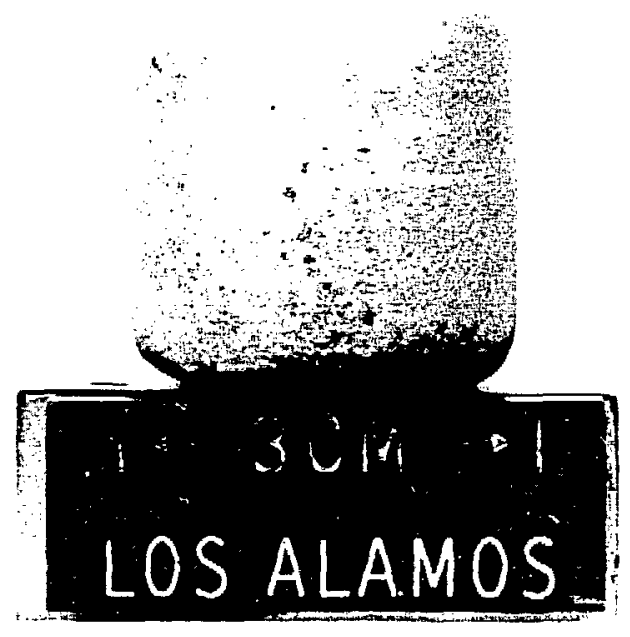

$1 .-15$

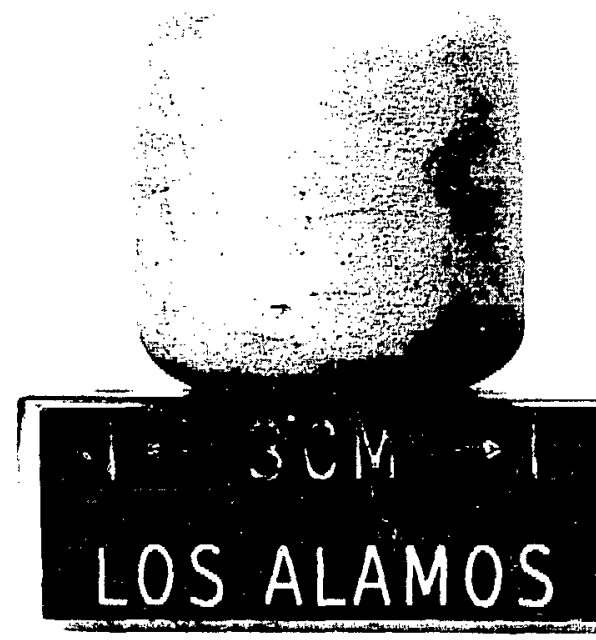

I. -23

Fig. 28. The simulant-fueled clads after (ST-4 at 12.2 MPa overpressure. 


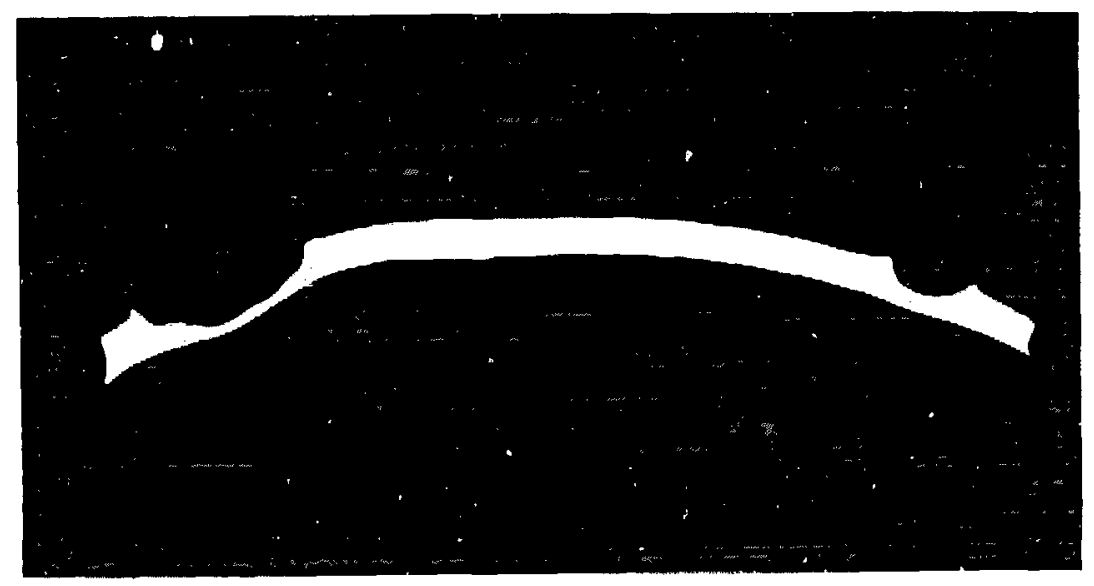

Fig. 29. A transverse section containing the large crater and a smaller indentation was removed from the L-10 weld shield cup; as polished, $7 \mathrm{X}$.

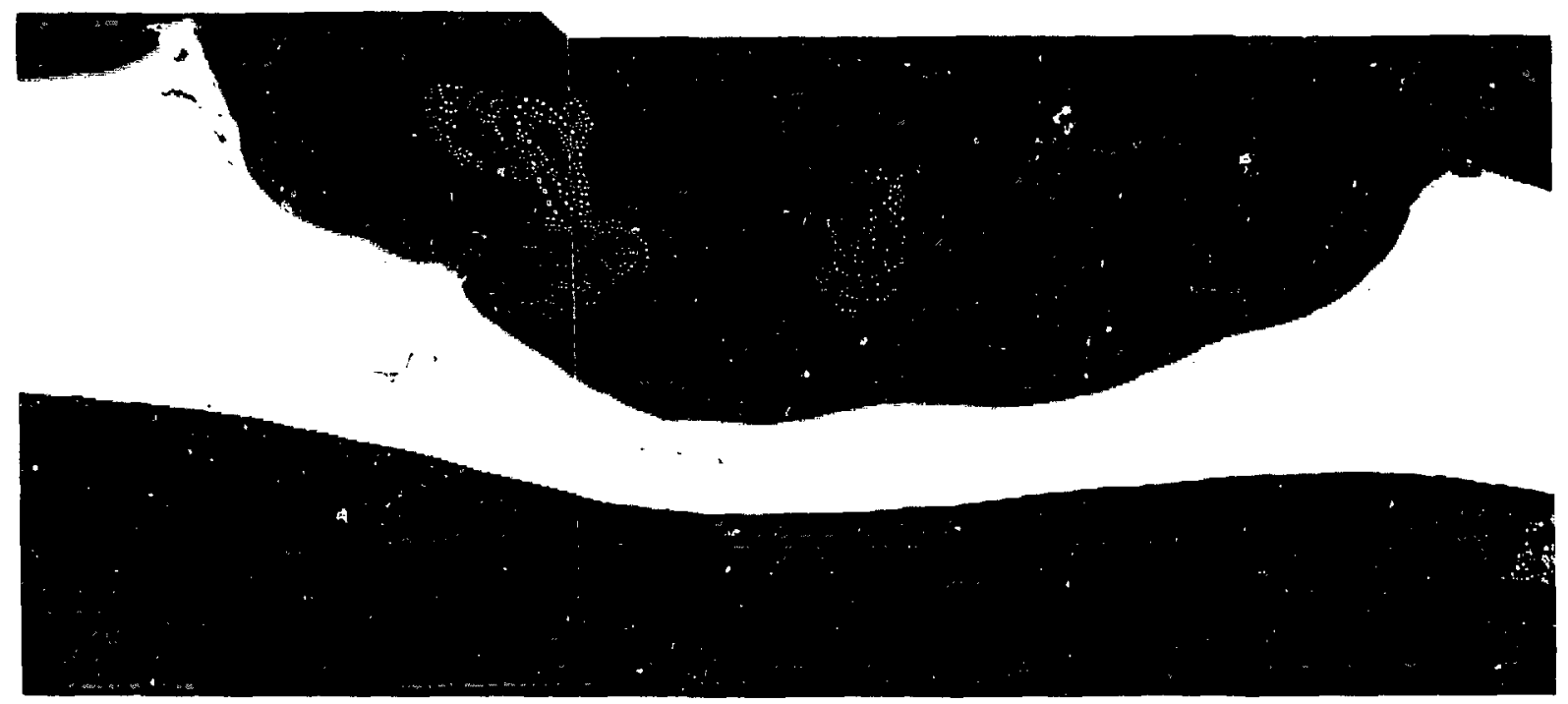

Fig. 30. The large crater penetrated more than $70 \%$ of the L- 10 capsule wall; as polished, $50 \mathrm{X}$. 


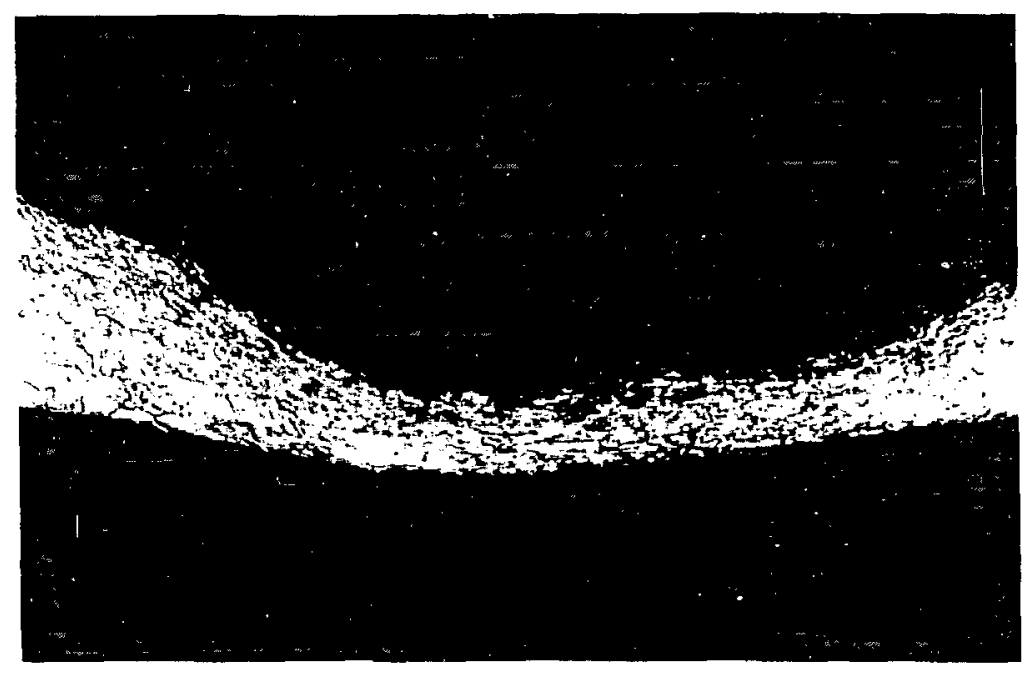

(a)

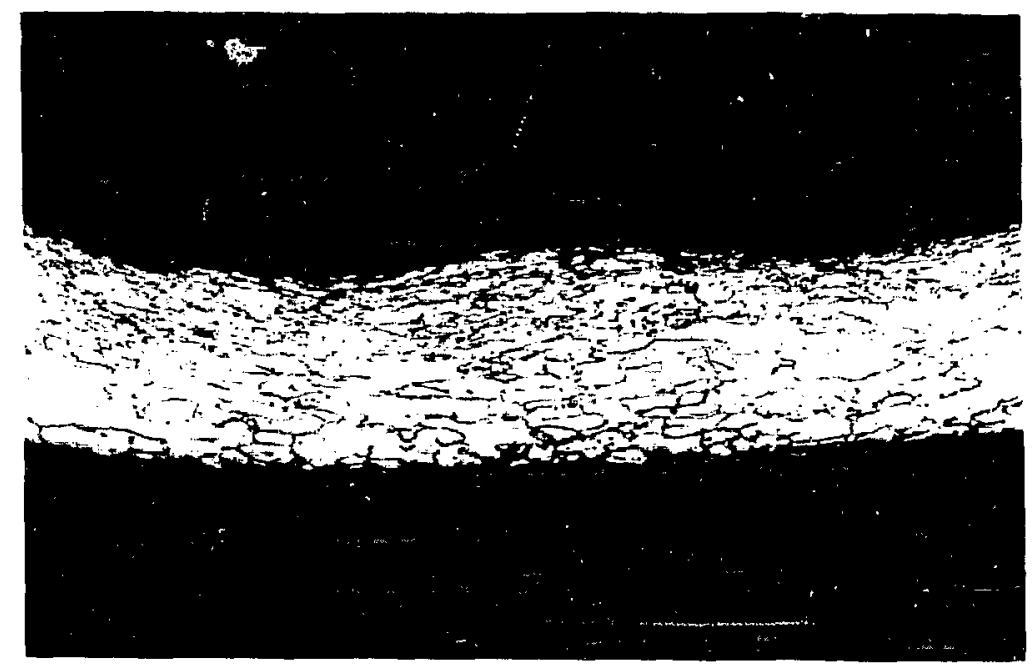

(b)

Fig. 31. The capsule wall within the crater was severely deformed. (a) Etched 50.X. (b) etched. Irox 

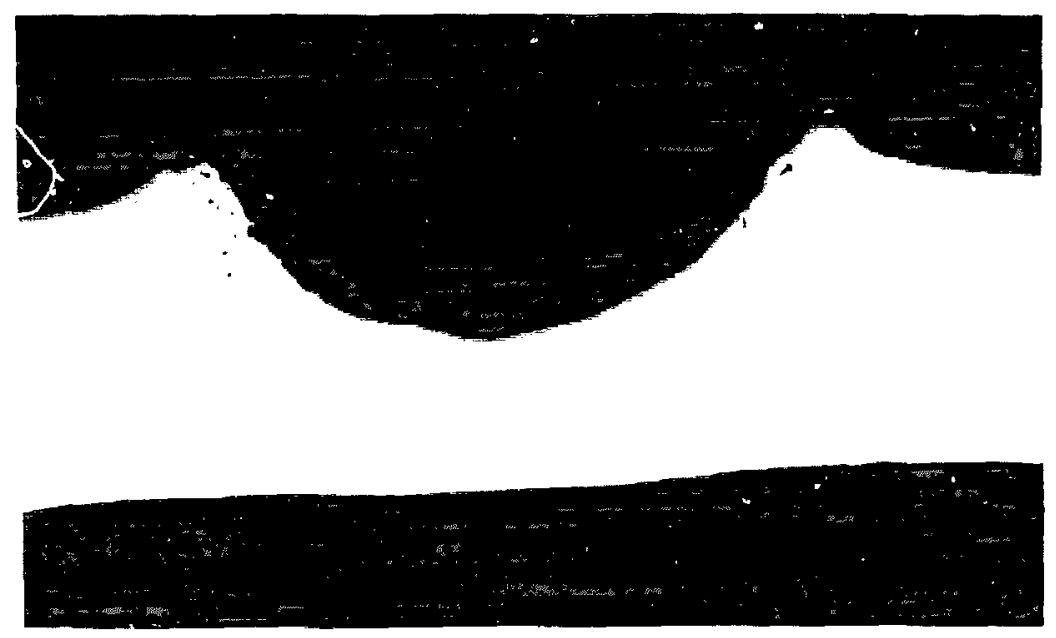

(a)

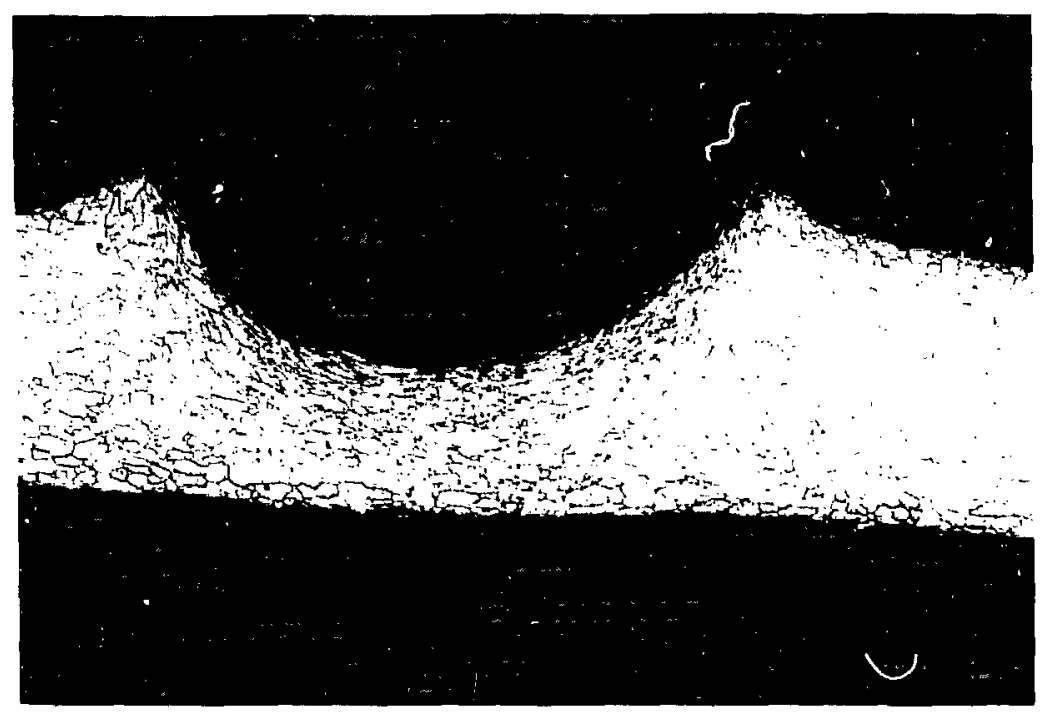

(b)

Fig. 32. The small indentation was similar to the large crater. (a) As polished and (b) eiched: both at $50 \mathrm{X}$ 


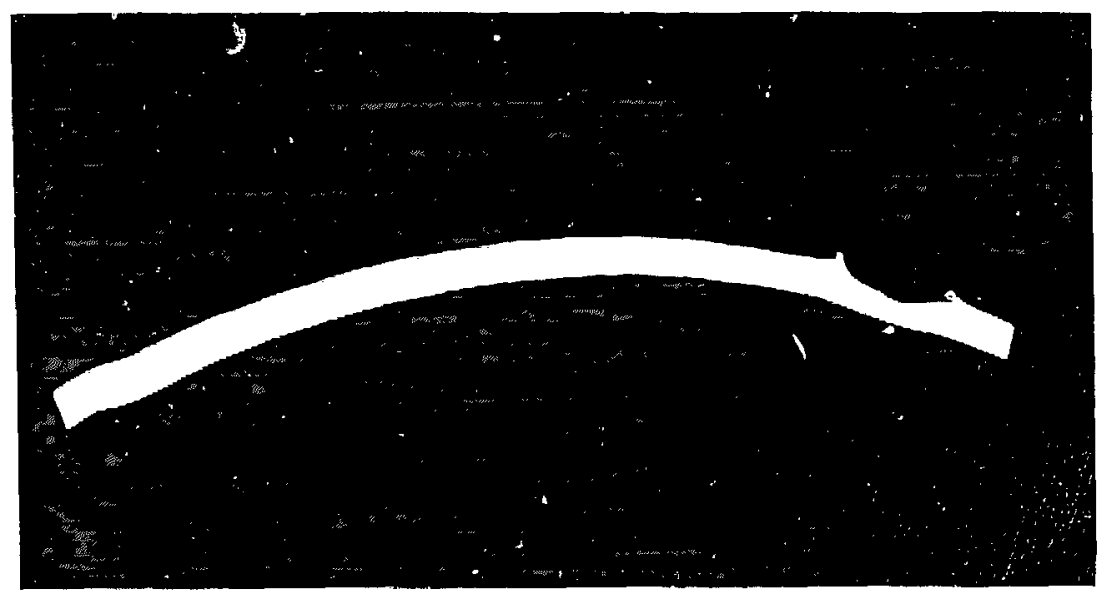

Fig. 33. A crater in the L-10 vent cup penetrated $40 \%$ of the wall thickness; as polished, $7 \mathrm{X}$.
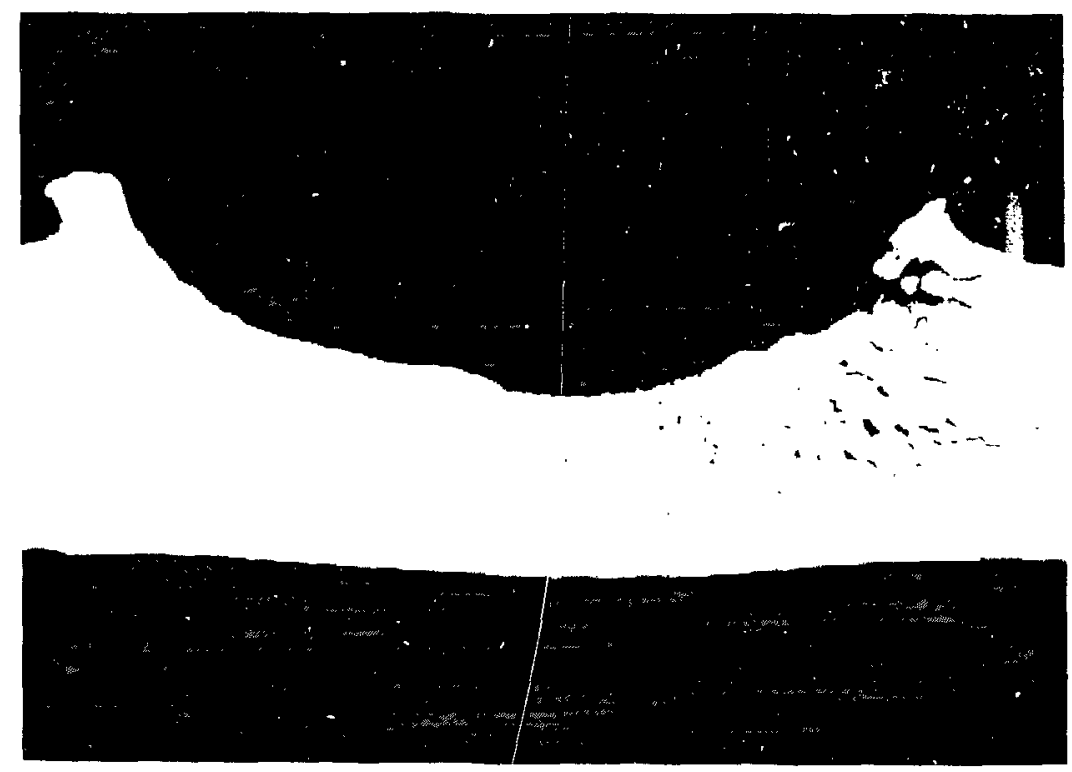

(a)

Fig. 34. The large crater in the vent cup of clad L-10 produced a pattern of internal grain boundary cracks. (a) As polished and (h) etched: houth at $50 \mathrm{X}$. 


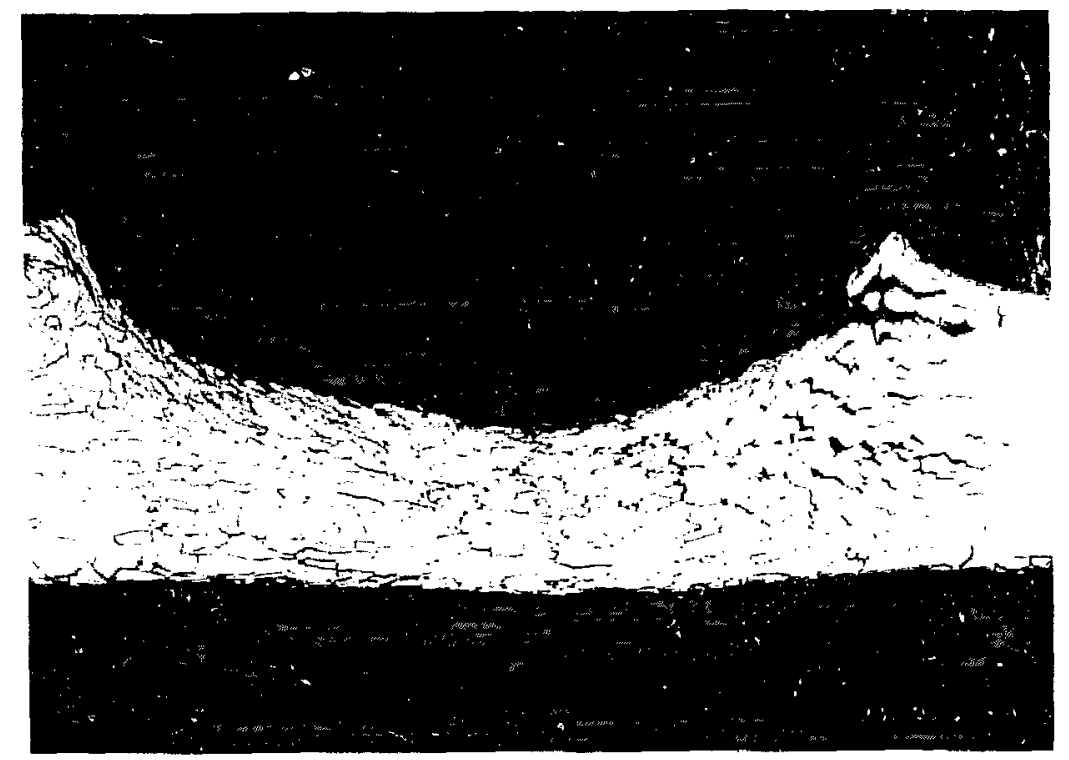

(b)

Fig. 34. (cont)

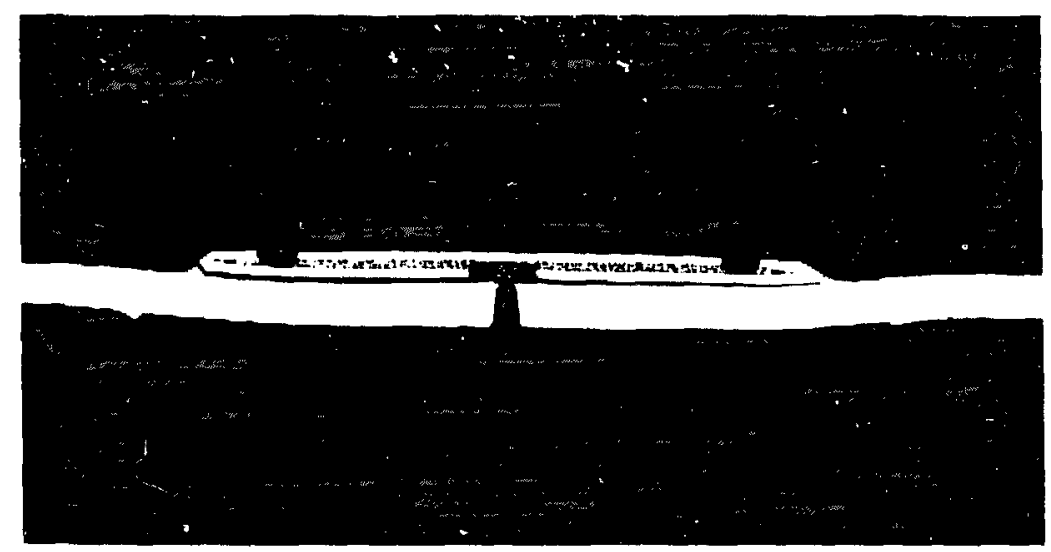

Fig. 35. The L-10 vent was not deformed: as polished. $7 \mathrm{X}$ 


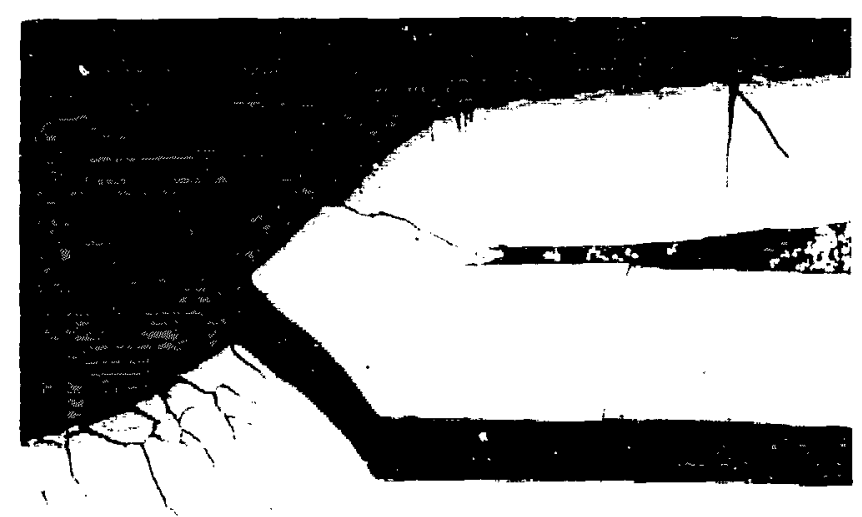

(a)

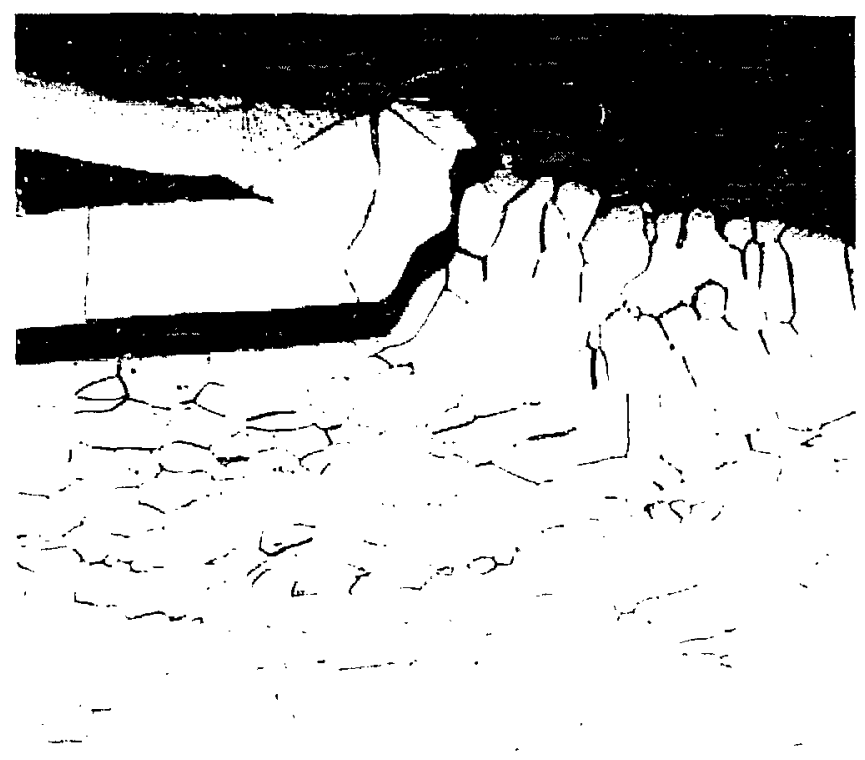

(b)

Fig. 36. Buth sides (a. b) of the L-10) vent assembly were cracked: etched. $50 \mathrm{~K}$. 
CST-5

$X$-RAY GEOMETRY

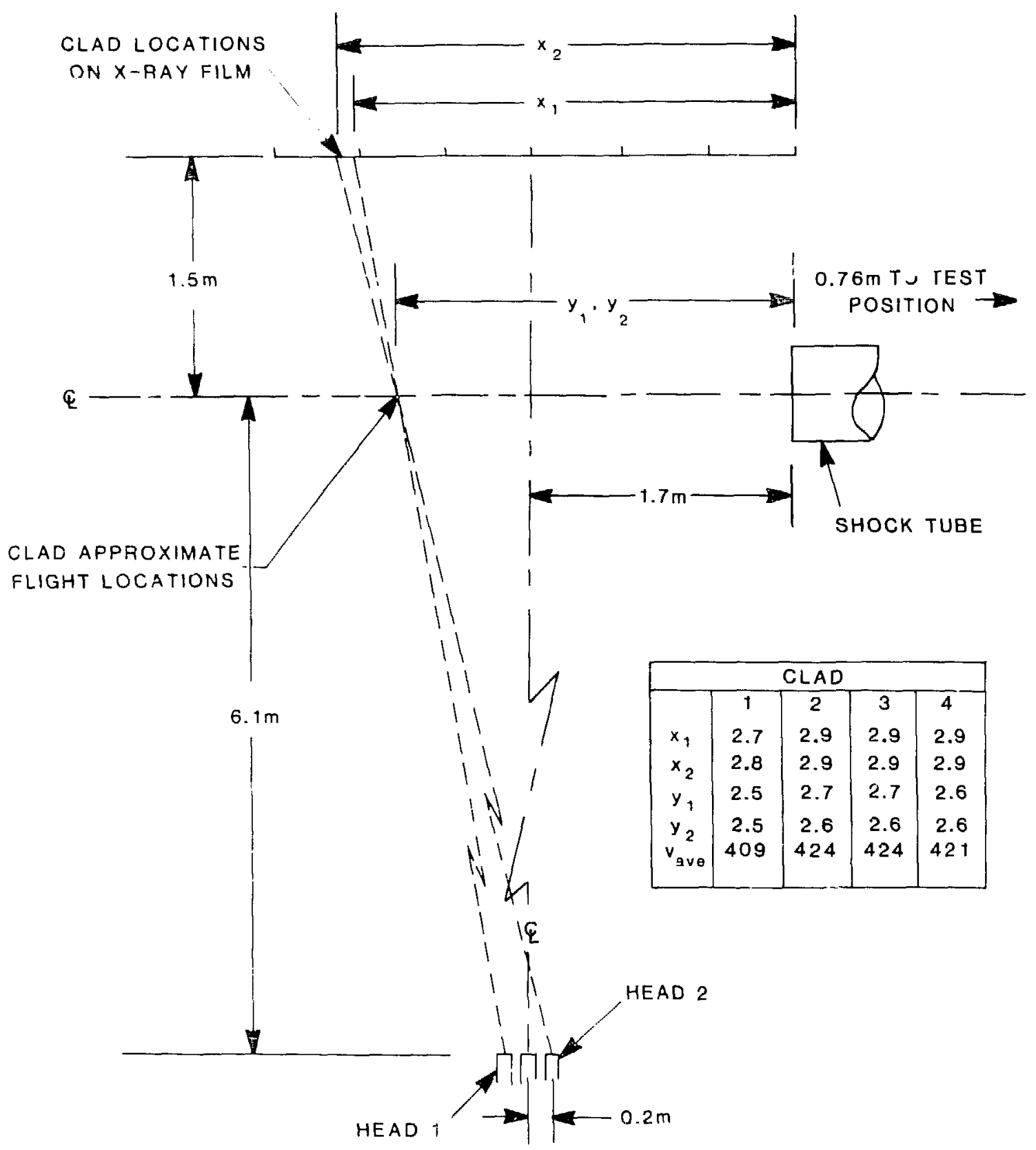

Fig. 37. -tll tisur smulant clads were imaged intact on the x-ray film' at approximately 34 m lassuming thes were

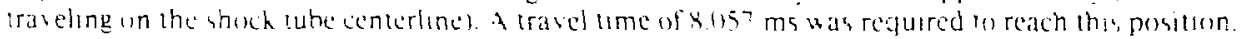




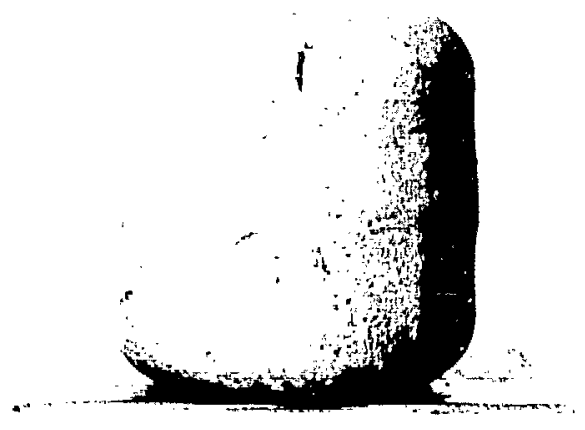

L-17

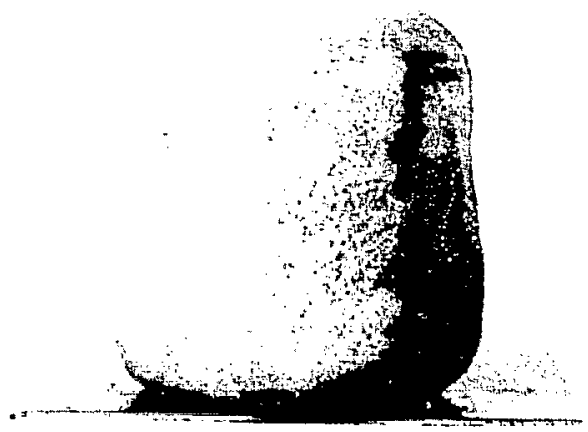

I. -22

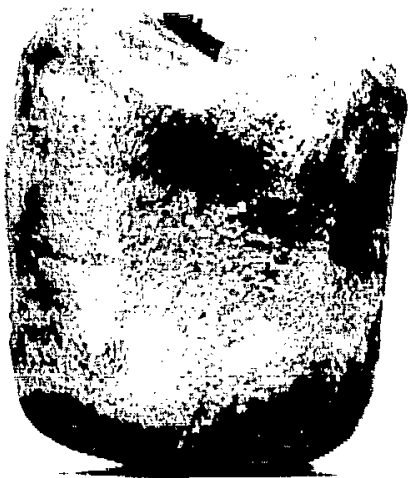

$1,-18$

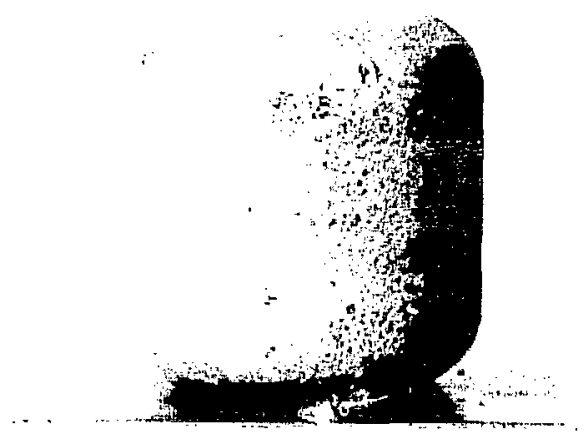

I.-24

Fig. 38. The simulant-fueled clads after ( - -5-RTC $;-1$ at $12.5 \mathrm{MPa}$. Clad L-1 8 was breached by a stainless steel weight segment from the cylindrica! RTG simulant. 


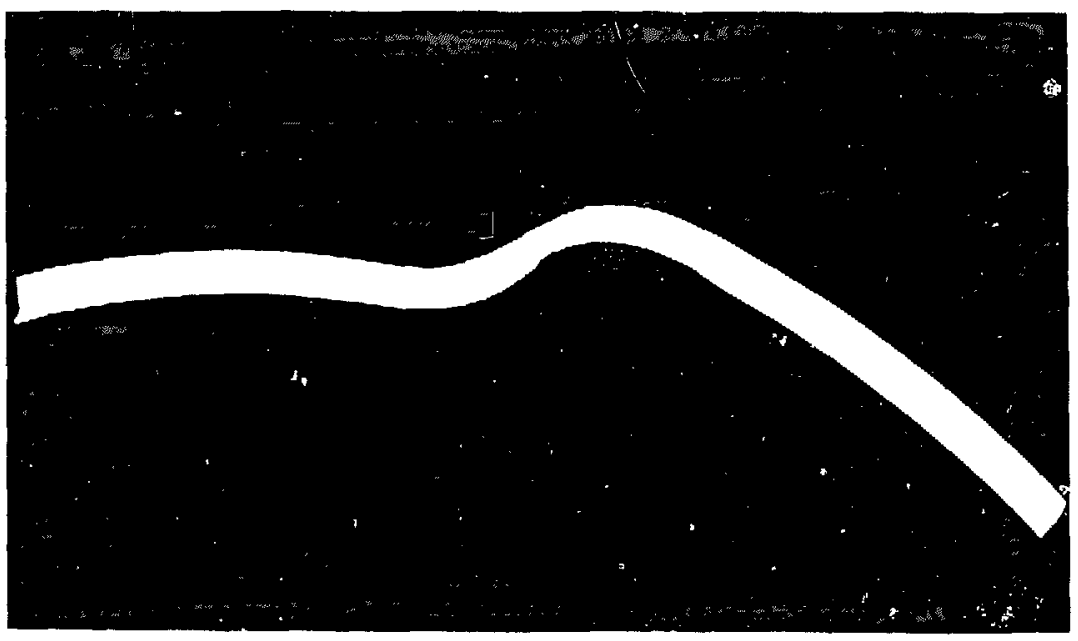

Fig. 39. Deep surface gouging $u$ as ohserved in a severely deformed section of the L-24 shield cup: as polished, $7 \mathrm{X}$. 

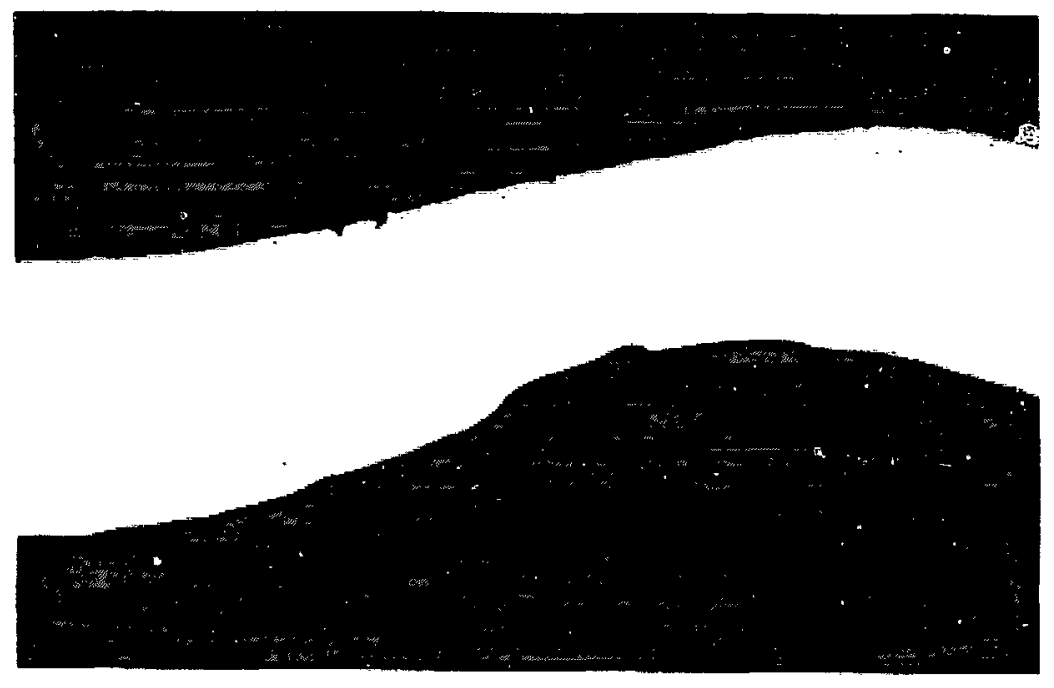

(a)

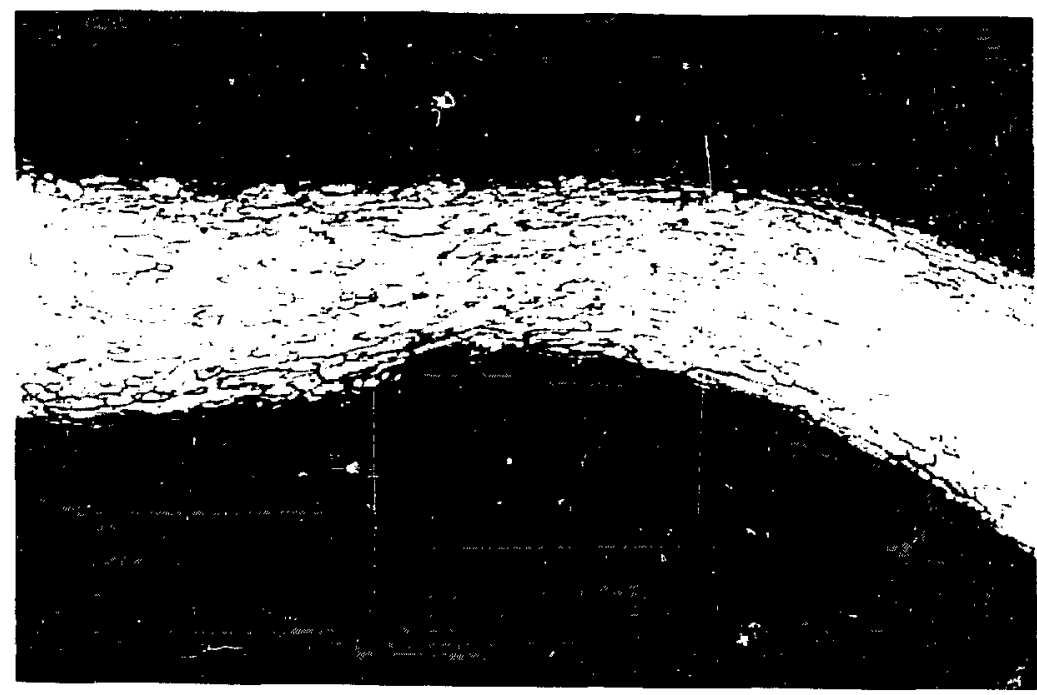

(b)

Fig. 40. Grain elongation uas also observed in the shield cup secionn. (a) is polished and (b) etched; both at $50 \times x$. 


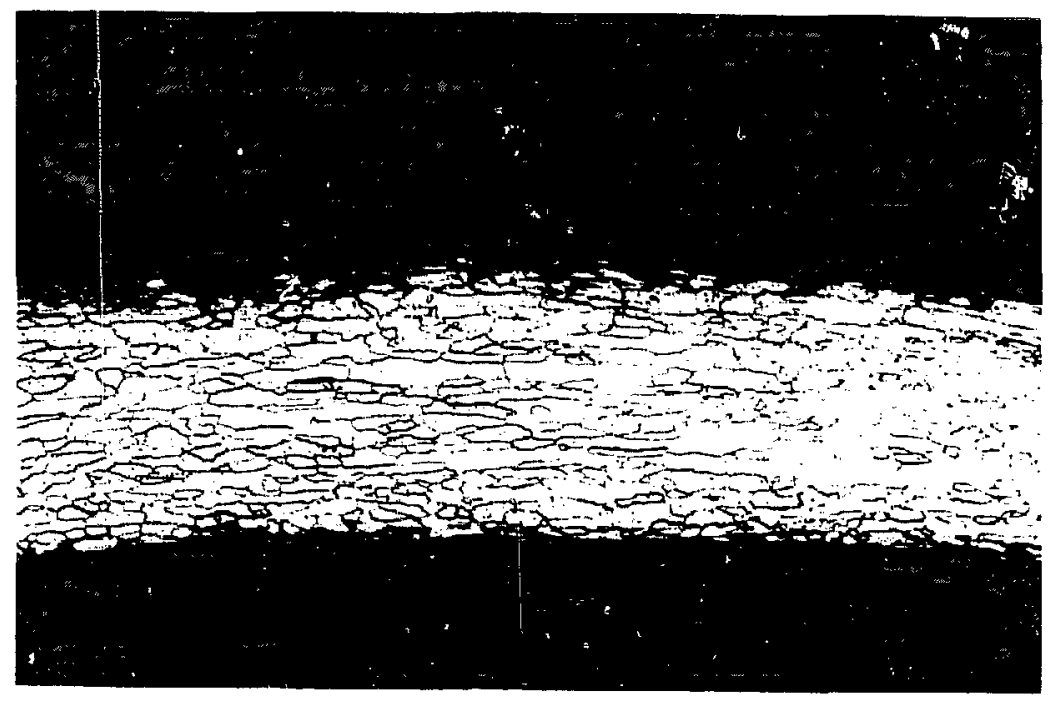

Fig. 41. Significant grain elongation was also observed in a deformed section of the L-24 vent cup; etched. $50 \mathrm{X}$. 


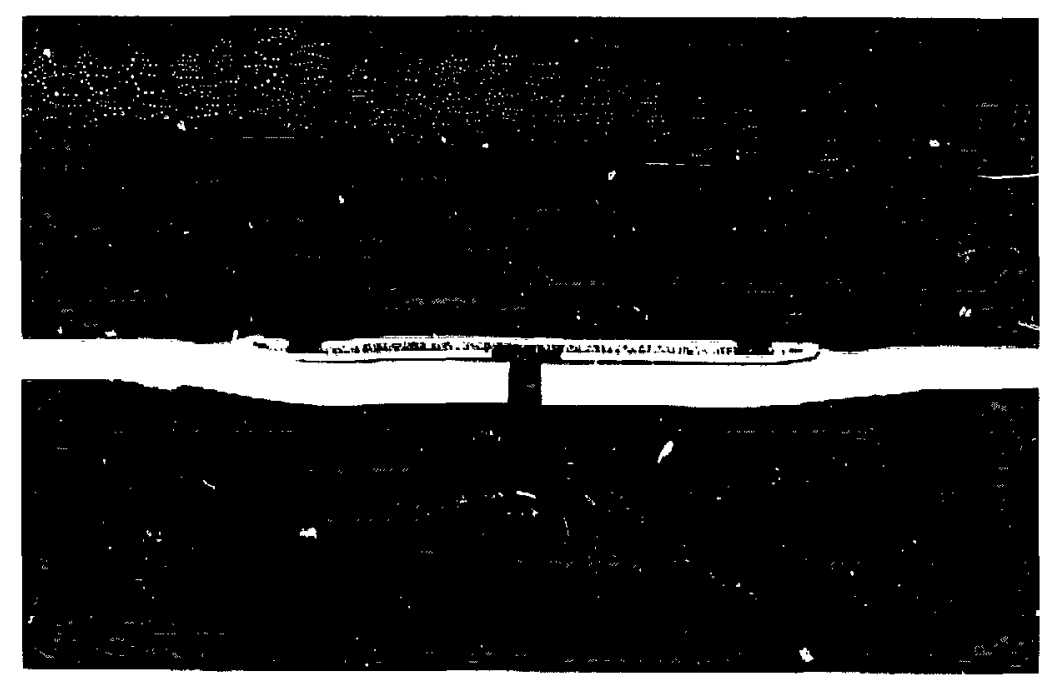

Fig. 42. The L-24 capsule vent was not significantly deformed; as polished, $7 \mathrm{X}$.

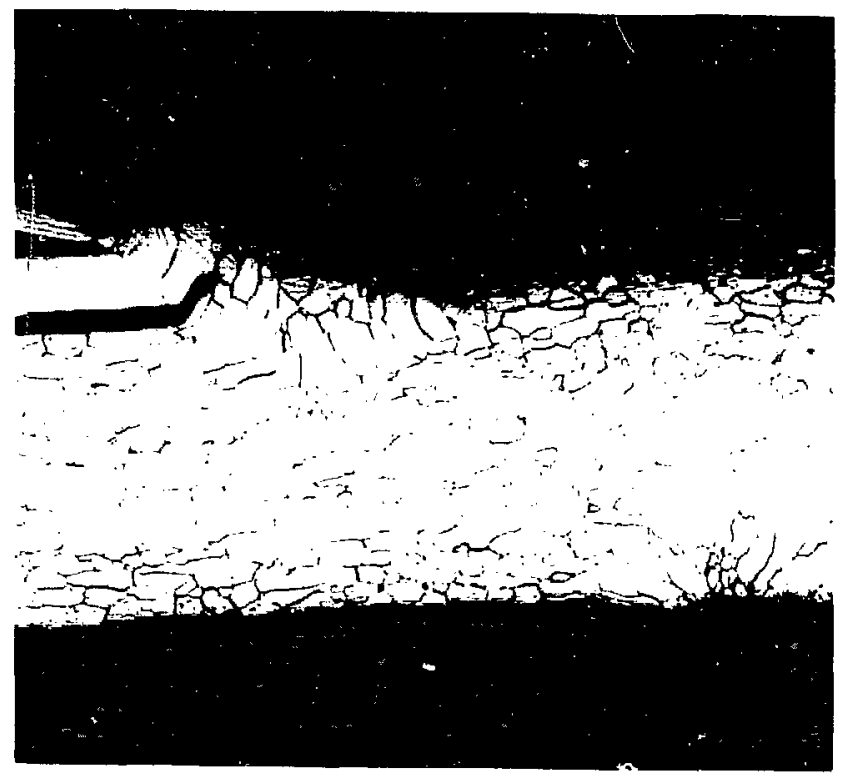

Fig. 43. One side of the L-24 vent assemily weld was cracked: etched. 50X. 


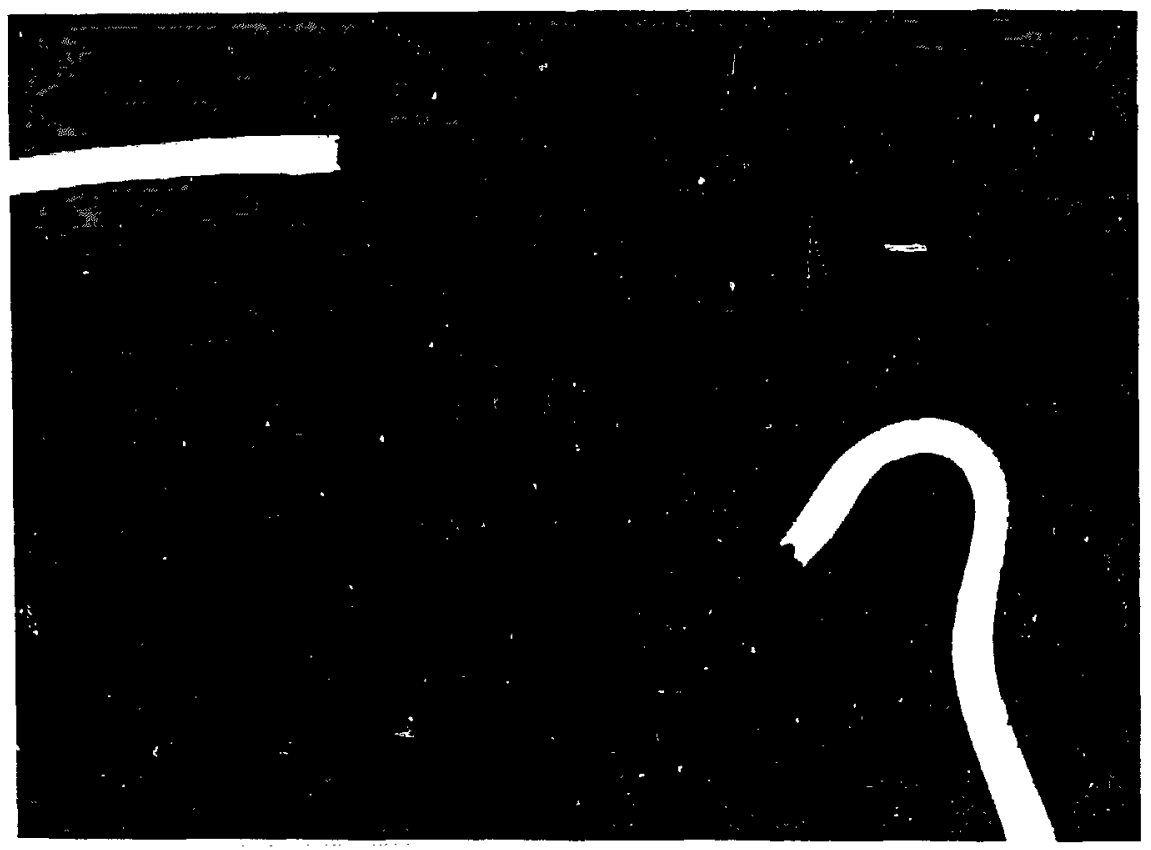

Fig. 44. A cross section of the L-18 breach was metallographically examined; as polished, $7 \mathrm{X}$. 

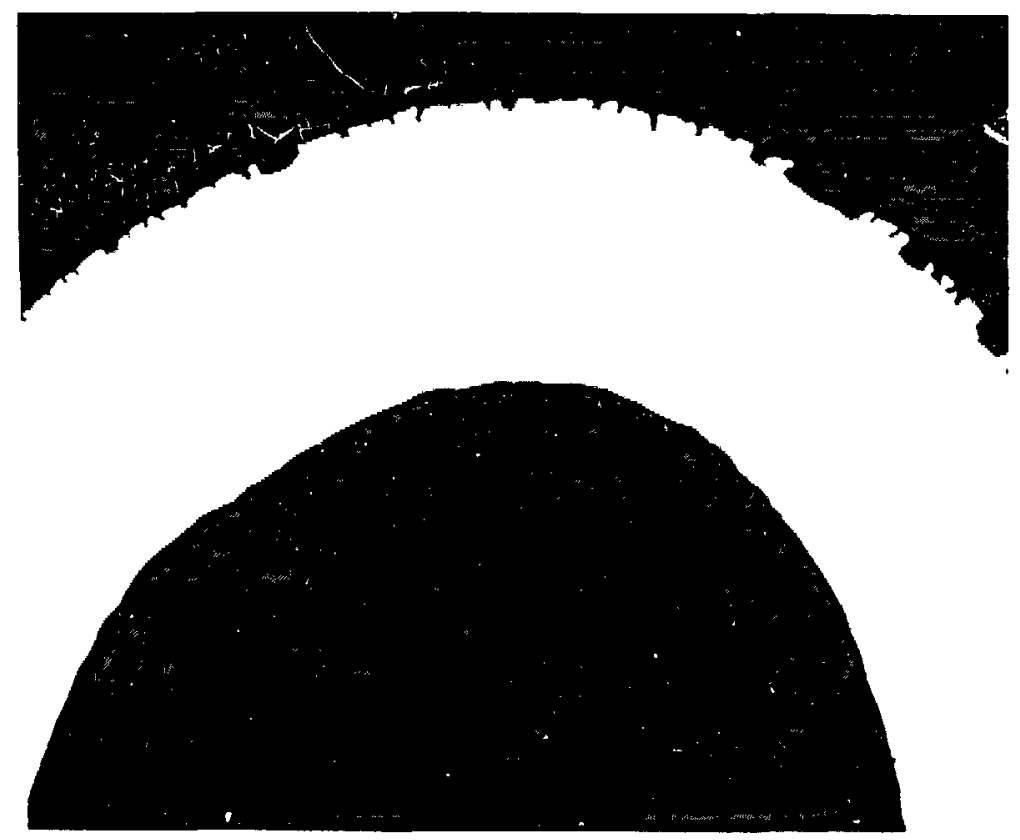

(a)
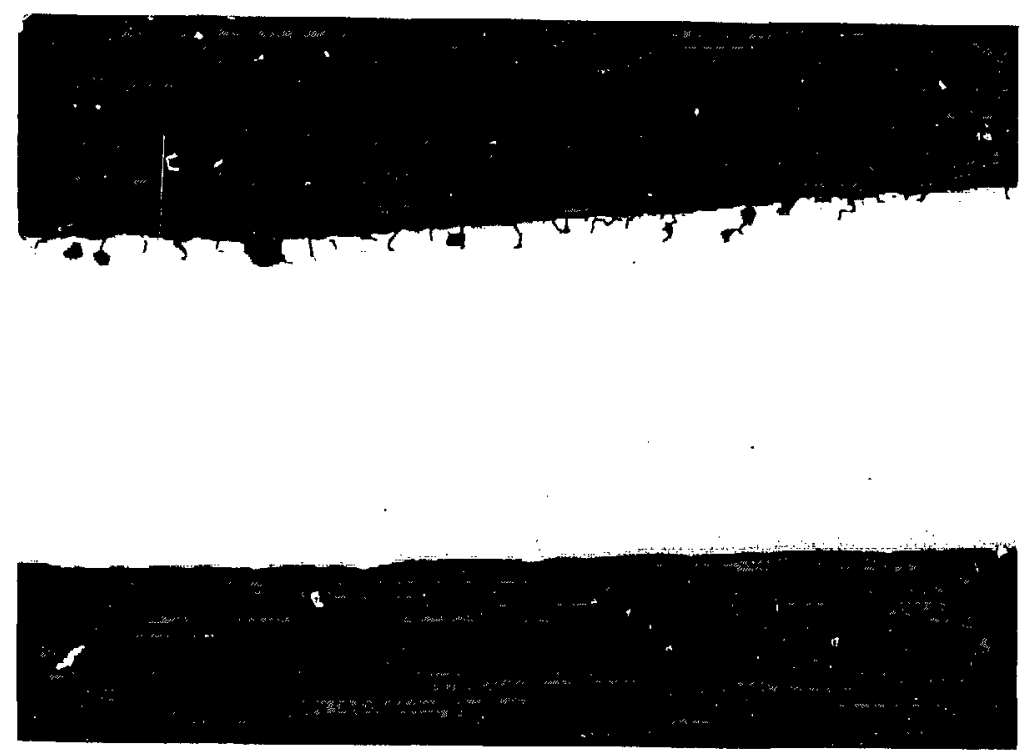

(b)

Fig. 45. One side of the L-1 8 breach was deeply gouged and cracked: two views (a. b), as polished. $50 \mathrm{X}$. 


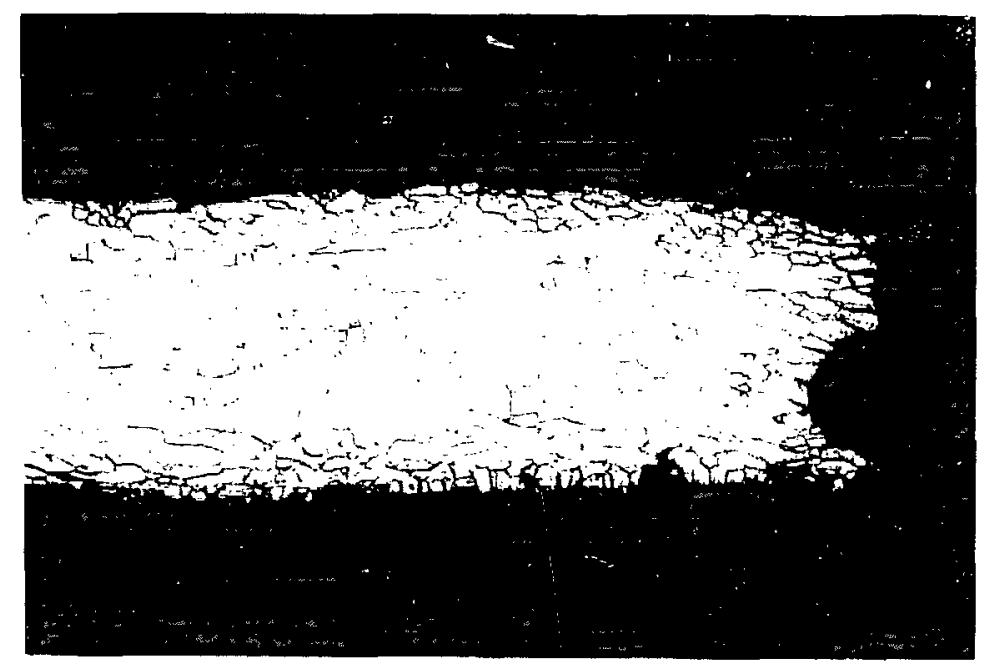

(a)

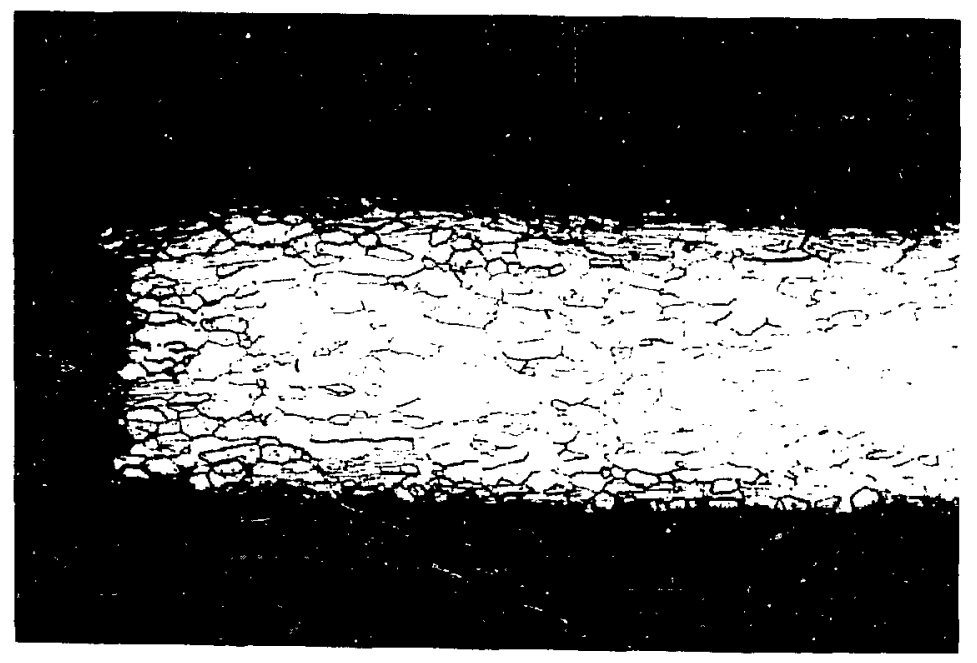

(b)

Fig. 46. Both sides (a. h) of the L-18 breach had a brittle. intergranular appearance: etched. $50 \mathrm{X}$. 


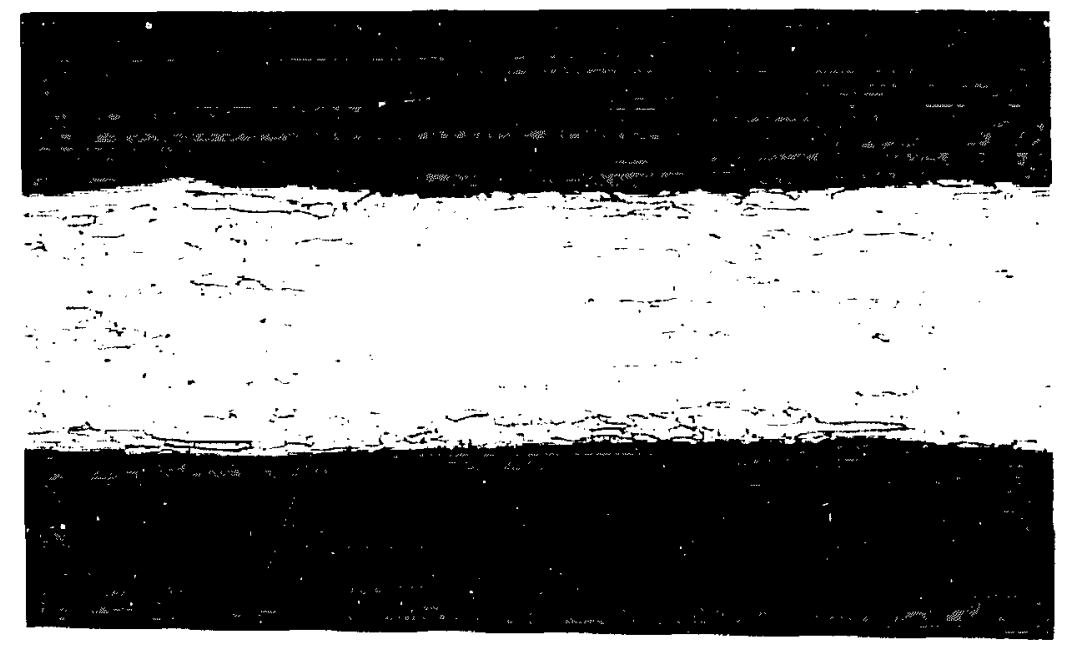

(a)

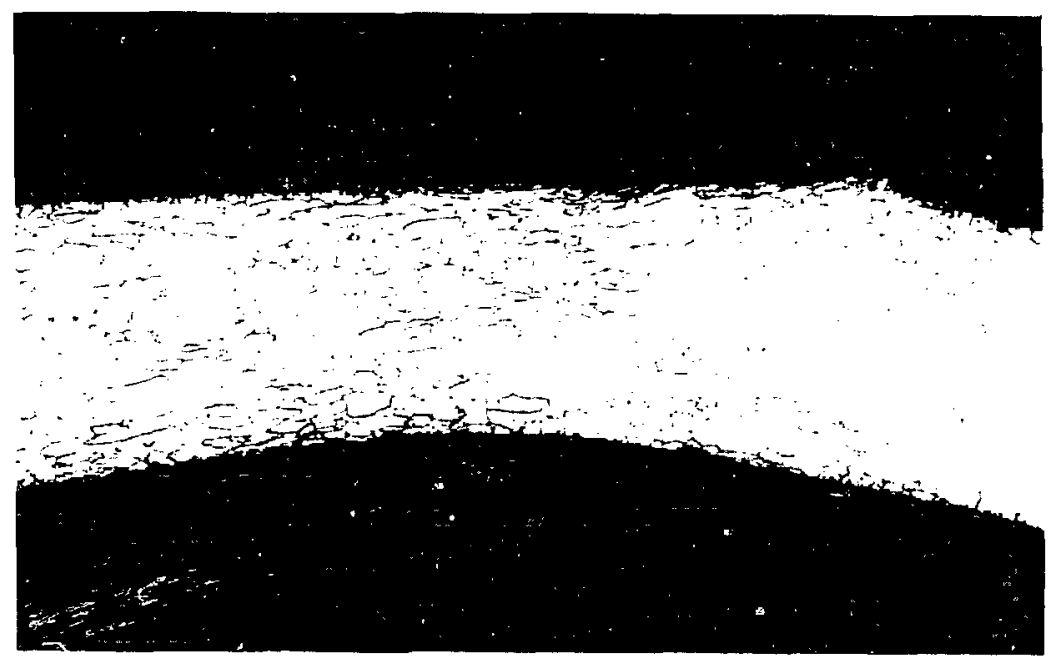

(b)

Fig. 47. Significant grain elongausen oxcurred in some areas of the L-18 weld shreld cup: tuo vieus (a. D). etched. 51) X. 


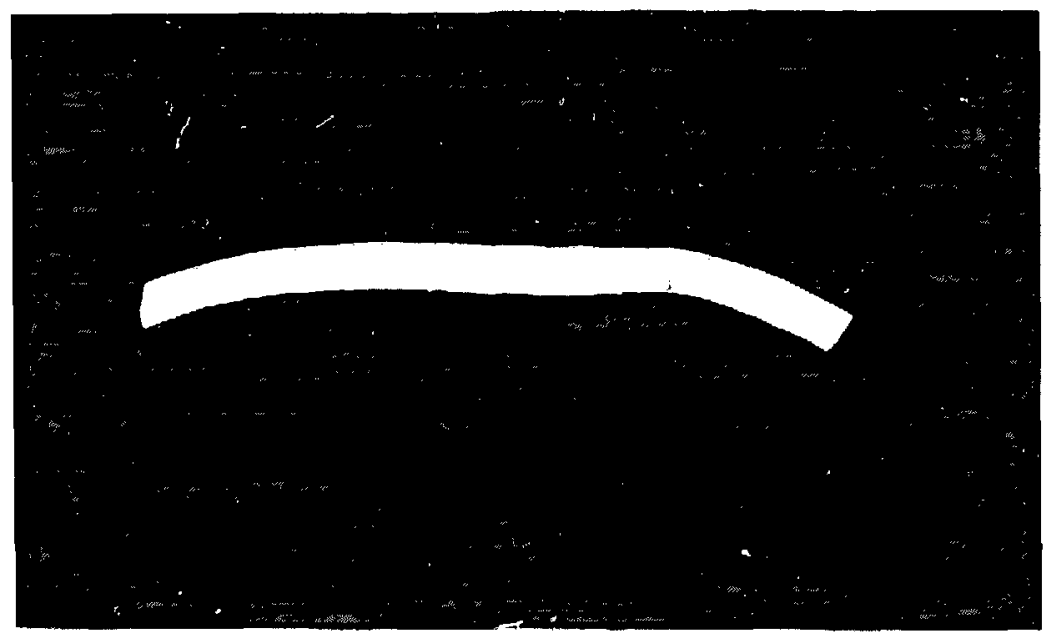

(a)

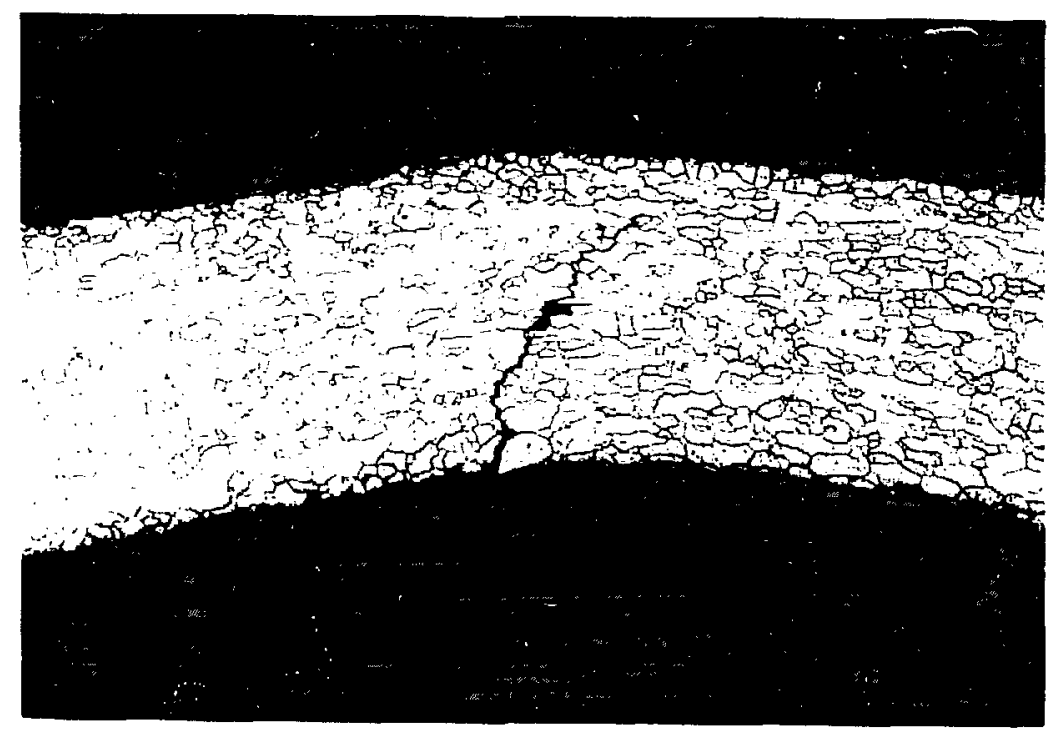

(b)

Fig. 48. A section of the $L-18$ vent cup contained a deep crack that penetrated $80 \%$ of the capsule wall. (a) As polished. $7 \mathrm{X}$. and (b) etched, $50 \mathrm{X}$. 


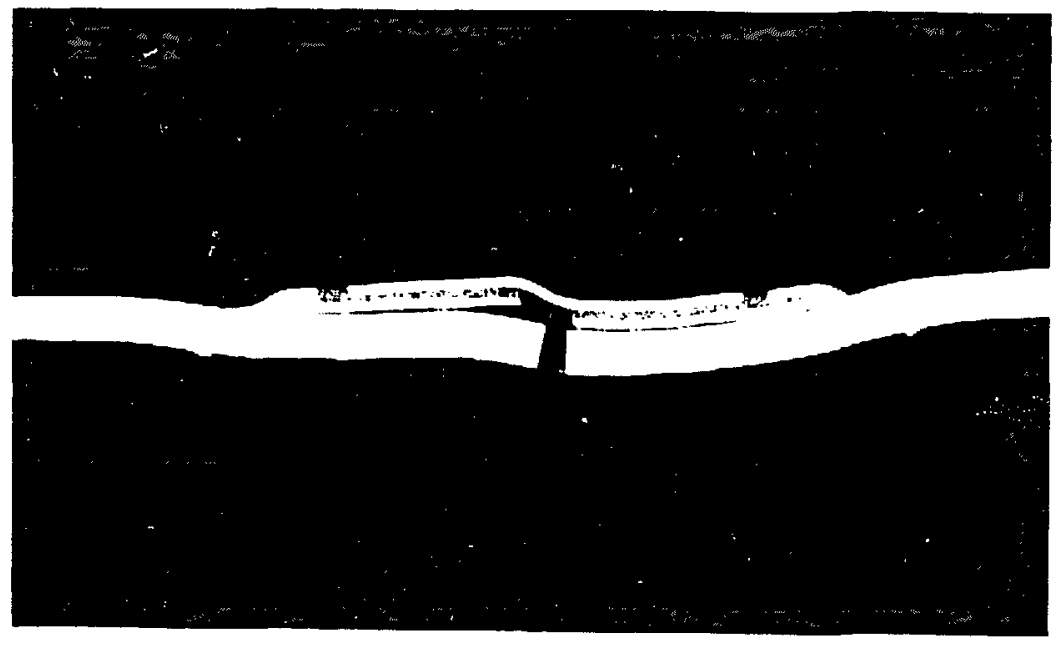

Fig. 49. The L-18 vent was severely deformed; as polished. 7X. 


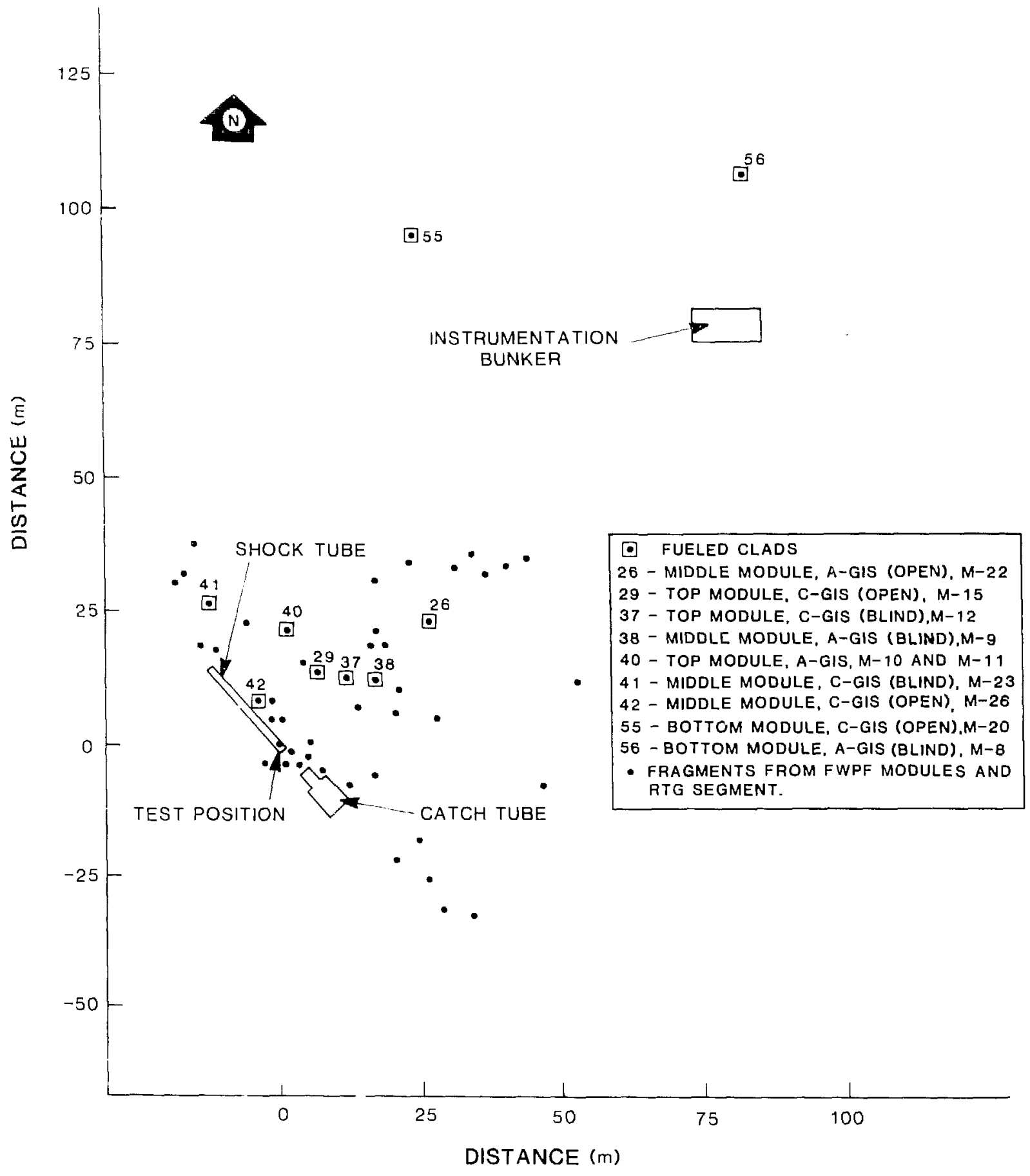

Fig. 50. The module lest atack in (ST-6-RT G-2. propeiled upward by a reflected component of the blast wave was scattered over a wide area. 


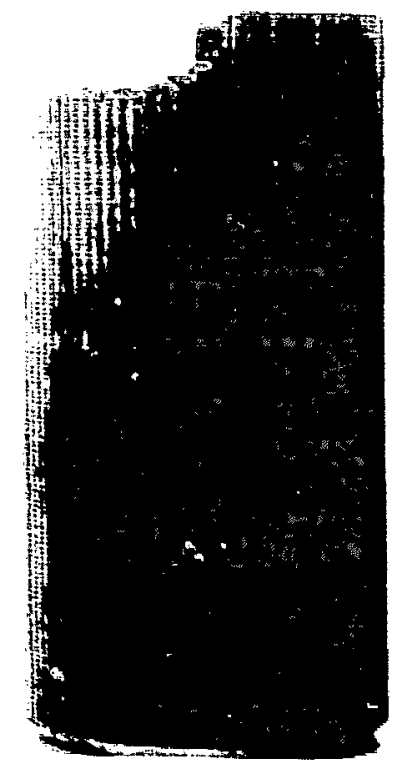

(a)
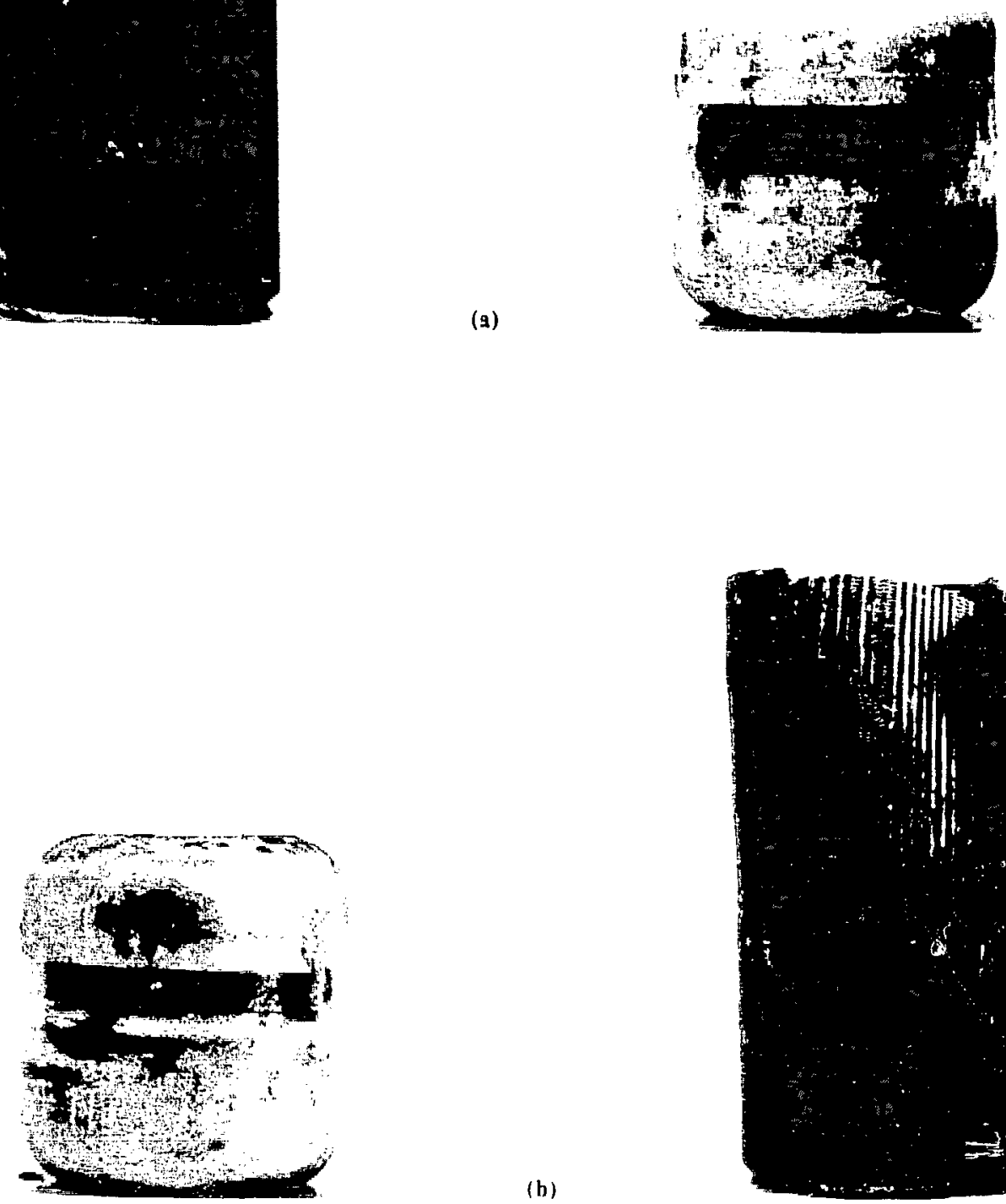

(b)

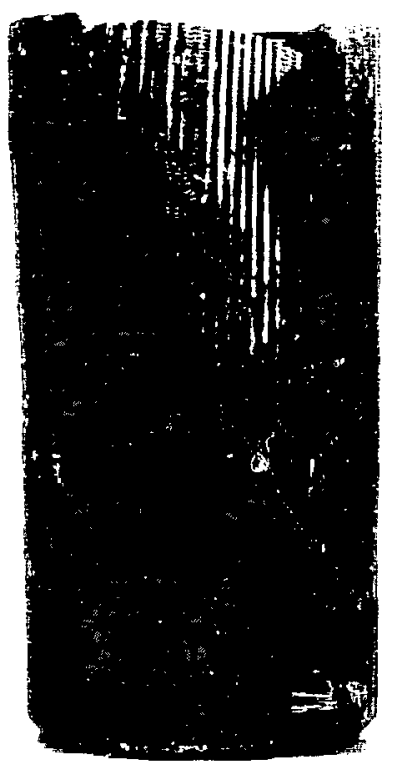

Fig. 51. (a) Clad M-12 (top module. C-CiSS) and (h) clad M-4 (middle murlule. A-CiIS) were ecovered integral in their graphite impact shells. (c) Clads $M-16$ and $M-11$ 1 isp module. A-(ilS) were also recovered integral in the (ilS. 

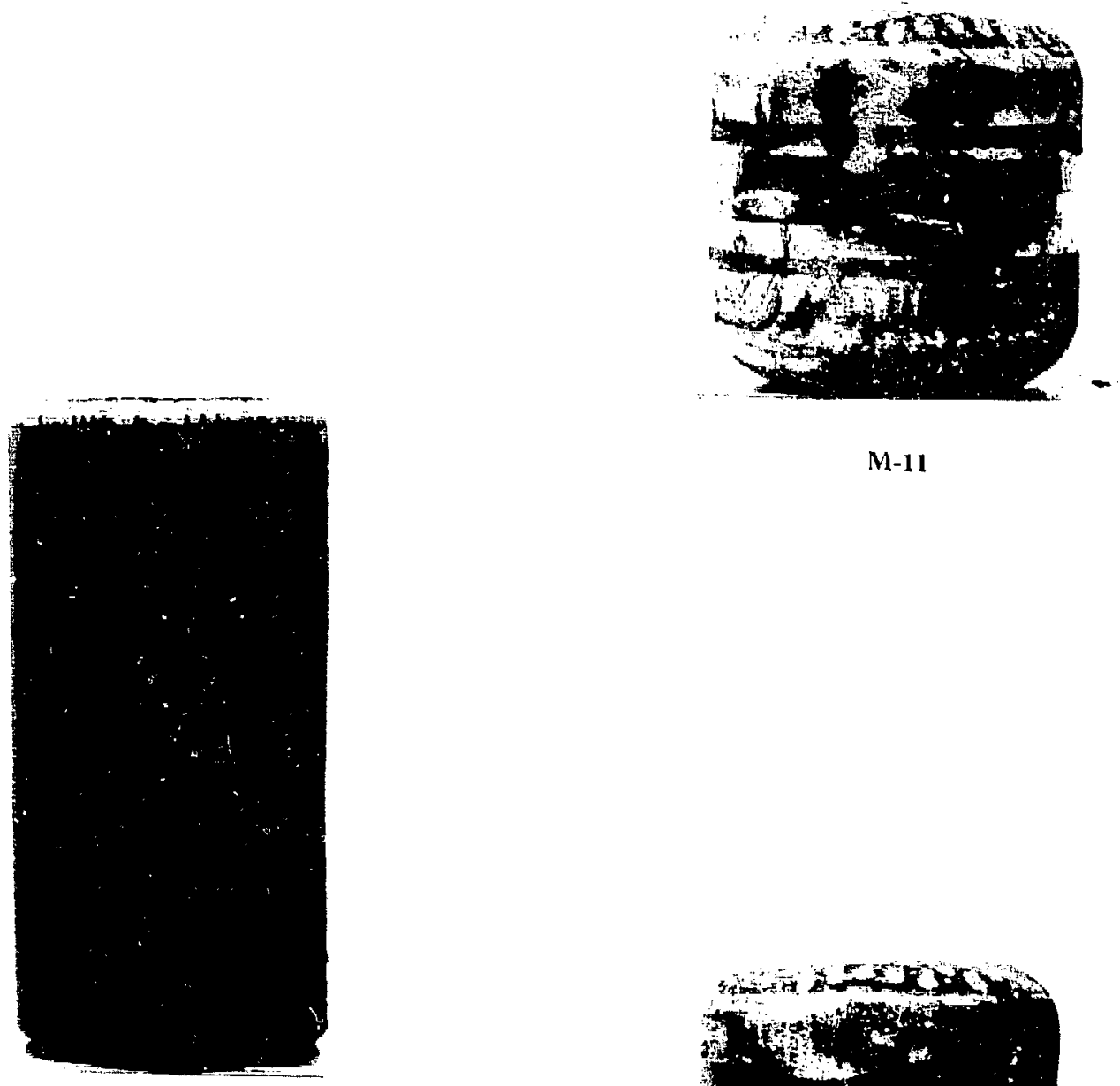

M-1 1

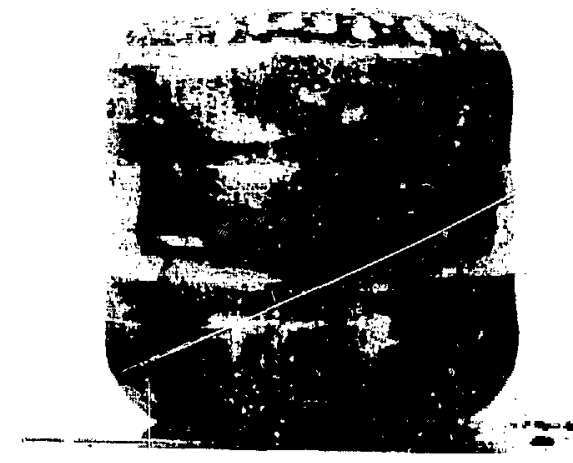

Mi-10

(c)

Fig. 51. (cont) 


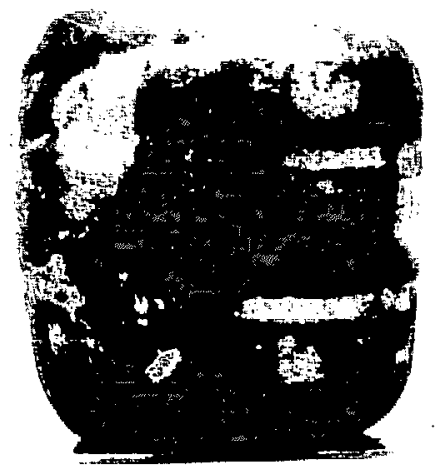

(a)

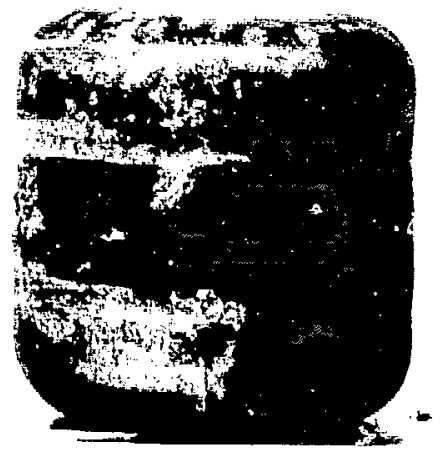

(b)

Fig. 52. Three bare clads were recovered integral: (a) M-26 (middle module, C-GIS): (b) M-15 (top module, C-GIS): and (c) M-23 (middle module. (-GIS). 


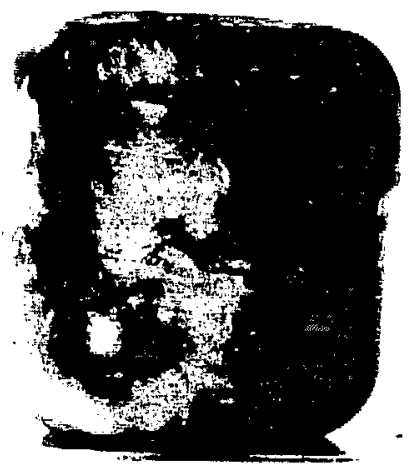

(c)

Fig. 52. (cont) 

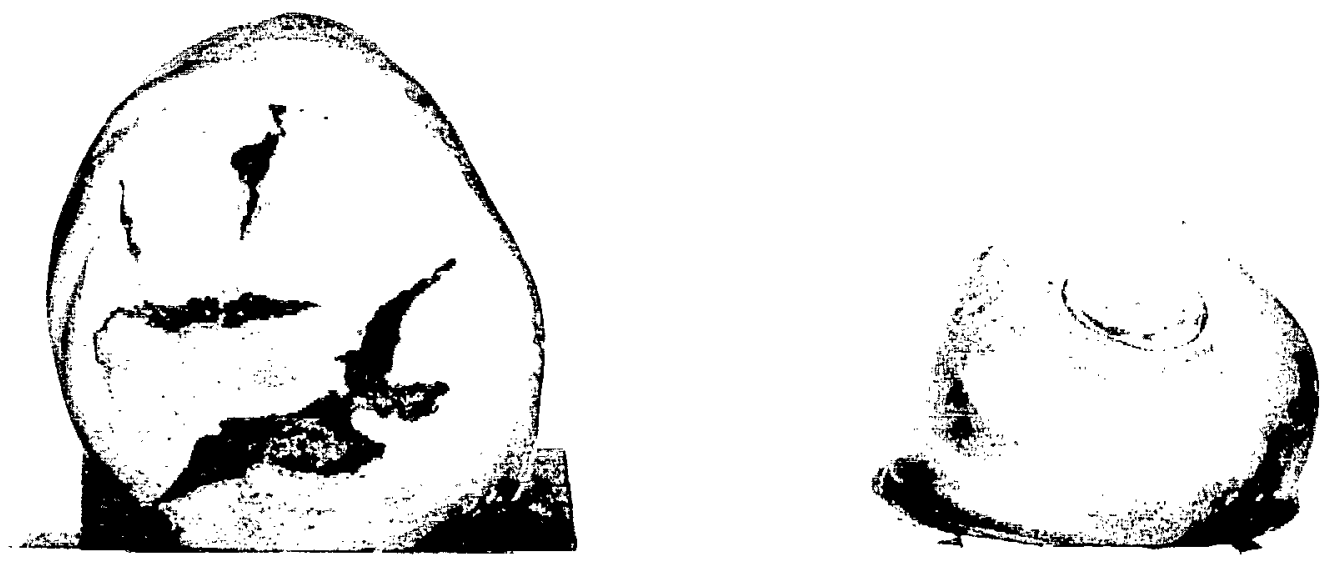

(a)

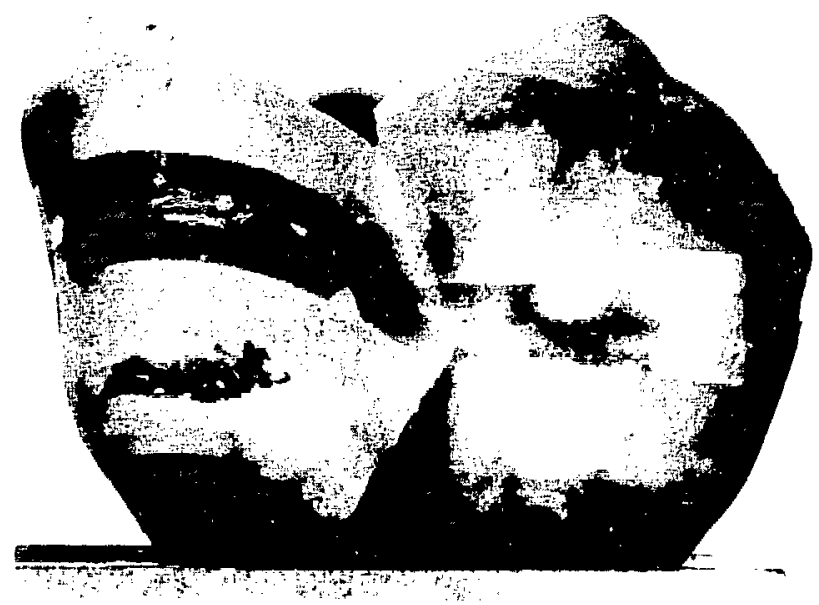

(b)

Fig. 53. Three clads were recovered breached: (a) $11-8$ (holtom

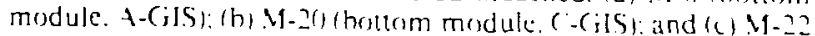
imiddle module t-rilsi). 


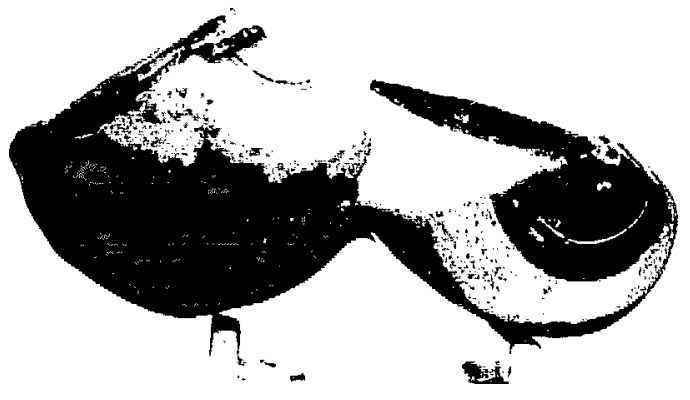

(b) (cont)
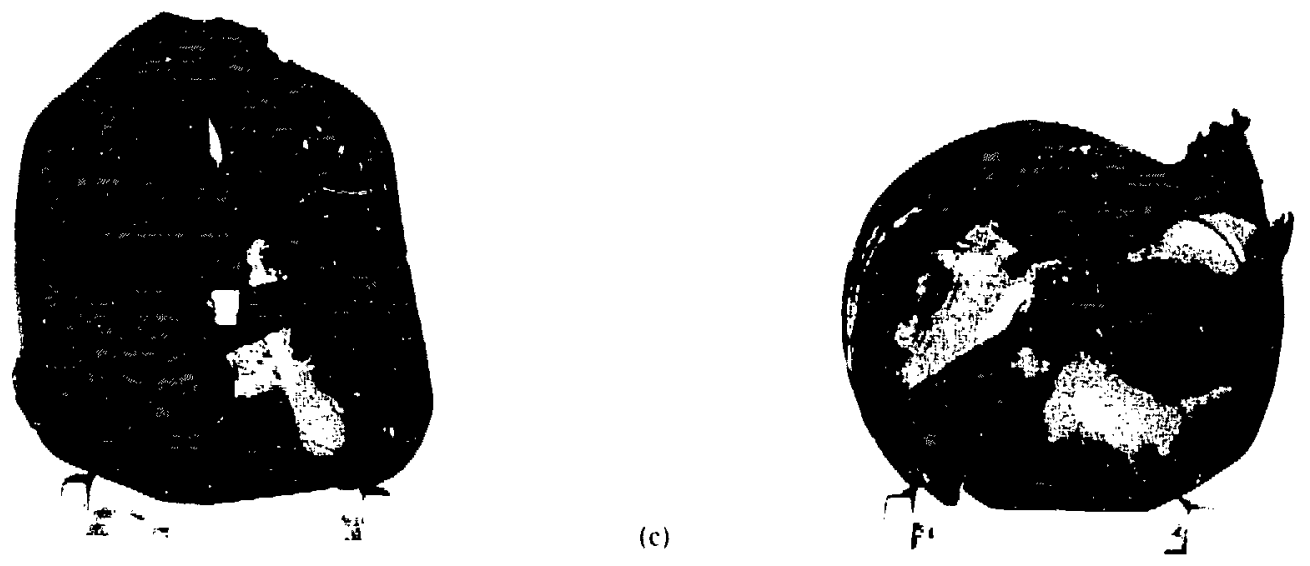

Fig. 53 (cont) 

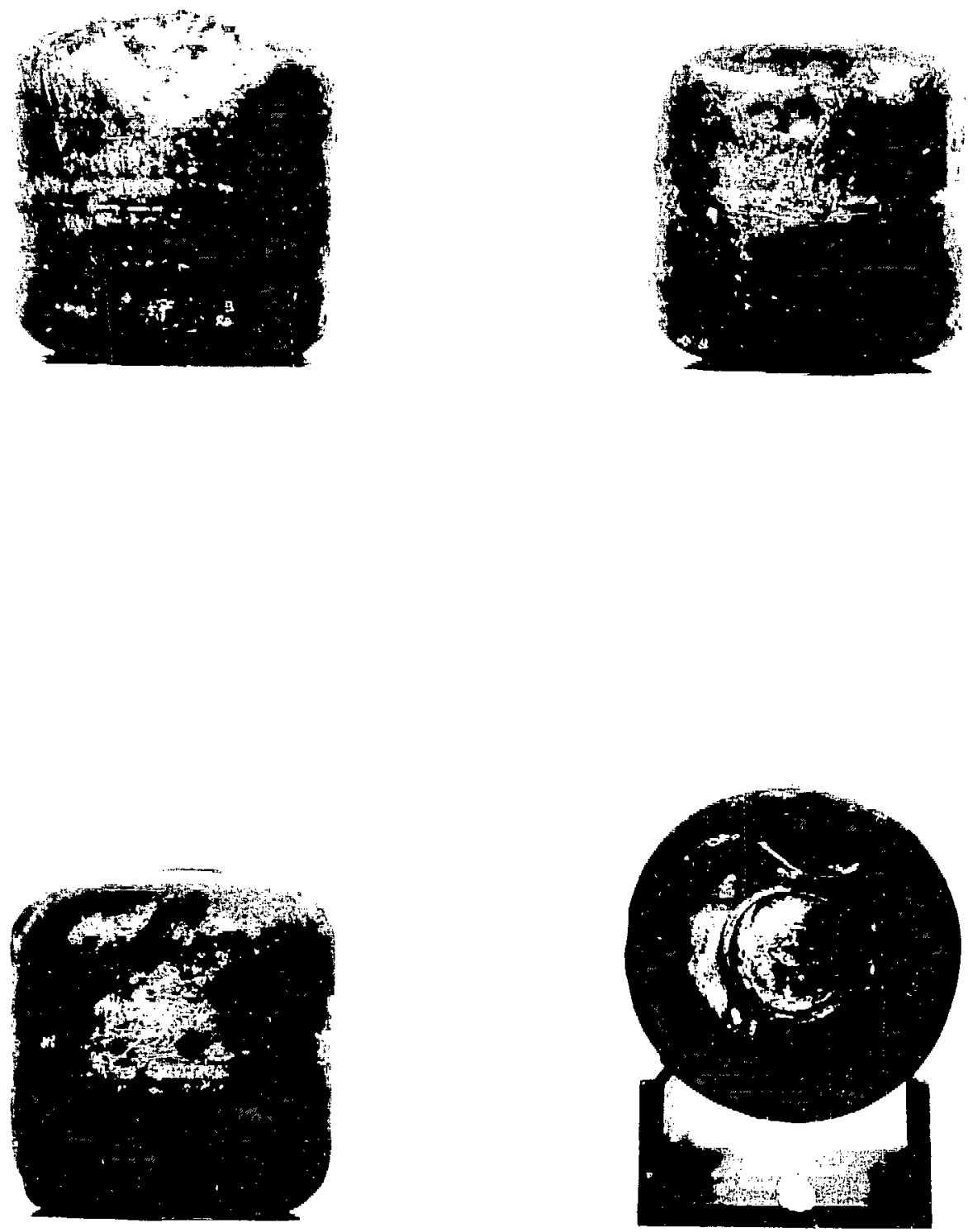

Fig. 54. Clad M-35 was recovered integral after CST-7-RTG-3 at $12.9 \mathrm{MPa}$. 

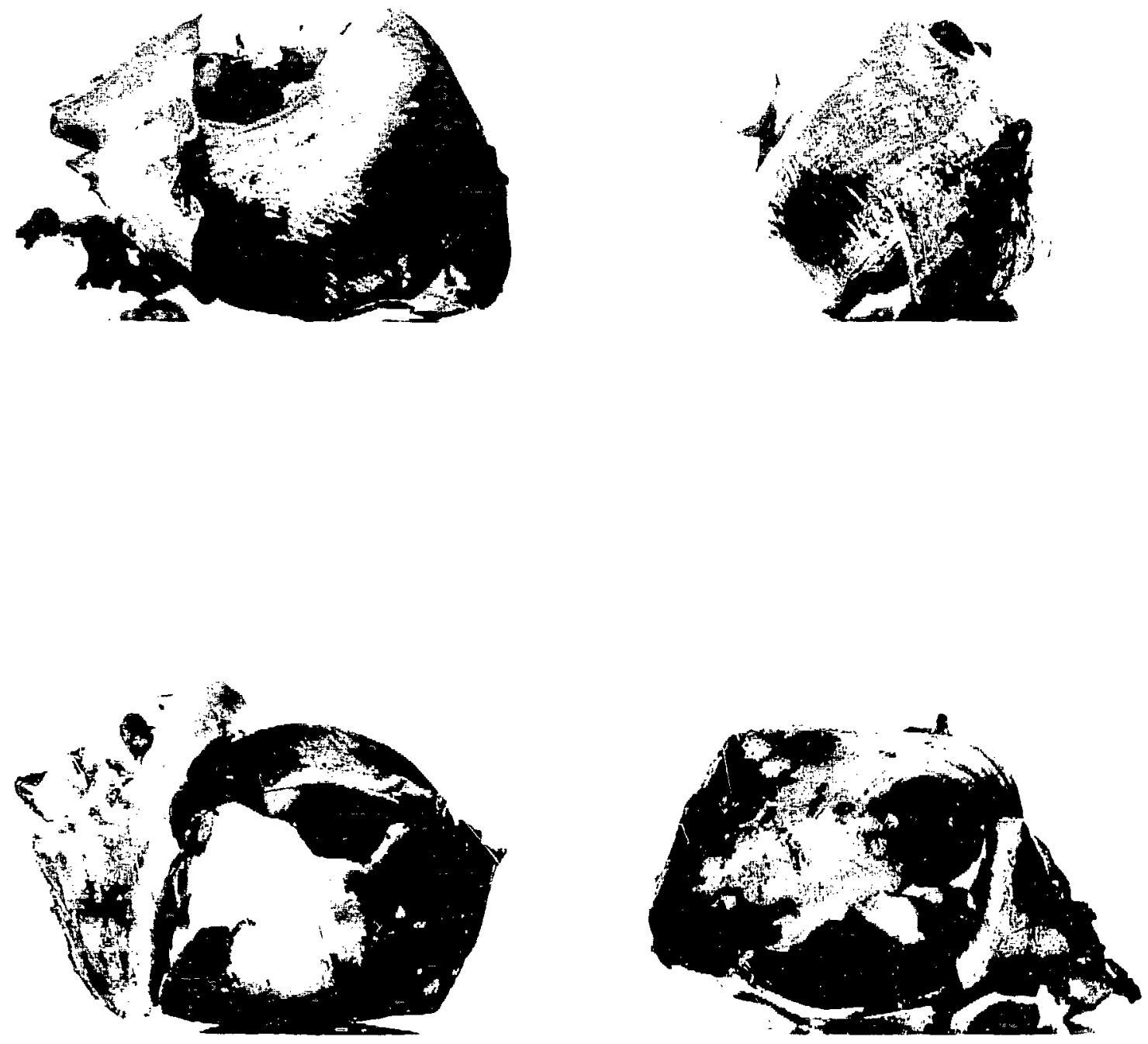

Fig. 55. (lad M-30 was breached in an overpre;sure test at $12.9 \mathrm{MPa}$ by collision with either the shock tube or catch tube walls. 


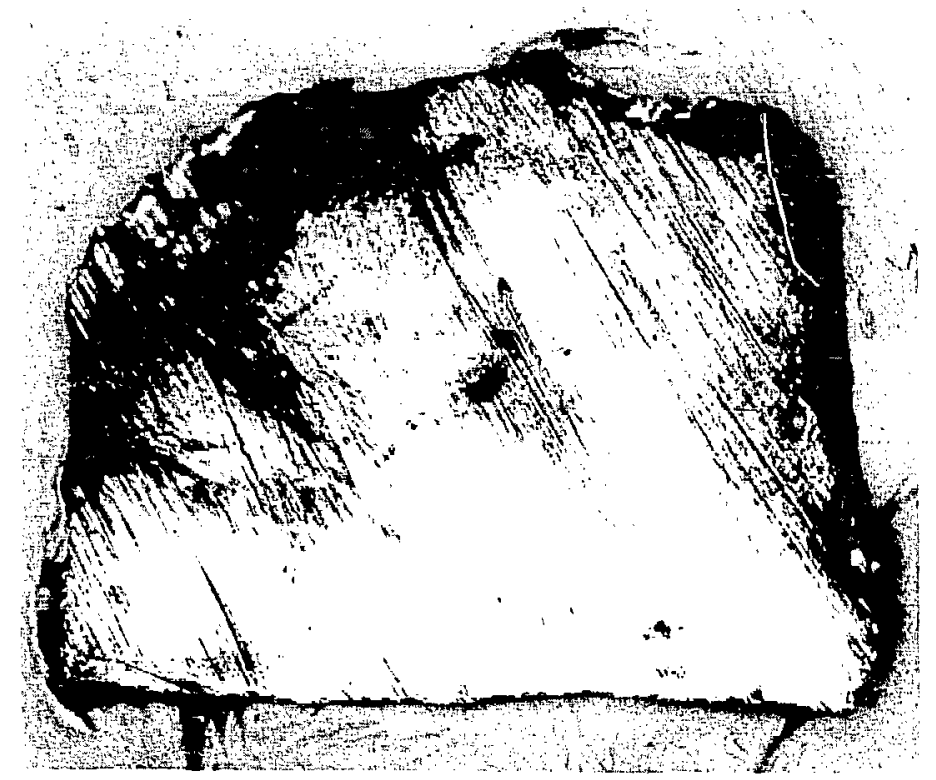

Fig. 56. Clad fragment from CST-7-RTG-3 recovered inside the catch tube; $40 \mathrm{X}$.

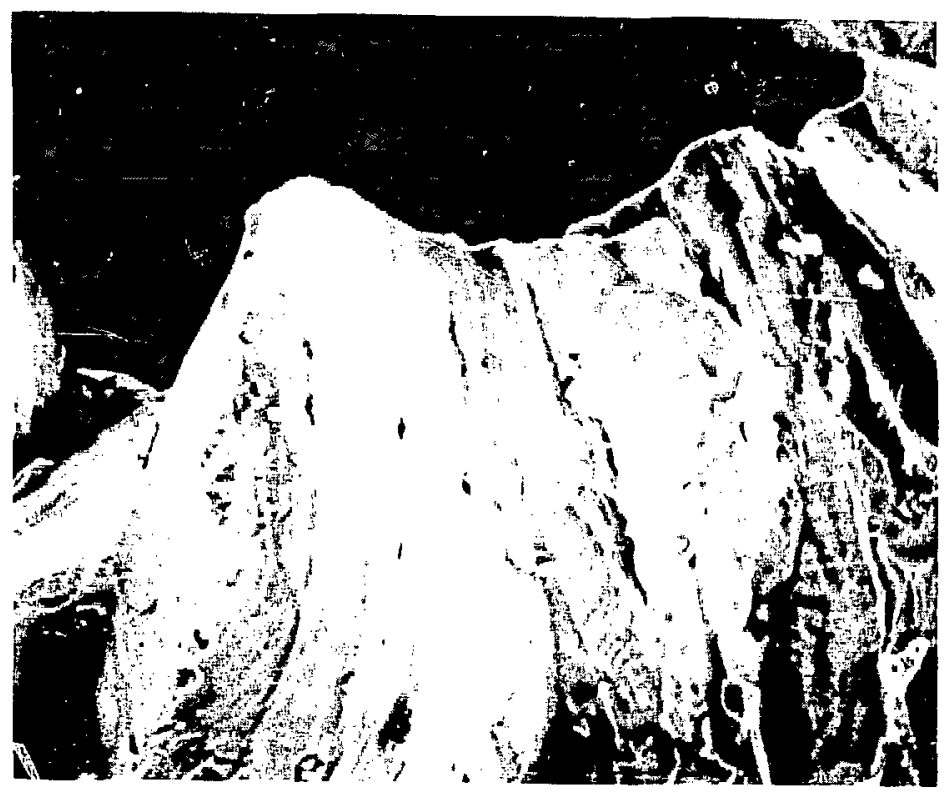

Fig. 57. Fractured area on the surface of the clad fragment: elestron micrograph, $2000 \mathrm{X}$ 


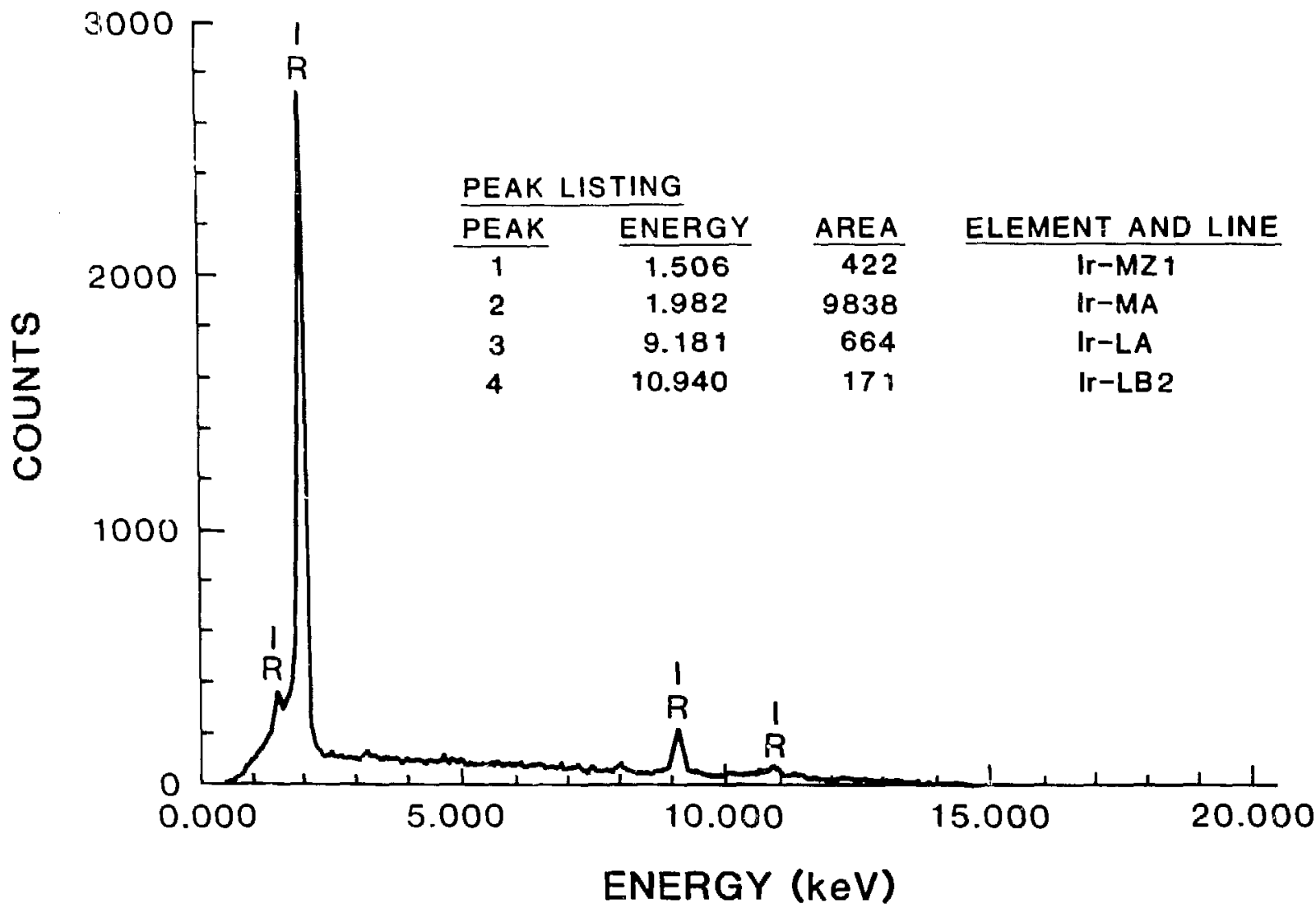

Fig. 58. X-ray speitrum from the area seen in Fig. 57 (50-s counting time). Only iridium was detected. 


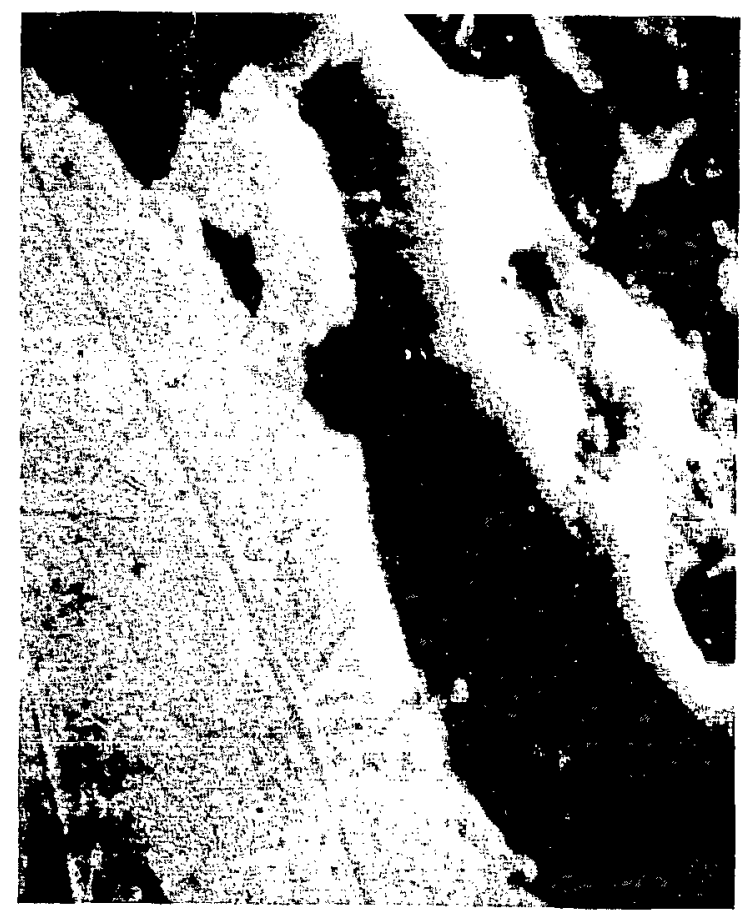

(a)

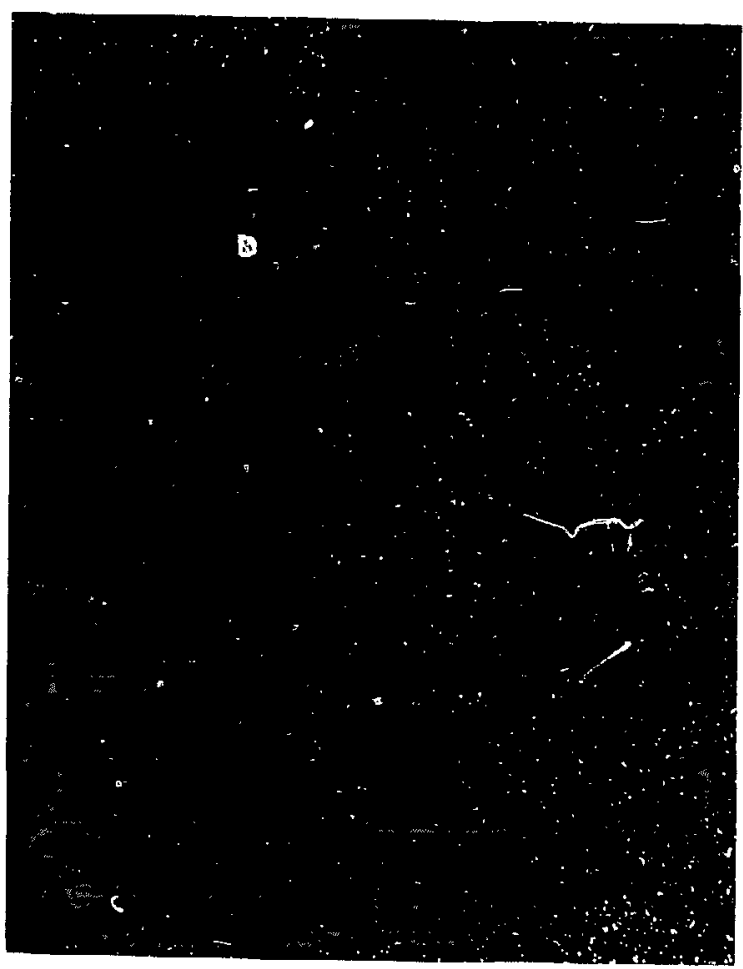

(b)

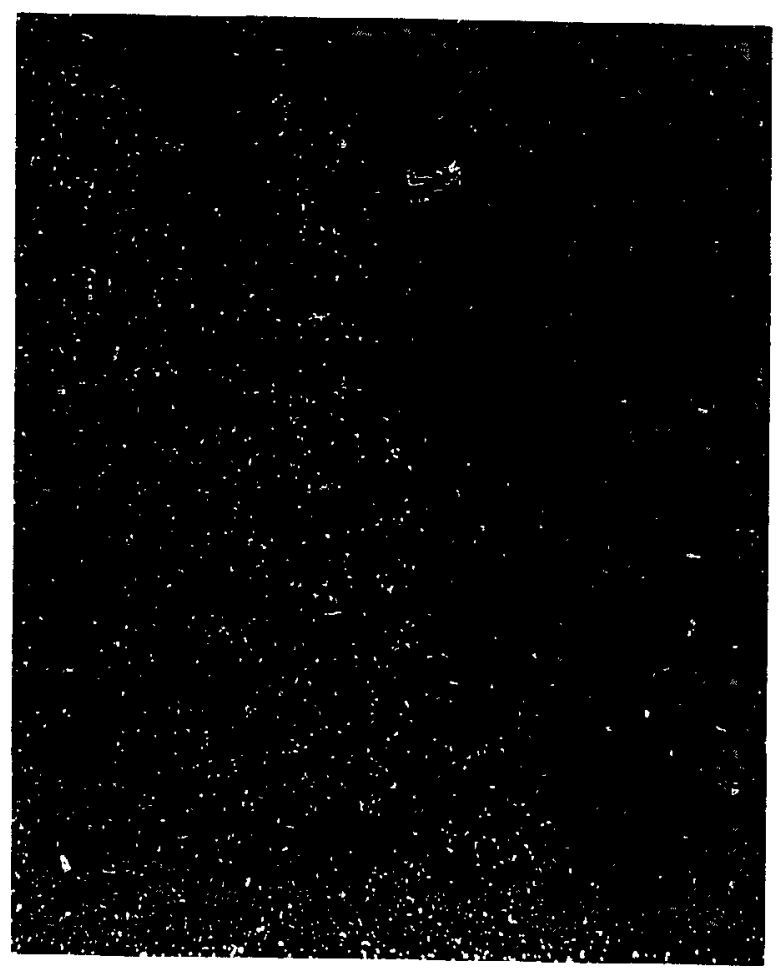

(c)

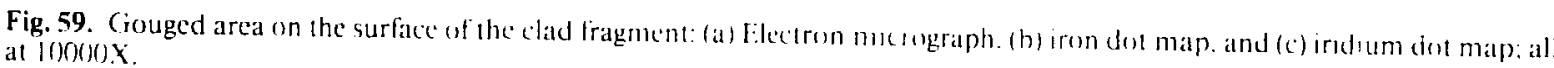




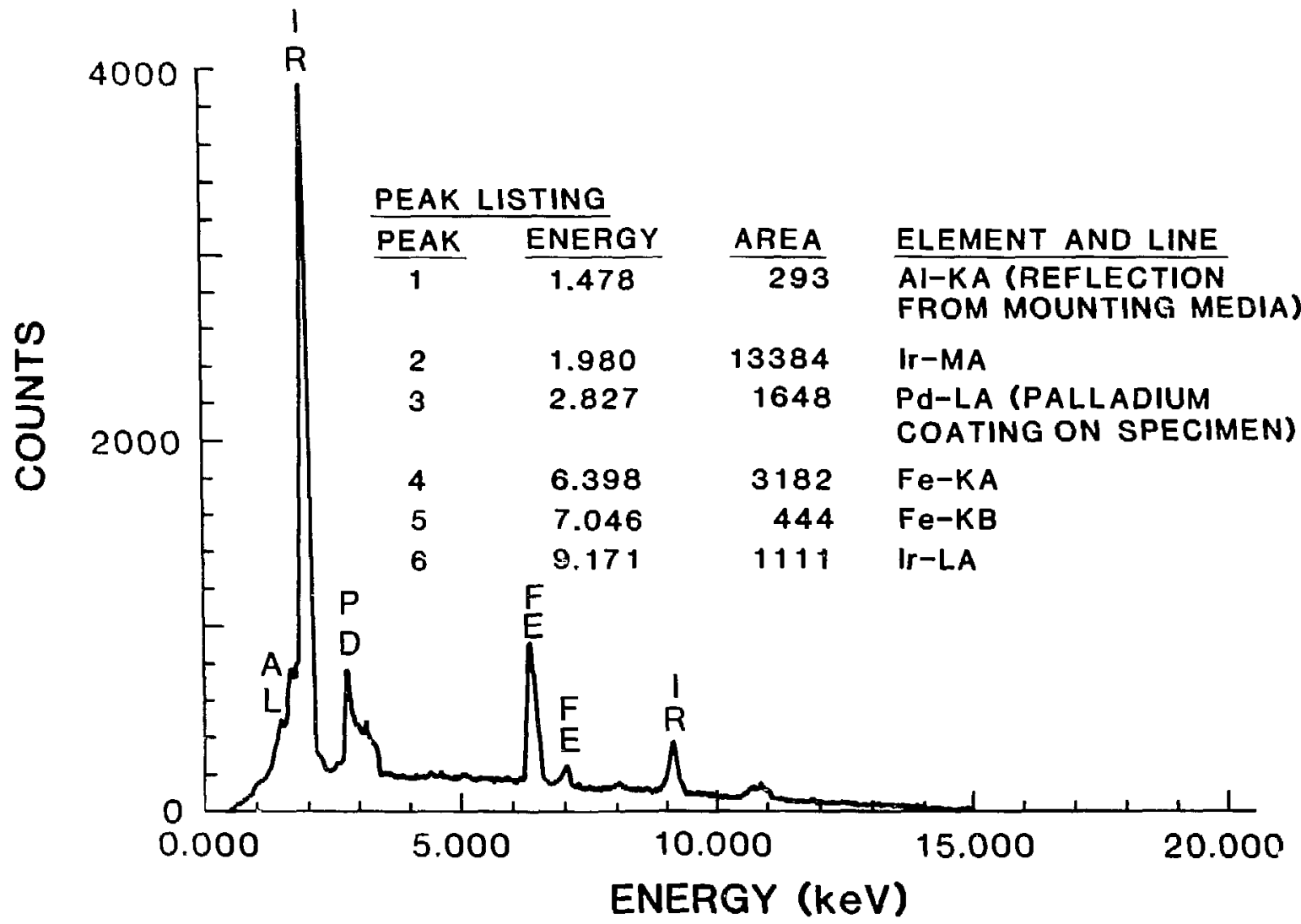

Fig. 60. X-ras spectrum from the area seen in Fig. 59(262-s counting time). Both iridium and iron were detected. 


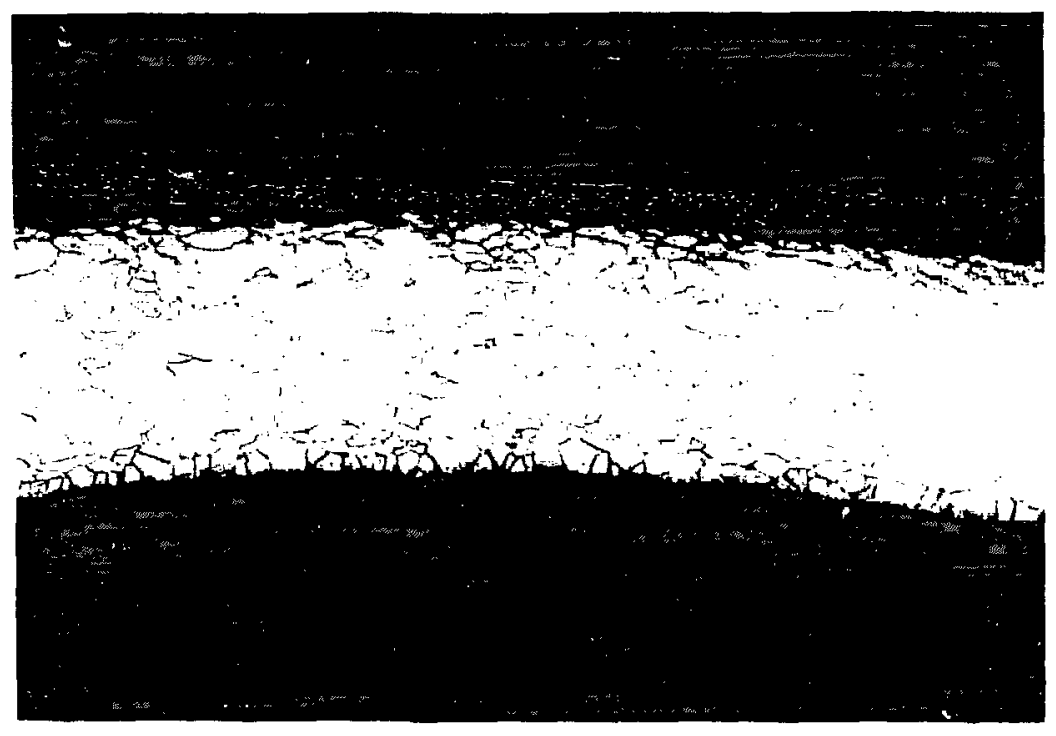

Fig. 61. Grain elongation and a reduction in thickness of $27 \%$ occurred in a section of the M-35 vent cup; $50 \mathrm{X}$.

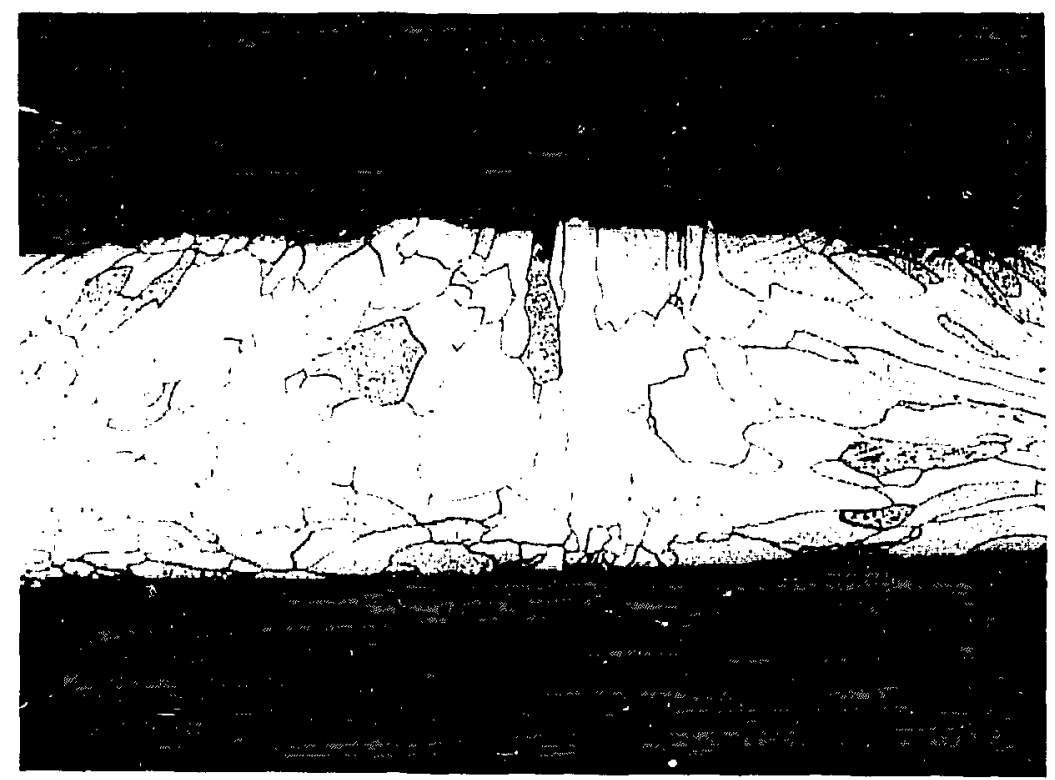

Fig. 62. The $M-35$ capsulc wcld was unusually coarse graincd: $51, X$. 


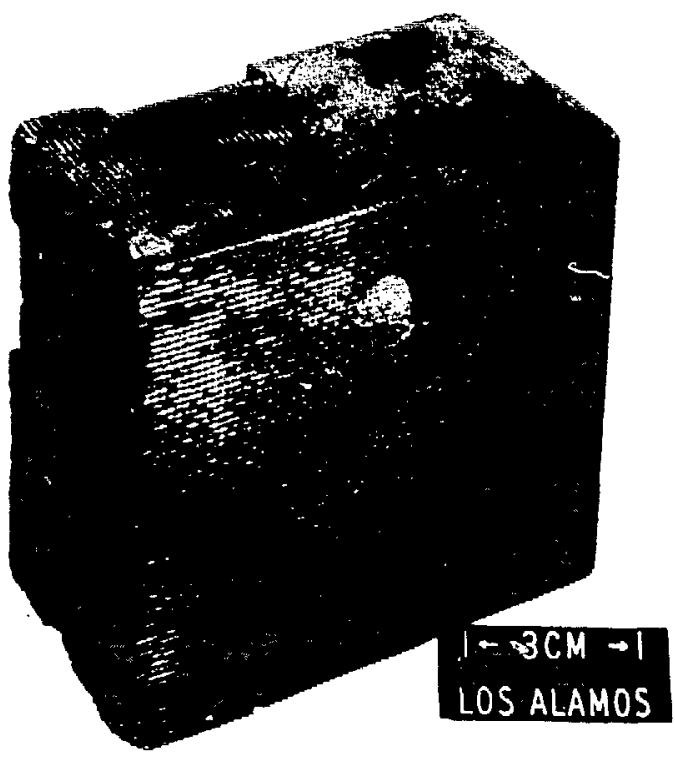

Fig. 63. The module exposed to an overpressure test at 2.96 MPa had a crack on each side of the broad faces of the aeroshell. 


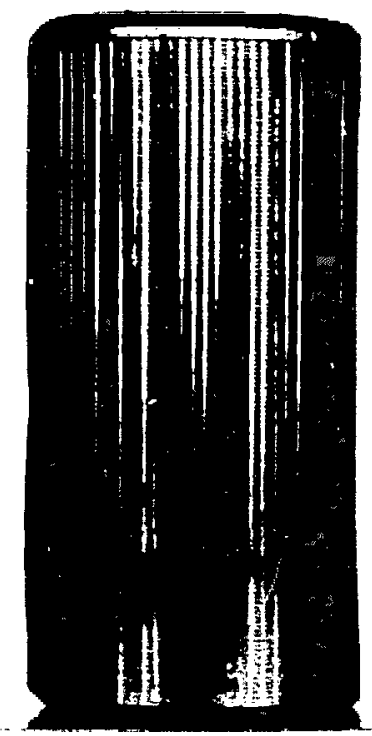

(a)

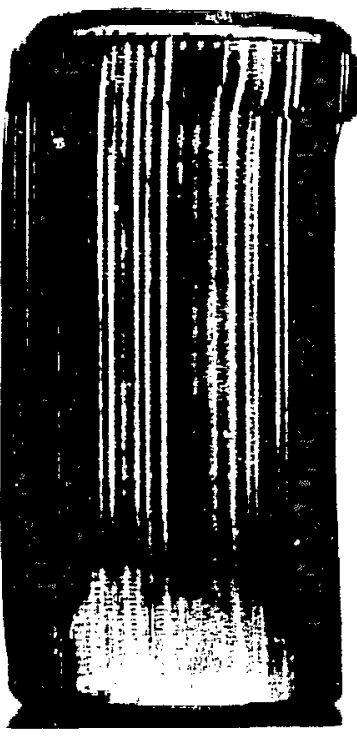

(b)

Fig. 64. The A-GIS (a) and the C-GiS (b) from CST-8-RTG-4 were cracked. 

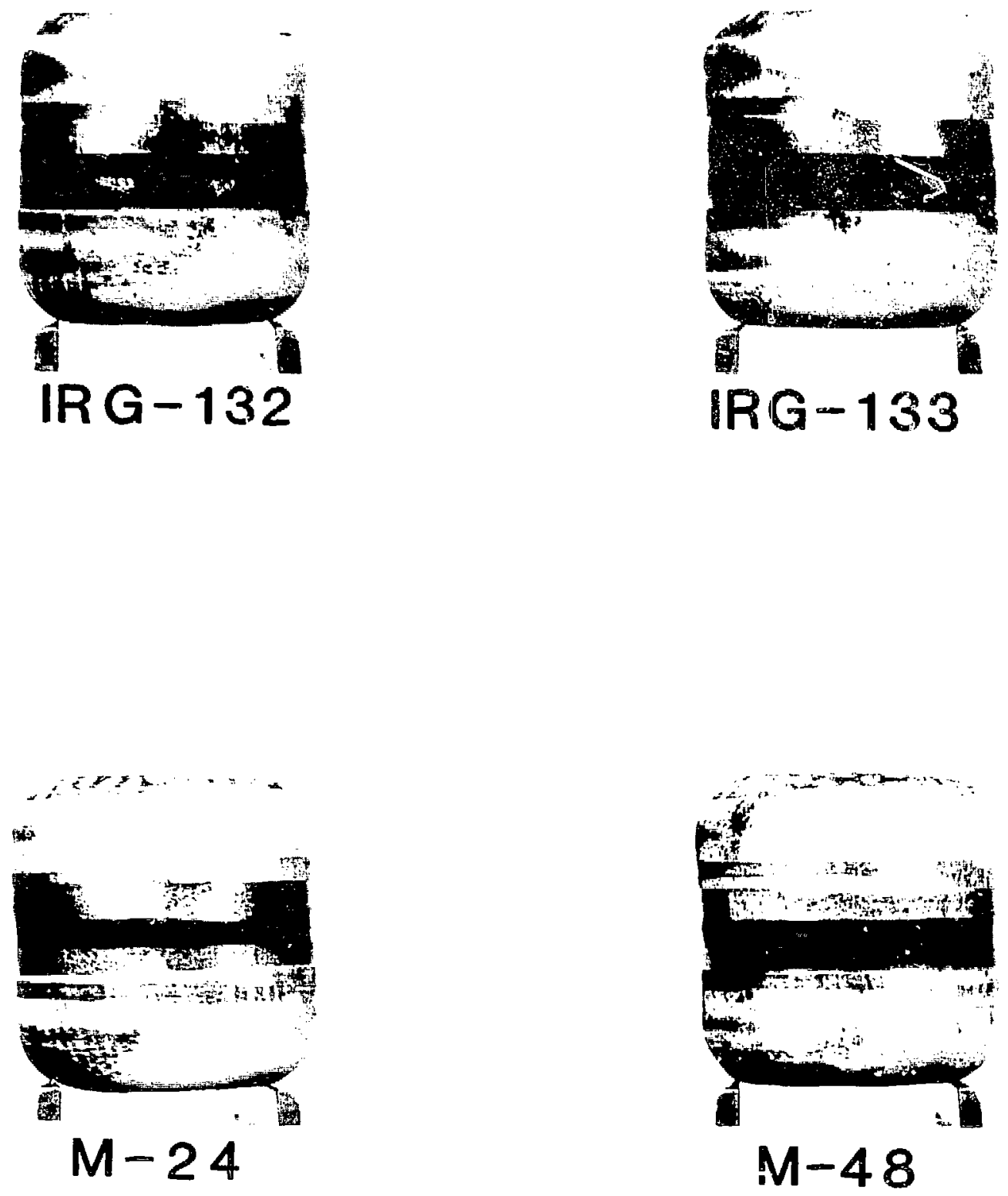

Fig. 65. The simulant-fueled clads exposed to $2.96 \mathrm{MPa}$ were only slightly deformed. 


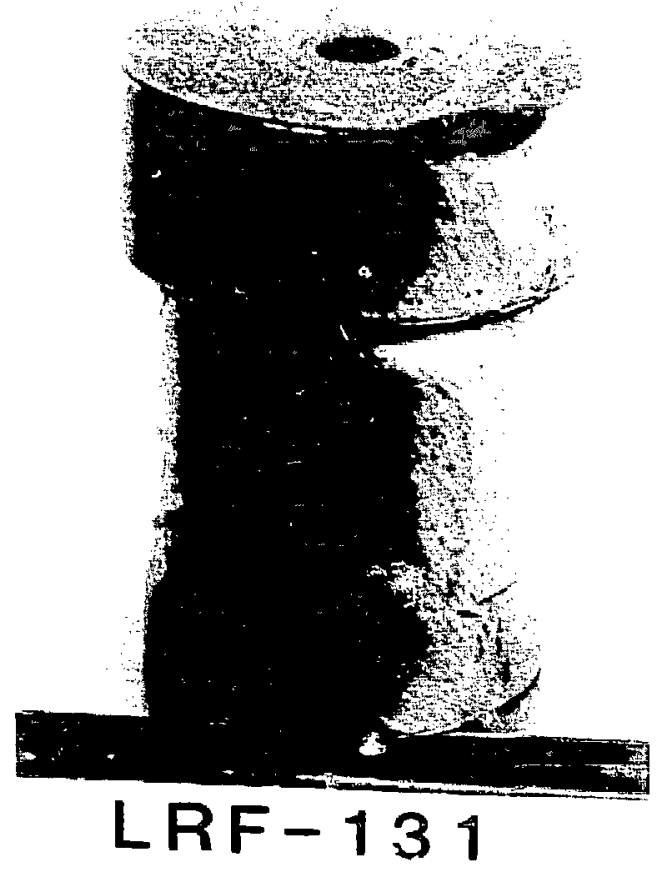

(a)

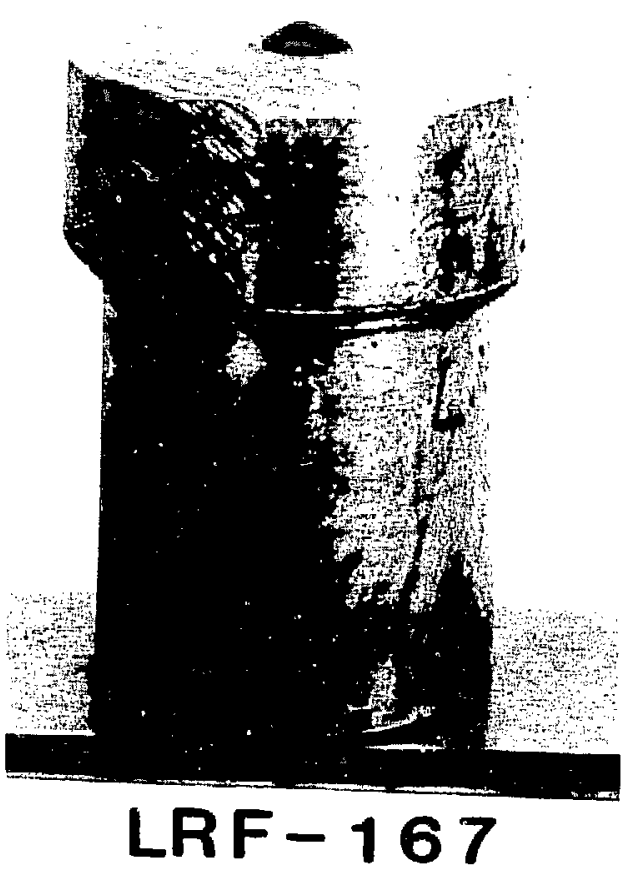

(b)

Fig. 66. The simulant-fueled LWRHUS were noi significantly deformed after an explosion test at $2.96 \mathrm{MPa}$. 


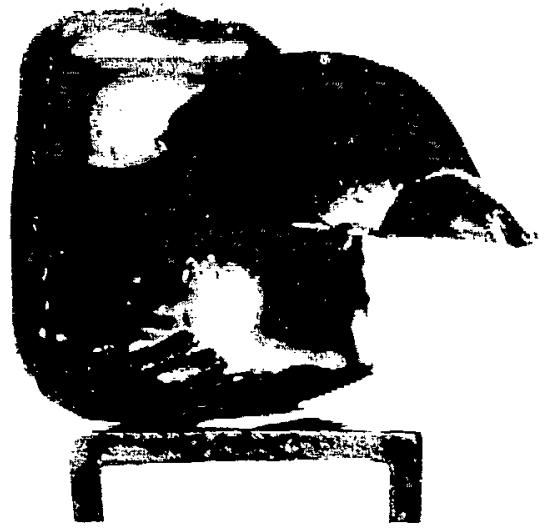

(a)

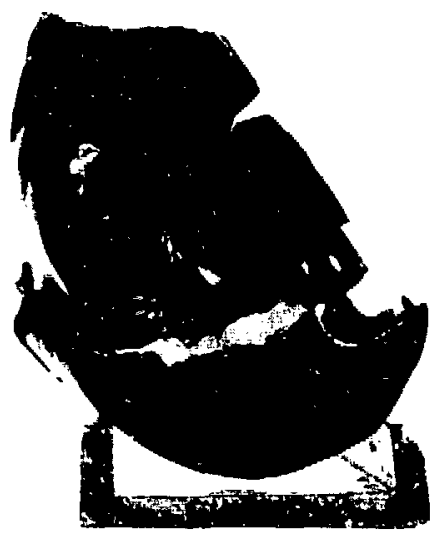

(c)

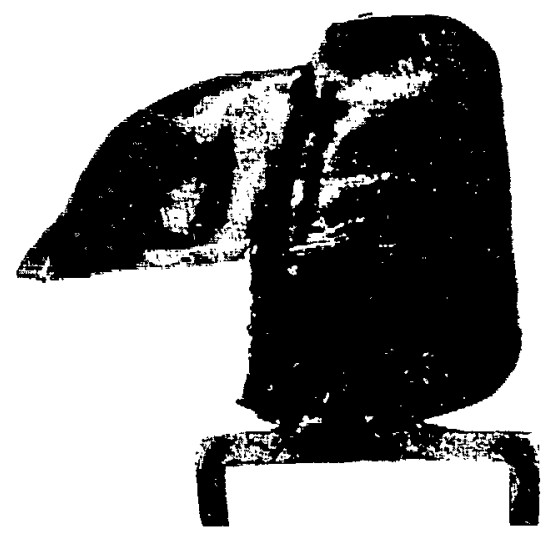

(b)

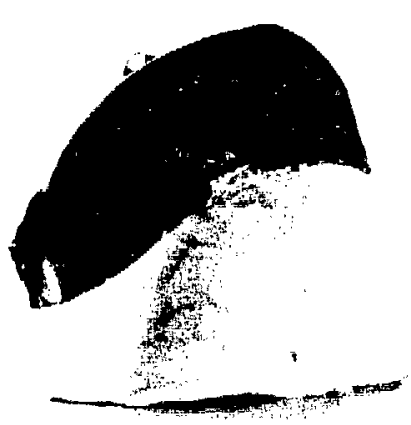

(d)

Fig. 67. Clad M-46 was recovered in two pieces atter CST-9-RTG-5. The breach was a result of collision with either the shock tube or catch tube walls. Four views (a. b. c, d). 


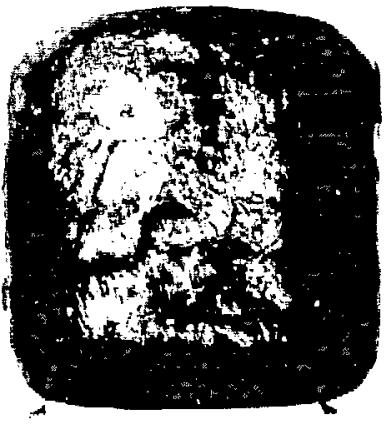

(a)

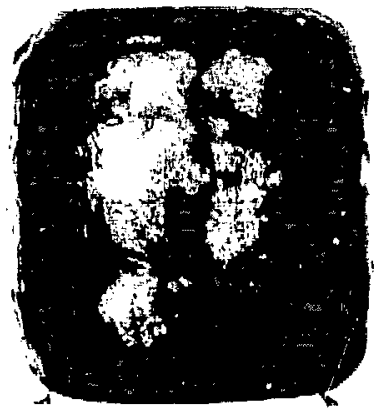

(b)

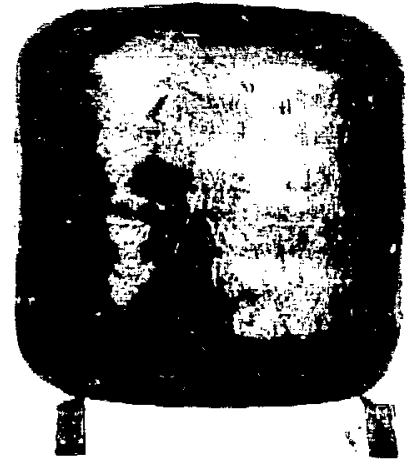

(c)

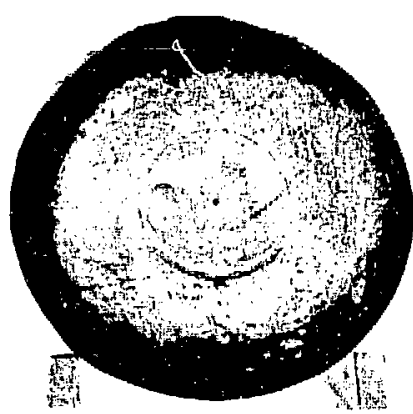

(d)

Fig. 68. Clad M-40 was recovered integral after exposure to 15.3 MPa in CST-9-RT (j-5. Four views (a, b, c. d). 


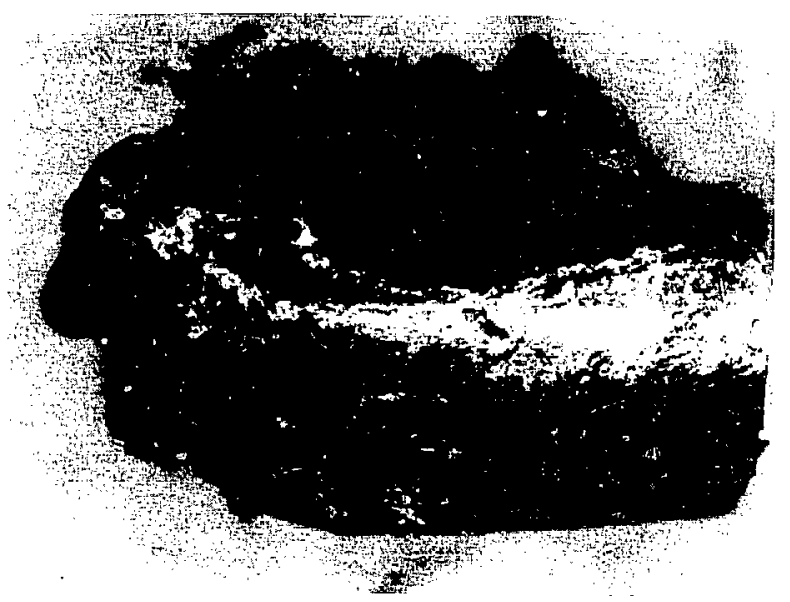

Fig. 69. An M-46 clad fragment containing striations and cracks on the external surface was selected for SFM examination; $7 \mathrm{X}$. 


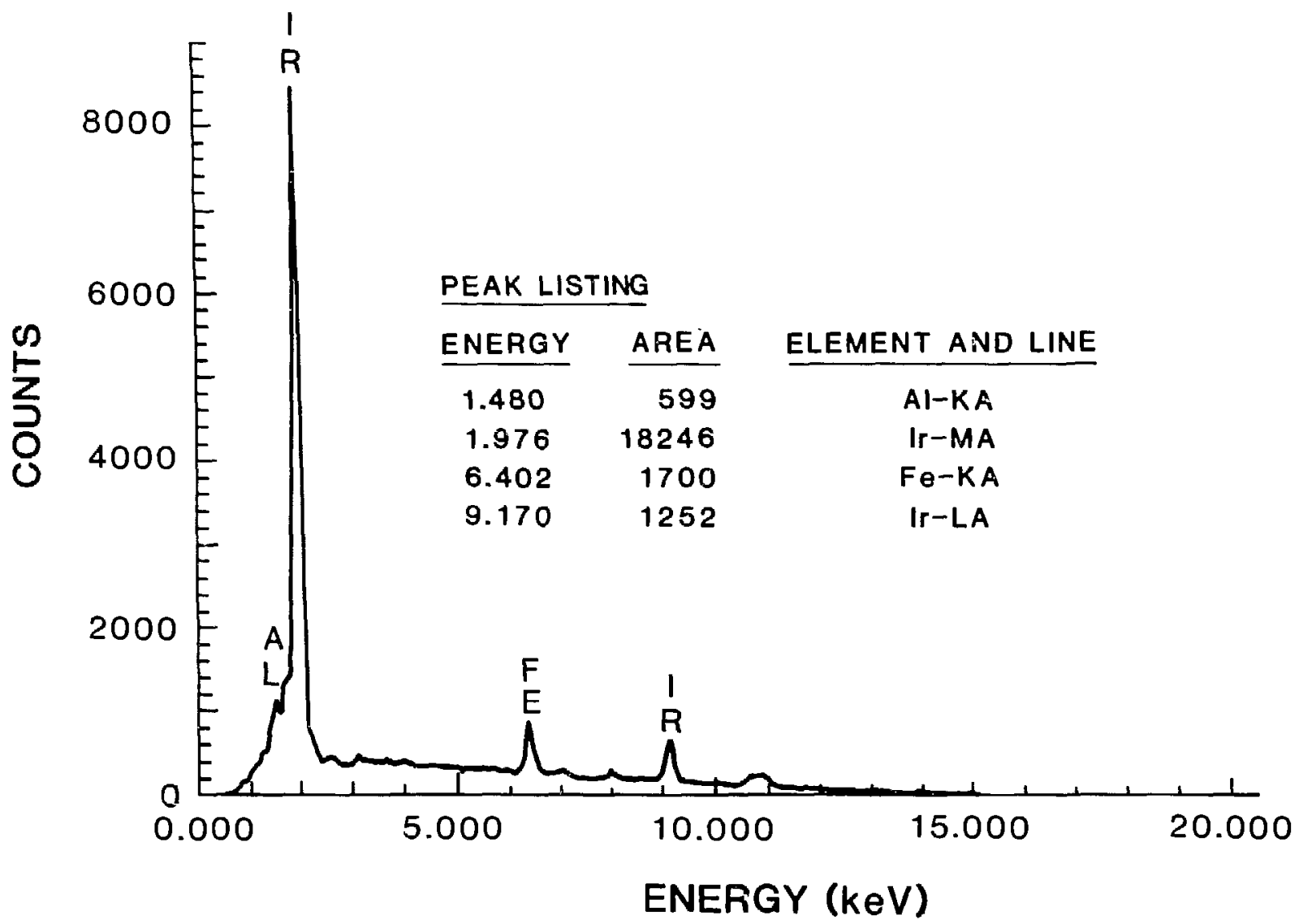

Fig. 70. Low-magnification $x$-ray spectra of the area in Fig. 71 a (20-s counting time). Iridium, iron, and aluminum were detected. 


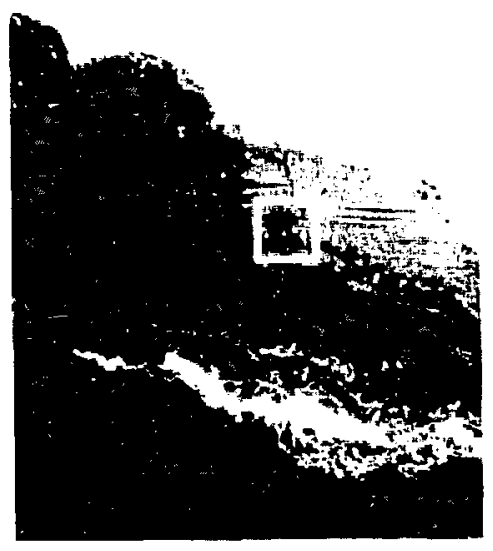

(a)

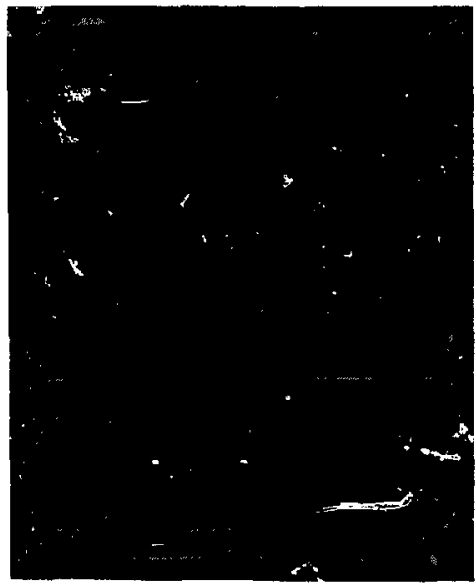

(b)

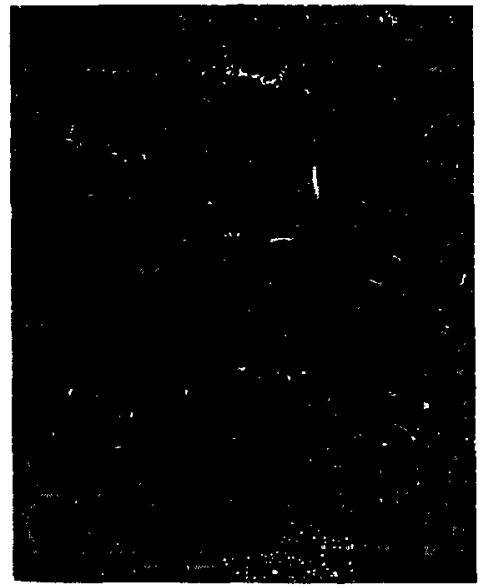

(c)

Fig. 71. M-46 fragment fracture surface: (a) Electron micrograph, (b) iridium dot map. and (c) iron dot map; all at $30 \mathrm{X}$.

Note:

Figures (b) and (c) are reversed. 


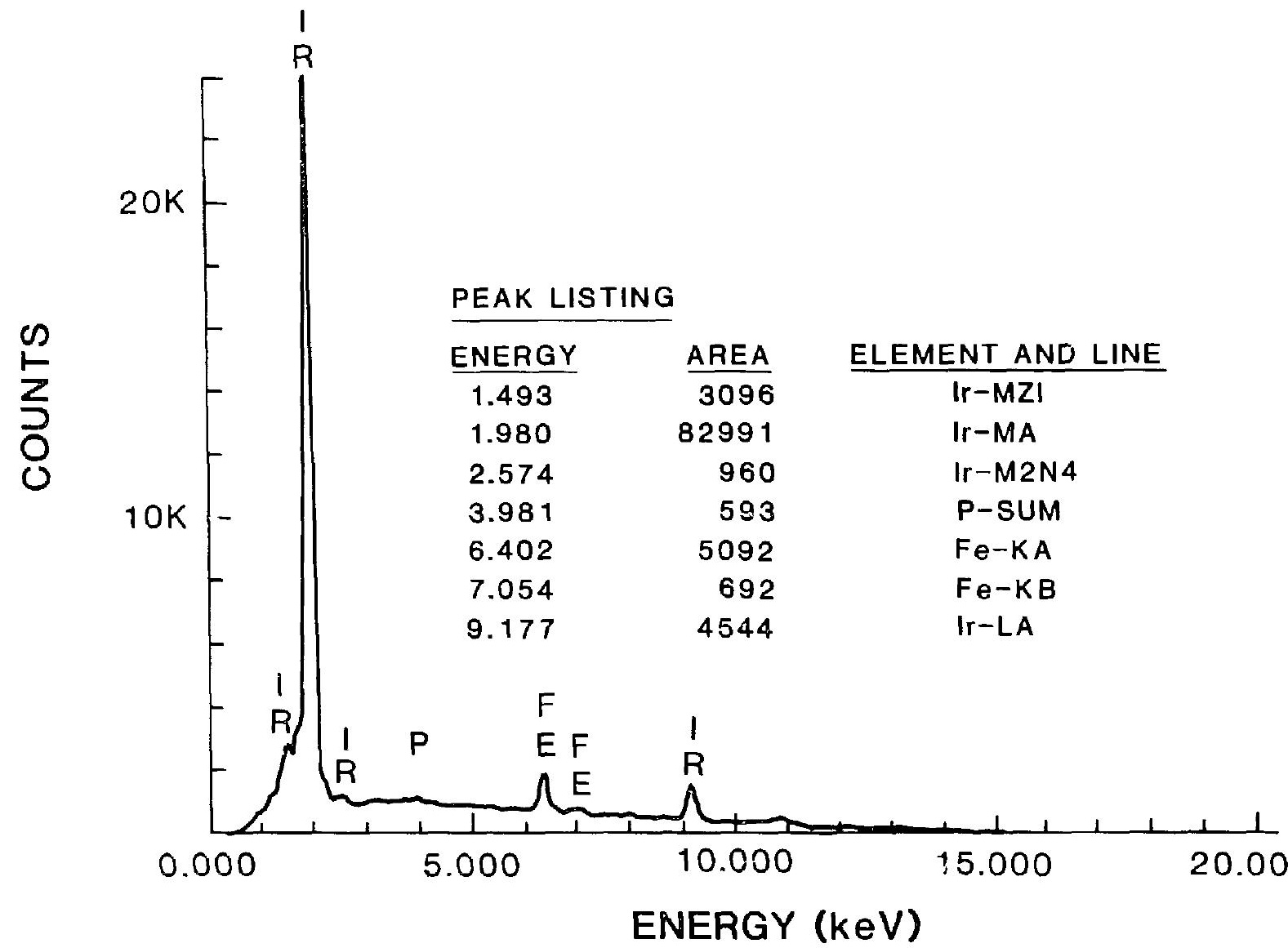

Fig. 72. X-ra! spectra trom the area in Fig. 73a (30)-s counting time). Iridium, iron. and phosphorus were detected. 


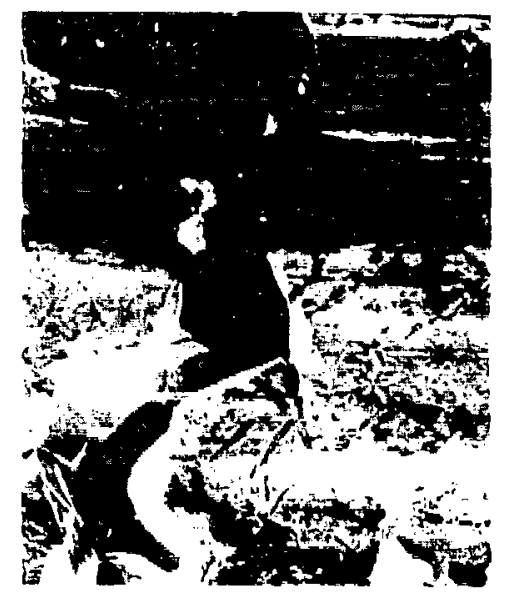

(a)

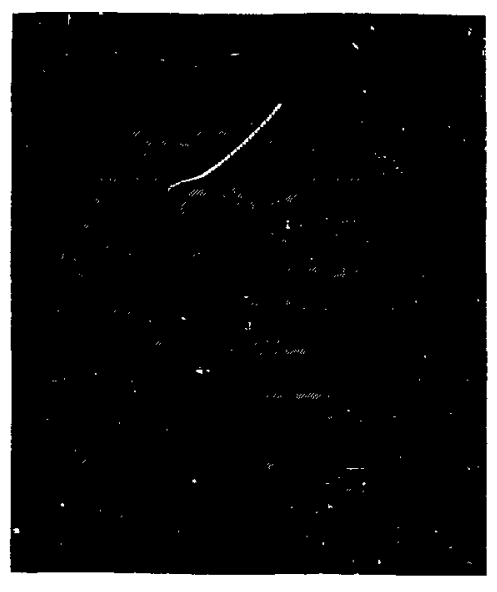

(b)

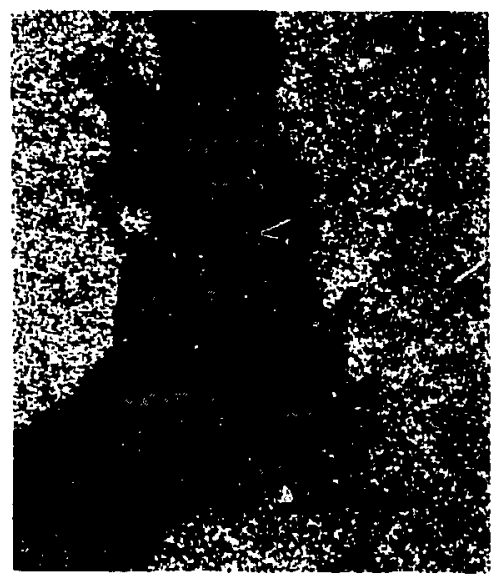

(c)

Fig. 73. Gouged area on surface of clad fragment: (a) Electron micrograph, (b) iridium dot map. and (c) iron dot map: all at 1000X.

Note:

Figures (D) and (C) are reversed. 


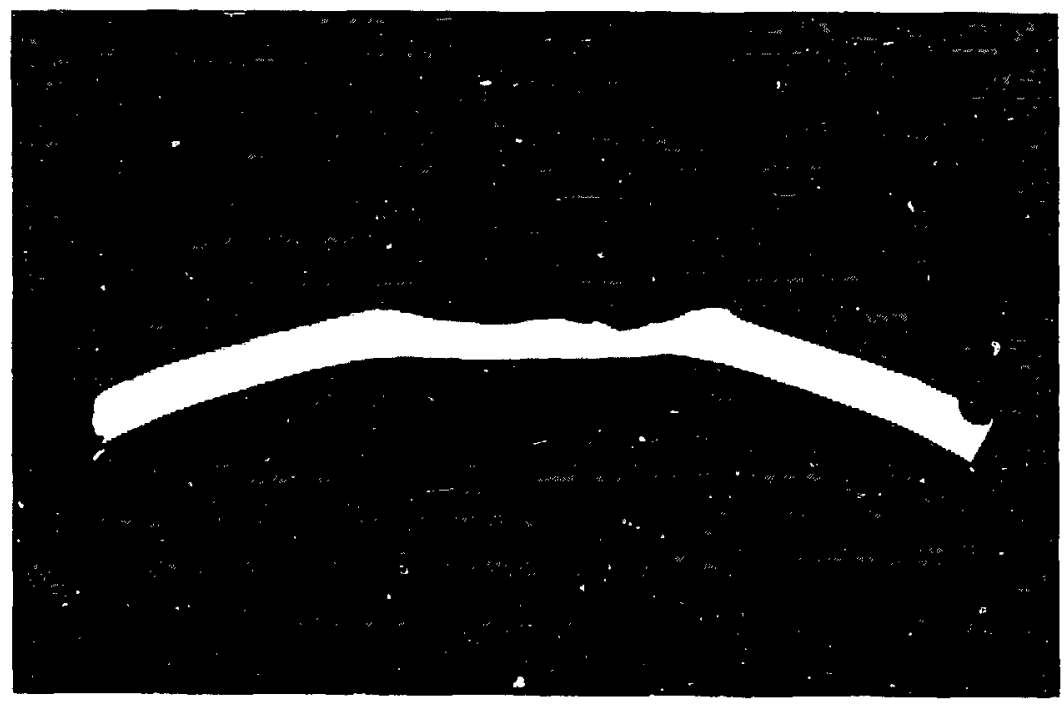

Fig. 74. A crater in the M-40 vent cup penetrated approximately $35 \%$ of the capsule wall; $6 \mathrm{X}$.

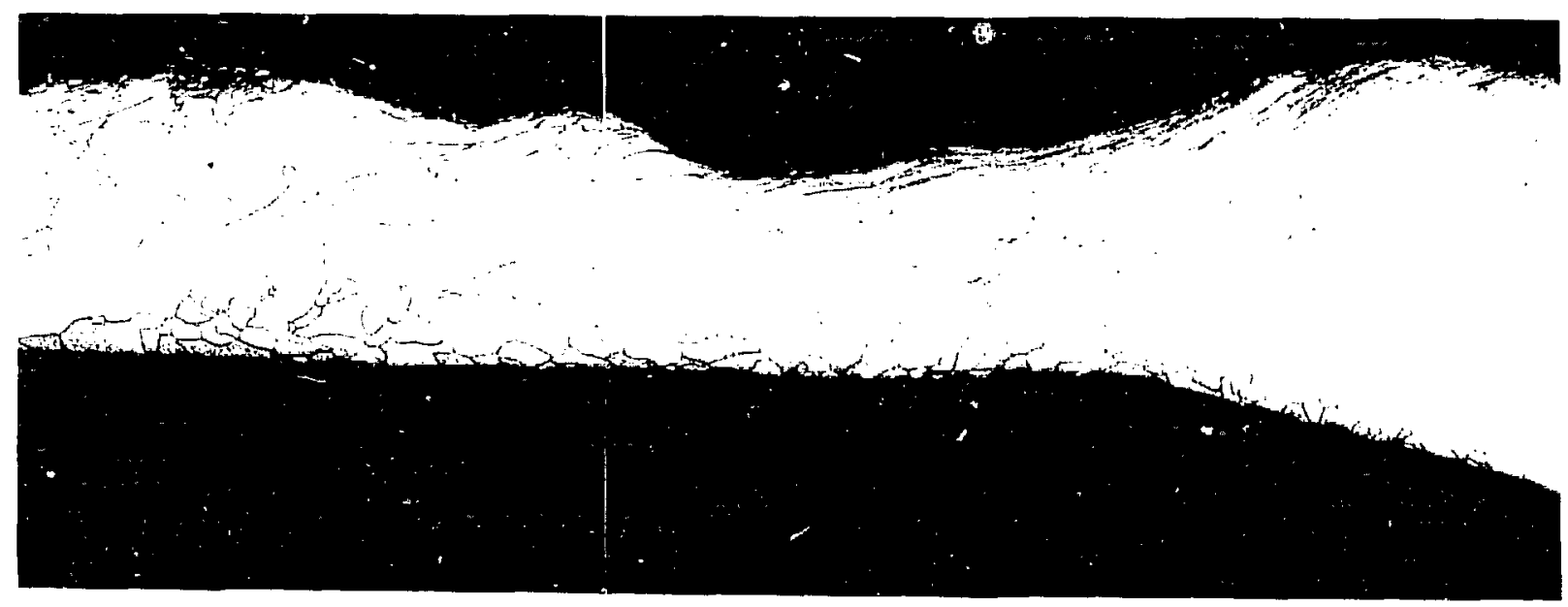

Fig. 75. Significant grain elongation teccurred in the crater of the M-40 vent cup; $50 \mathrm{X}$. 